Florida International University FIU Digital Commons

$5-25-2010$

\title{
International Education and the Post-9/11 Syndrome: A Study of International Educators in Selected Miami-area Colleges
}

Oluyinka Tella

Florida International University, oluuyinka@yahoo.com

DOI: $10.25148 /$ etd.FI10080411

Follow this and additional works at: https://digitalcommons.fiu.edu/etd

\section{Recommended Citation}

Tella, Oluyinka, "International Education and the Post-9/11 Syndrome: A Study of International Educators in Selected Miami-area Colleges" (2010). FIU Electronic Theses and Dissertations. 236.

https://digitalcommons.fiu.edu/etd/236 


\title{
FLORIDA INTERNATIONAL UNIVERSITY
}

\author{
Miami, Florida
}

\section{INTERNATIONAL EDUCATION AND THE POST-9/11 SYNDROME: A STUDY OF INTERNATIONAL EDUCATORS IN SELECTED MIAMI-AREA COLLEGES}

A dissertation submitted in partial fulfillment of the

requirements for the degree of

DOCTOR OF EDUCATION

in

HIGHER EDUCATION

by

Oluyinka Tella

2010 
To: Interim Dean Marie McDemmond

College of Education

This dissertation, written by Oluyinka Tella, and entitled International Education and the Post-9/11 Syndrome: A Study of International Educators in Selected Miami-Area Colleges, having been approved in respect to style and intellectual content, is referred to you for judgment.

We have read this dissertation and recommend that it be approved.

$\begin{array}{r}\text { Glenda Musoba } \\ \hline \text { Roger Geertz Gonzalez } \\ \hline \text { Eric Dwyer } \\ \hline \text { Benjamin Baez, Major Professor }\end{array}$

Date of Defense: May 25, 2010

The dissertation of Oluyinka Tella is approved.

Interim Dean Marie McDemmond College of Education

Interim Dean Kevin O'Shea University Graduate School

Florida International University, 2010 
C Copyright 2010 by Oluyinka Tella

All rights reserved. 


\section{DEDICATION}

I dedicate this dissertation to my selfless father, Benjamin Olasunkanmi Tella, and my dear mother, Alice Olanike Tella. The values of hard work, honesty and discipline that they poured into me, and their sacrifices over the years, made this study possible. 


\section{ACKNOWLEDGMENTS}

First and foremost, I am indebted to my darling wife, Shola (so adoring, so beautiful, so thoughtful!), my talented son, Kolade (the world's six billionth citizen), and my loving daughter, Fadekemi (what a precious princess you are!), for their unconditional love, quiet understanding and toleration of my mental and physical absences as I worked on this dissertation. Truly, I cannot thank God enough for blessing me with the most beautiful family in the world!

I will like to thank the University Graduate School and the College of Education for the opportunity I had to drink from the wellspring of knowledge of an exceptional faculty, of accomplished students, and of committed administrators. I wish to especially appreciate the pioneer director of FIU's doctoral program in Higher Education Administration, Dr. Michael Parsons, and the program's former administrative coordinator, Ms. Jeanine Higdon, for their passion and doggedness. I am also grateful to my former professors at Western Illinois University: Dr. Tracy Davis, Dr. Garry Johnson, Dr. Dea Forney, and Dr. Tom Cody, for the solid foundation they gave me while in Macomb.

Also worthy of recognition is Dr. Ana Sippin, Director of International Student and Scholar Services at FIU, who encouraged me every step of the way since she learned about my intended topic of research in 2005. Also noteworthy is Dr. Donna Shalala, the president of the University of Miami, who firmly used her prerogative to support my study when it appeared that doors were being systematically shut on me at UM. Special thanks to Dr. Al O’Dono, Dr. Diana Little and Ms. Jennifer E. Reid for their help at various stages of this dissertation and to Broward College for paying my tuition. 
Most importantly, I will be forever grateful to my dissertation chair and major professor, Dr. Benjamin Baez. He displayed considerable patience and understanding, an uncompromising craving for excellence, tenacity of purpose, and uncommon wisdom throughout this process. His re-assuring mien and practiced guidance was invaluable every step of the way. I am also grateful to my committee members, Dr. Eric Dwyer, Dr. Roger Geertz Gonzalez, and Dr.Glenda Musoba as well as Dr. Claudia Matus, a former member, for their thoughtful suggestions and critical feedback during the dissertation proposal, writing, and revision process. 


\section{ABSTRACT OF THE DISSERTATION \\ INTERNATIONAL EDUCATION AND THE POST-9/11 SYNDROME: A STUDY OF INTERNATIONAL EDUCATORS IN SELECTED MIAMI- AREA COLLEGES \\ by}

Oluyinka Tella

Florida International University, 2010

Miami, Florida

Professor Benjamin Baez, Major Professor

This dissertation investigated the relationship between the September 11, 2001 terrorist attacks and the internationalization agenda of U.S. colleges and universities. The construct, post-9/11 syndrome, is used metaphorically to delineate the apparent state of panic and disequilibrium that followed the incident. Three research questions were investigated, with two universities in the Miami-area of South Florida, one private and the other public, as qualitative case studies. The questions are: (a) How are international student advisors and administrators across two types of institutions dealing with the post9/11 syndrome? (b) What, if any, are the differences in international education after 9/11? (c) What have been the institutional priorities in relation to international education before and after $9 / 11$ ?

Data-gathering methods included interviews with international student/study abroad advisors and administrators with at least 8 years of experience in the function(s) at their institutions, document and institutional data analysis. The interviews were based on the three-part scheme developed by Schuman (1982): context of experience, details of 
experience and reflection on the meaning of experiences. Taped interviews, researcher insights, and member checks of transcripts constituted an audit trail for this study.

Key findings included a progressive decline in Fall to Fall enrollment of international students at UM by $13.05 \%$ in the 5 years after $9 / 11$, and by $6.15 \%$ at FIU in the seven post-9/11 years. In both institutions, there was an upsurge in interest in study abroad during the same period but less than $5 \%$ of enrolled students ventured abroad annually. I summarized the themes associated with the post-9/11 environment of international education as perceived by my participants at both institutions as 3Ms, 3Ts, and 1D: Menace of Anxiety and Fear, Menace of Insularity and Insecurity, Menace of Over-Regulation and Bigotry, Trajectory of Opportunity, Trajectory of Contradictions, Trajectory of Illusion, Fatalism and Futility, and Dominance of Technology. Based on these findings, I recommended an integrated Internationalization At Home Plus Collaborative Outreach (IAHPCO) approach to internationalization that is based on a post-9/11 recalibration of national security and international education as complementary rather than diametrically opposed concepts. 


\section{TABLE OF CONTENTS}

CHAPTER

PAGE

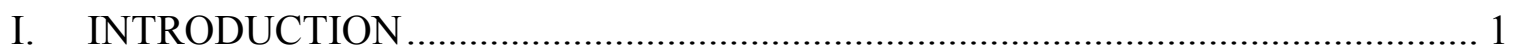

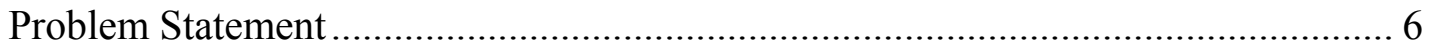

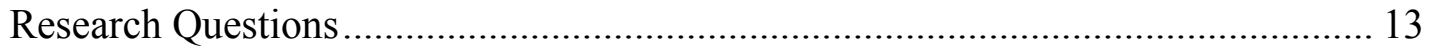

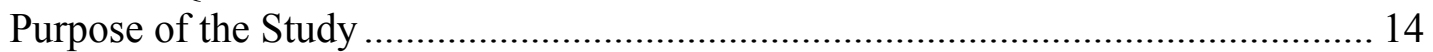

Assumptions and Delimitations of the Study..................................................... 15

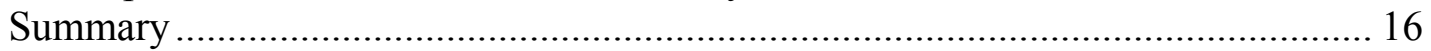

II. REVIEW OF RELATED LITERATURE ……..................................................... 17

Historical Evolution of International Education .................................................. 18

Theoretical Foundations of International Education................................................ 20

International Education in the United States Before the 9/11 Era ............................ 25

International Education in the United States After the 9/11 Era ............................... 31

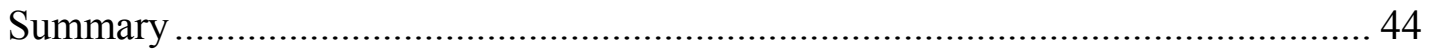

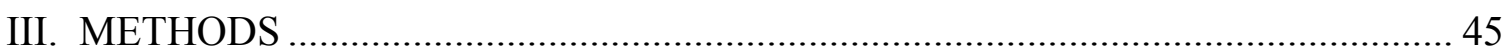

The Qualitative Research Tradition ..................................................................... 45

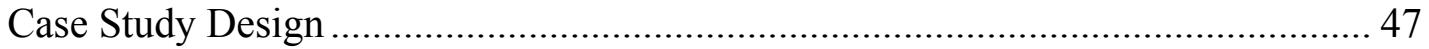

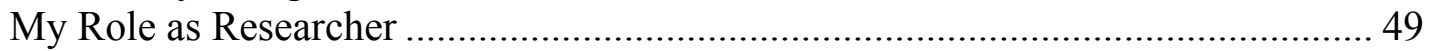

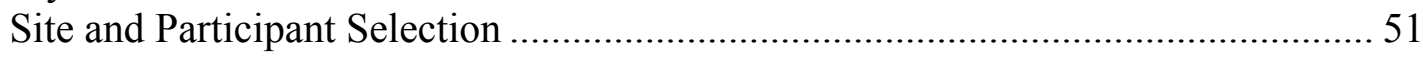

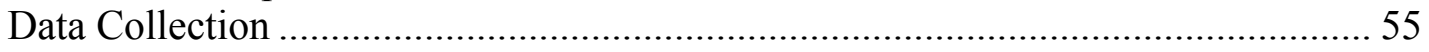

Data Organization and Analysis...............................................61

Dependability and Consistency of the Study..................................64

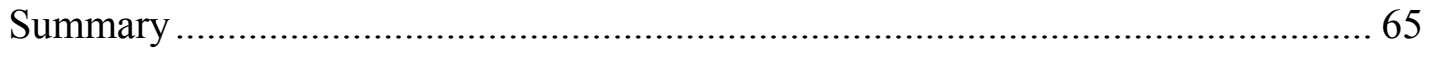

IV. ANALYSIS AND FINDINGS: FLORIDA INTERNATIONAL UNIVERSITY ... 66

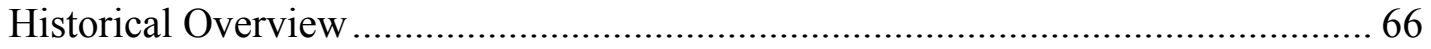

International Student Enrollment Data at FIU: 1996 to 2008 ..................................... 69

Organization of the International Education Function.............................................. 74

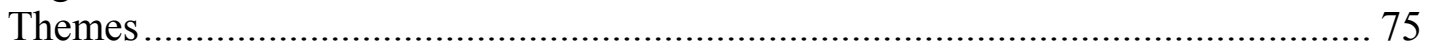

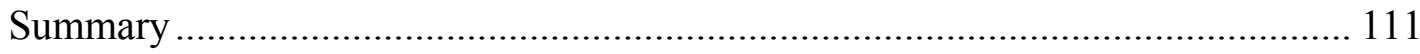

V. ANALYSIS AND FINDINGS: UNIVERSITY OF MIAMI................................ 113

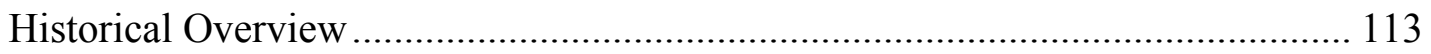

International Student Enrollment Data at UM: 1996 to 2009................................ 116

Student Participation in Study Abroad Data at UM: 1997 to 2007 ......................... 121

Organization of the International Education Function............................................ 124

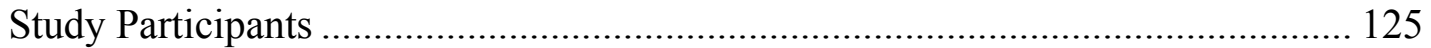

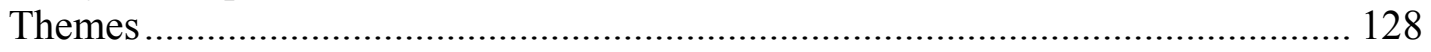

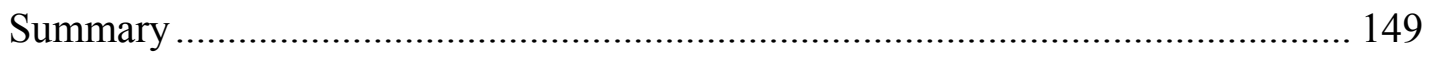




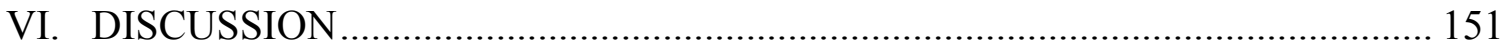

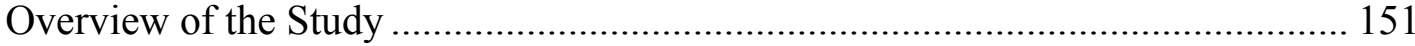

Conclusions: The "Post-9/11 Syndrome" at FIU and UM...................................... 155

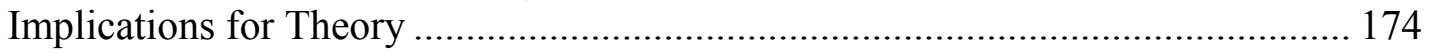

Implications for Practice ................................................................................ 177

Implications for Policy................................................................................. 180

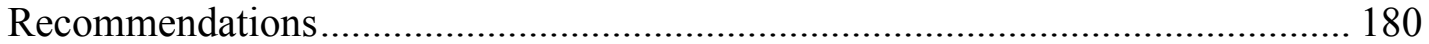

Suggestions for Future Research ...................................................................... 190

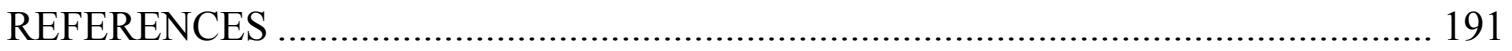

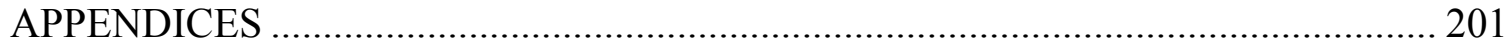

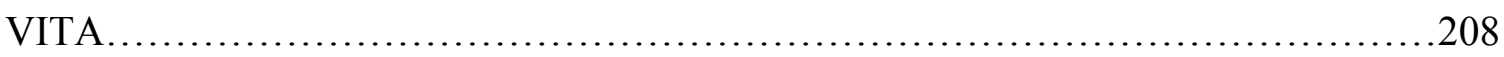




\section{LIST OF TABLES}

TABLE

PAGE

1. International Student Enrollment at FIU (Fall): 1996-2008.................... 70

2. Student Participation in Study Abroad at FIU: $1998-2008 \ldots \ldots \ldots \ldots \ldots \ldots \ldots \ldots \ldots \ldots \ldots$

3. New Freshmen (International) by World Region Headcounts: UM (Pre-9/11).... 116

4. All International Students by World Region Headcounts: UM (Pre-9/11)......... 117

5. New Freshmen (International) by World Region Headcounts: UM (Post-9/11)..... 119

6. All International Students by World Region Headcounts: UM (Post-9/11)........ 120

7. Student Participation in Study Abroad at UM (1998-2008).................... 123 


\section{LIST OF FIGURES}

FIGURE

PAGE

1. Estimated Number of International Students in the U.S., 1984 to 2008. .7

2. Top Host Country Destinations for Post-secondary International students (2008).......9

3. Fall Enrollment Data of International Students at FIU, 1996 to $2001 \ldots \ldots \ldots \ldots \ldots \ldots . . . . .71$

4. Fall Enrollment Data of International Students at FIU, 2002-2008..................72

5. UM International Students by World Region Headcounts (Pre-9/11)............. 119

6. UM International Students by World Region Headcounts (Post-9/11).....................122

7. Themes Associated with the 9/11 Syndrome at FIU and UM.....................157 


\section{CHAPTER I}

\section{INTRODUCTION}

The interplay between the September 11, 2001, terrorist attacks and international education in the U.S. is the focus of this study. Specifically, I sought to ascertain how international student advisors and administrators are interpreting and responding to the post-9/11 era of international education. I investigated what has changed about their work, its context, and outcomes in the aftermath of the incident.

In this regard, the terms "international education" and "internationalization" have been used interchangeably to encompass all curricular and co-curricular actions focused on integrating global content, language, and culture into U.S. higher education. They encompass the recruitment, retention, and integration of students from foreign countries into the U.S. educational system, as well as the deliberate action to expose domestic students to foreign educational socio-cultural experiences and internships through study abroad and exchange programs. The word "syndrome" in the title of this study implies a pattern of disorder symptomatic of some sickly state. The construct, "post-9/11 syndrome," is used metaphorically to capture the apparent, overwhelming state of panic and disequilibrium in the security, diplomatic, political, social, and educational situation of the U.S. in the wake of the September 11 attacks. On that day, a group of hijackers deliberately crashed two U.S. commercial airliners into the Twin Towers of the World Trade Center and another into the Pentagon, leaving 2,725 persons dead. An additional 256 persons died on a fourth plane that was forced to crash in Pennsylvania.

Overall, the 9/11 attacks inflicted on the U.S. a death toll that surpassed the infamous December 7, 1941, Pearl Harbor invasion by the Japanese that claimed 2,117 
casualties - the highest number of war deaths on U.S. soil in the pre-9/11 era. While the Japanese attacked a military installation, however, the 9/11 attacks were directed at civilians engaged in everyday activities by a shadowy group of non-state actors. The bipartisan 9/11 commission (National Commission on Terrorist Attacks Upon the United States, 2004) set up by the U.S. Congress to investigate the incident found that the hijack was carried out by 19 young Arabs at the behest of Al-Qaeda, a terrorist group apparently based in Afghanistan. Hani Hasan Hanjour, a 29-year-old Saudi Arabian veteran of the Afghan-Soviet war, who received a student visa to attend an English-as-a-SecondLanguage school in Oakland, California, was one of the hijackers. He never reported for studies at the school. Two other hijackers, including Egyptian- student Mohammed Attah, the assumed leader of the group, who attended Huffman Training School in Venice, South Florida, while awaiting approval of their switch from tourist to student status, were sent a letter -6 months after their murder-suicide in the 9/11 attacks - that their visa applications to attend flight school was approved.

Historically, the U.S. has been the choice destination of international students; one out of three students who study outside their home countries attends college in the U.S. This invariably has some benefits, but the economic upside has tended to attract more attention from policy wonks (e.g., NAFSA- Association of International Educators, 2007). A 2000 study by the American Council of Education (ACE) estimated that international students bring in some $\$ 13$ billion annually to the U.S. During the 2008/2009 academic session, international students and their dependents contributed approximately $\$ 17.6$ billion dollars, according to the latest economic impact analysis by NAFSA: Association of International Educators (NAFSA, 2009). 
However, the involvement of "students" in the $9 / 11$ attacks culminated in a national-security frenzy (Johnson, 2003). New immigration laws were enacted amid the perceived inability of the erstwhile Immigration and Natural Services (INS) - later restructured and renamed as the United States Citizenship and Immigration Services (USCIS) - to account for thousands of other foreign students in the country. The regulations helped tighten the government's anti-terrorist efforts but also had the unintended consequence of restricting the flow of intellectual capital (Kless, 2005). The new regulatory ambience continued a pattern of cracking down on international students that began after a similar attack in 1993. Following an allegation that one of the perpetrators of the 1993 bombing of the World Trade Center had originally entered the U.S. on a student visa, the U.S. Congress passed the Illegal Immigration Reform and Immigrant Responsibility Act (IIRIRA) in 1996. IRRIRA compels the government to maintain up-to-date information on international students and exchange visitors.

In the wake of $9 / 11$, Congress similarly passed the Uniting and Strengthening America by Providing Appropriate Tools Required to Intercept and Obstruct Terrorism Act of 2000 (USAPATRIOT). Also known as the Patriot Act, the law introduced even more stringent restrictions and accelerated the process of setting up a monitoring mechanism, including the collection of $\$ 100$ per international student for maintaining the Student and Exchange Visitors Information System (SEVIS). SEVIS is an internet-based system that allows higher education institutions to file information electronically about the status of their foreign students directly to the USCIS.

In line with the emerging post-9/11 mindset, the National Security Entry Exit Registration System (NSEERS) was introduced on September 11, 2002. NSEERS 
subjects individuals from 25 predominantly Arab and Muslim countries to special inspection when entering or leaving the U.S. Until very recently, if already in the U.S., people from these countries had to register with their closest Immigration and Customs Enforcement (ICE) office and report monthly. The affected nations that were further divided into groups are Iran, Iraq, Sudan, Libya, and Syria (Group 1); Afghanistan, Algeria, Bahrain, Eritrea, Lebanon, Morocco, North Korea, Oman, Qatar, Somalia, Tunisia, United Arab Emirates, and Yemen (Group 2); Pakistan, Saudi Arabia (Group 3); as well as Bangladesh, Egypt, Indonesia, Jordan, and Kuwait (Group 4).

Under this program, 13,799 of the 83,519 individuals who reported as of May 2003 were immediately processed into deportation proceedings. Despite recent relaxation of the reporting guidelines, these special registrants must still enter or exit the United States through designated ports of departure. In addition, the Consular Lookout and Support System (CLASS), a security system required by the Visa Mantis System, conducts interagency security checks based on the citizenship, nationality, country of birth, and field of study of a student, and could trigger screening because of involvement in high-technology fields or because the student is on the Technology Alert List (Kless, 2005). Together with the implementation of NSEERS, which targets international students and scholars from certain countries for closer scrutiny, the Visa Mantis System heightened visa problems faced by scholars and scientists. According to the U.S. Department of State, the number of visas issued to international students declined by $25 \%$ between 2001 and 2004.

International student advisors and administrators were given the legal responsibility for implementing these new regulations. By job description, they were also 
responsible for promoting and advancing the cause of international education on their campuses. The code of ethics of NAFSA, adopted on May 8, 1989, charges international education advisors and administrators to respect the civil rights, privacy, and confidentiality of records of all individuals regardless of race, creed, or gender. Thus, these advisors and administrators were now entangled in a conflict: following the law and following NAFSA's code of ethics.

The NAFSA code is much like the concept of academic freedom, which holds that the public good is better served by the unfettered pursuit by faculty of research, writing, teaching, and political speech (Bowden \& Marton, 1998). Such time-honored academic values and principles are increasingly challenged by government agencies and private organizations under the guise of keeping terrorists and their sponsors at bay. For example, the American Council of Trustees and Alumni (ACTA), co-founded by Lynn Cheney and Joe Lieberman, issued a report, Defending Civilization: How the Universities are Failing America and What Can Be Done about It, in which they accused universities of being fifth-columnists in the war on terror. Scholars like Professor Tariq Ramadan, a Swiss Muslim reformer and academic, have been denied visas on the basis of racial and political profiling (Doumani, 2005). These developments apparently put academic institutions, which hitherto "protected the alienated critic along with the football player" (Versey, 1965, p. 442), firmly in the partisan arena. Essentially, the implementation of the Patriot Act, as well as SEVIS, has attracted a horde of critics (e.g., Treyster 2003), who argue that focusing so much attention on students and scholars who represent a small minority of non-immigrants in the country does little to improve national security when millions of people illegally enter the United States each year. 
In sum, the post-9/11 security frenzy has been a by-product of the global war on terrorism declared by the U.S. Federal Government. It appears to have created a negative climate for international education in the U.S. As a corollary, the academy's role as the bastion of informed, independent, and alternative perspectives, crucial to a better understanding of our world, may be threatened.

\section{Problem Statement}

The overtly suspicious security posture adopted by the U.S. in the wake of the $9 / 11$ attacks apparently added the "potential terrorist" or "threat to national security" narrative to the other underlying themes of xenophobic narratives popular with the nation's antiimmigrant activists (Hondagneu-Sotelo, 1999, p.16). Johnson (2005) contrasted what he saw as the U.S.'s paranoid treatment of international students and scholars with the determined drives of its competitors to snare international students with irresistible scholarship offers and other benefits, such as spousal right-to-work (Canada) and offcampus student work permit (United Kingdom). Additionally, despite the 2004 and 2005 terrorist attacks in Great Britain and Spain respectively, these countries did not follow the U.S. model of reacting: instead, unlike in the U.S., virtually no new regulations or legislations have been enacted to restrict the free flow of students and scholars in these countries (Hirsch, 2008).

Anderson (2005) argues that post-9/11 policy changes have made it more difficult to redress this trend. In 2004, there was a $2.4 \%$ decrease in enrollments of international students. This was the first such occurrence since 1971-72, when enrollments declined 3\% (see Figure 1). In 2005, there was a further 1.3\% drop in enrollment figures to 


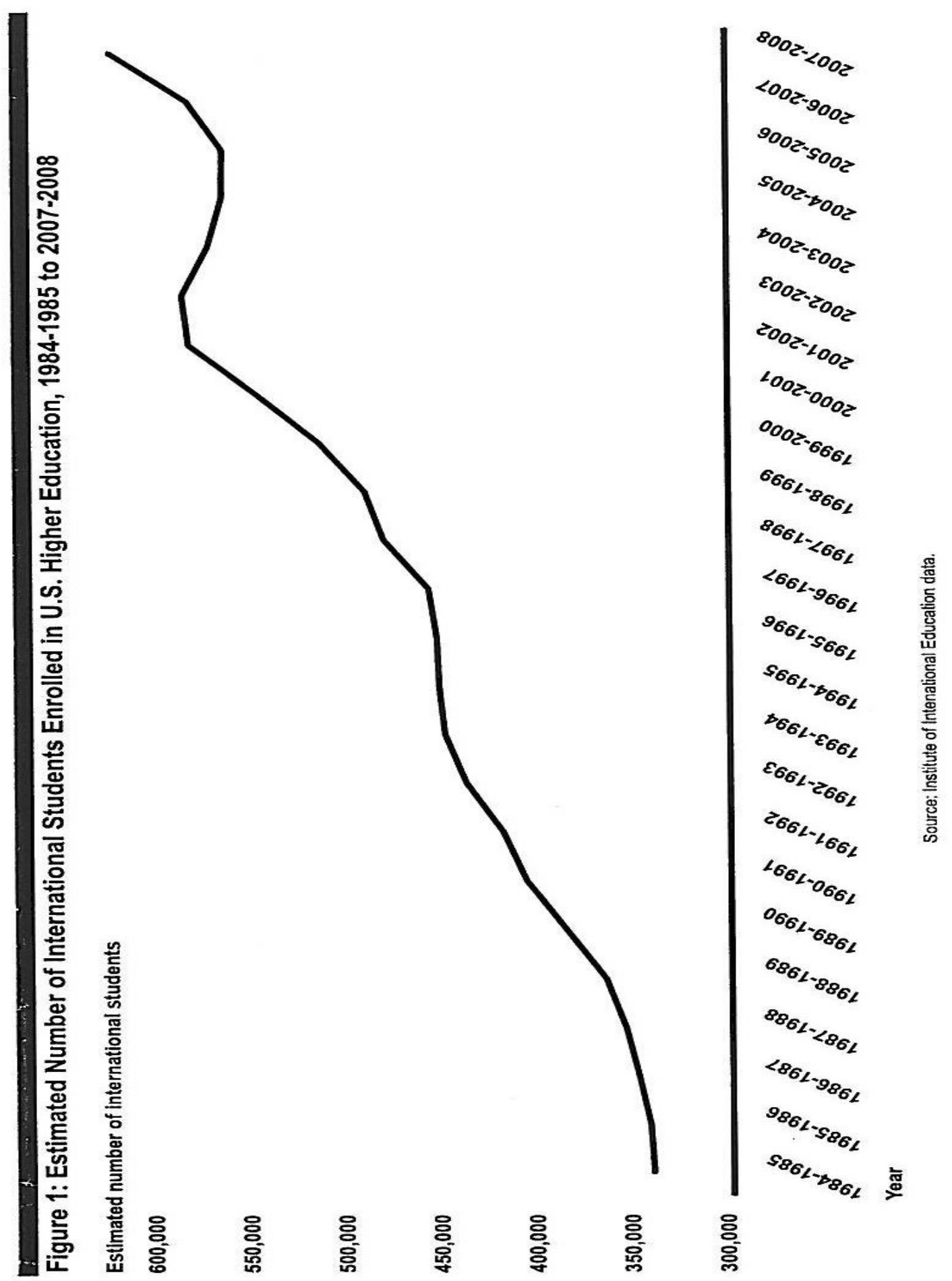

Figure 1. Estimated number of international students in the U.S., 1984 to 2008. 
565,039 (Open Doors, 2005). In 2006 (see Figure 1), international student enrollment in U.S. universities and colleges dropped slightly by $0.2 \%$ to 564,766 (Open Doors, 2006). However, things now appear to be on the upswing, with a $3 \%$ increase in international student enrollment in the U.S. in the 2007/2008 session, the first such increase since $2001 / 2002$. A further $7 \%$ increase to 623,805 international student enrollees in 2008 would seem to underline this narrative of recovery and reverse trends suggesting that international education in the U.S. has been in a stagnant state of growth in terms of inflow of foreign students. It represents a psychological boost for proponents of internationalization in the U.S., where annual growth in international student enrollment dipped from $8.4 \%$ in the 1970 s to $1.3 \%$ in the 1980 s, while Australia was able to increase its growth rate from $2.3 \%$ to $10.7 \%$ during the same period in what was portrayed as a "reversal of fortunes" (Welch, 2002, p. 442).

Indeed, the targeting of international students and scholars in the U.S.'s push against extremist Islamists does not appear to have caught on with other destination countries, which continued to gain in market share. The U.S.'s share of the international student market dwindled from $40 \%$ to $32 \%$ in the 10 years preceding the September 11 , 2001 terrorist attacks, indicating a trend that predated 9/11. Between 2000 and 2008, there was a further $6 \%$ drop from $26 \%$ to $20 \%$ in the U.S.'s market share of the international student market (See Figure 2). Pew Global Attitudes Project found that the U.S's image declined in the Muslim world and among its traditional allies.

Thus, while the proportion of international students to their domestic counterparts is $16 \%$ in Switzerland, $12.6 \%$ in Australia, $10.8 \%$ in the United Kingdom, about $8 \%$ in Germany, and about $9 \%$ in France, it is a mere $3.9 \%$ in the U.S., which ranks $12^{\text {th }}$ in this 


\section{Figure 2: Top Host Destinations for International Students at the Postsecondary}

\section{Level in 2008}

(Estimated total 2.9 million students)

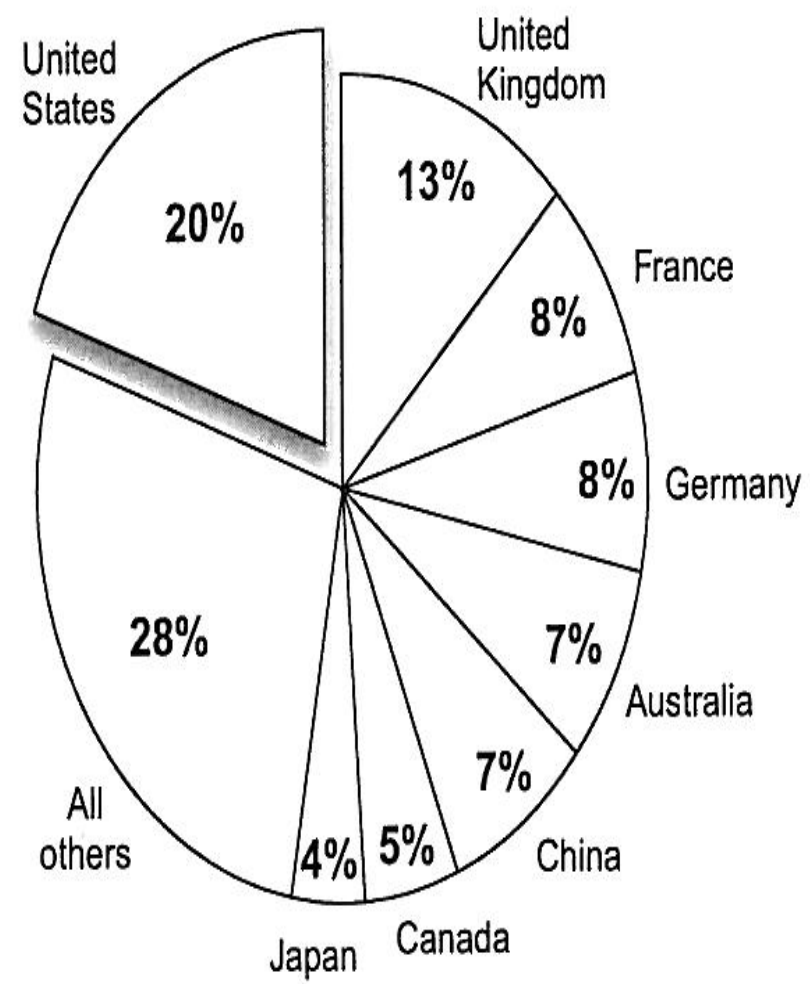

Source: Institute of International Education (based on Project Atlas 2007 data and United Nations Educational, Scientific and Cultural Organization / Organisation for Economic Co-operation and Development 2006 data).

Figure 2. Top host country destinations for post-secondary international students (2008). 
category among the 30 countries in the Organization for Economic Cooperation and Development (OECD). In this regard, the climate of international education as perceived by international student advisors and administrators after $9 / 11$ is an important index to consider. Unlike previous studies, which concentrate on number-crunching in an attempt to track the ebb and flow of intellectual capital into the U.S. after the 9/11 attacks (e.g., Anderson, 2005, Duverneuil, 2003, Urias, 2003), my study sought to go beyond numbers to examine the policy and implementation challenges confronting international education professionals and administrators in the wake of the incident.

In essence, my study focused on phenomena coming out of the emergent policy environment and the reactions provoked by the new reality as perceived by critical stakeholders. It drew on the thoughtful analysis by Inyatullah (1998) that the modern university stands at the gateway of a range of futures signposted by four trends and emerging issues. The trends are globalism (the university as a business), multiculturalism (deep inclusiveness), virtualization (the promise of the Internet) and politicization (the role of the violent state) that promise to transform the nature of the university. According to Inyatullah, these changes have not only generally affected the governance of education but "the character of international education" (p. 591).

Inyatullah's analysis introduces some problematic dilemmas that partly constituted the focus of my study. For example, if U.S. universities were to function strictly as businesses, they would increase outreach efforts to attract students from the oilrich Middle Eastern states. Ironically, these source countries have been identified as hotbeds of Islamic radicalism. A 2007 report by the Congressional Research Service specifically identified Saudi Arabia and Qatar as centers of Wahhabism and Salafiyya, 
two ultra-purist Jihadist forms of Islam that preach extreme intolerance of other religious beliefs and traditions. The only surviving aspect of Inyatullah's future university as it relates to international education in the U.S. would seem to be the political university, wedded to the violent or paranoid state in an unremitting physical struggle with religious extremists and social deviants in far-away places like Afghanistan and Iraq, coupled with an ideological battle within the homeland.

Caught in the web of this unfolding university landscape are the international students who constantly grapple with issues bordering on "marginality and mattering" (Schlossberg, 1998, p.16). To Tanaka (2003), the level of inclusiveness in the campus community can be measured by how far (if any) it has outgrown the "objectification of others" (p. 175), which, he argues, has been the by-product of Eurocentrism, Catholicism, Heterosexism, and Maleness/Masculinity that have been the dominant ideas on campus.

Islam and other frames for looking at the world would have no place on the university campus unless conscious efforts are made to construct physical and psychological infrastructure that go beyond positioning others as straw men or bogey men. In this regard, engendering "mattering" in international students and scholars is a key function of international education offices at colleges and universities. Dealing with this dilemma is a core aspect of the post-9/11 world and represents a major thrust of the present study. As Stringer (2002) has rightly observed, "there may be an infinite variety of organizational climates" (p. 45), meaning that different segments of the university community, such as international students and domestic students, might experience the institutional climate in different ways on the same campus. 
The challenge of multiculturalism is to engender an inclusive climate with the digital tools of virtualization used to further this process rather than impede it.

For instance, a certain level of frustration seems to have crept into the international programs of many institutions in the aftermath of the $9 / 11$ attacks. These programs began to focus almost exclusively on study abroad programs and the learning that may occur as a result of them. The phrase, Internationalization at Home (IaH), defined as "any internationally-related activity with the exception of outbound student mobility" (Nilsson 2003, p. 29), was largely developed by Bengt Nilsson in 1998 and introduced in Sweden's Malmo University to counter a similar tendency and achieve some balance. IaH includes curricular and co-curricular activities, communityinvolvement, international/domestic student interactions, and the teaching-learning experience on campus. One of the main goals of IaH is to "give all students an intentional international dimension to their learning and not just the small percentage who actually study abroad" (p. 29). The key idea is to develop a conceptually integrated systemsapproach to international education that encompasses the entire university. When internationalization is framed in this fashion, it pervades the entire university so that all students (as well as faculty and staff) are intentionally engaged in global issues at least at some point during their college careers. The significance of this distinction becomes manifest when it is noted that less than 200,000 (representing less than $1.33 \%$ ) of the U.S.'s 15 million students study abroad each year (Open Doors, 2006).

My study looked at the changes that have been brought to bear on this vital function in the post-9/11 period. Given globalization and the role that satellite communication, cable television, air travel, and cross-cultural and inter-boundary 
interaction and procreation have played in the development of global cultures, what have U.S. colleges and universities done or left undone for the needs, values, and dreams of the ever-evolving population of students and scholars? How have international educators, encompassing advisors and administrators, evolved in their roles and perspectives to understand and meet the challenges of this new era? More specifically, how are two selected universities in South Florida balancing the reality of the post-9/11 security ambience with active promotion of international education? How far are they able to advocate and enable an integrative pluralistic college environment for all students and scholars regardless of creed and pedigree?

\section{Research Questions}

My study sought to ascertain how international education advisors and administrators at colleges and universities are interpreting and responding to the "post9/11 syndrome" by investigating the following three research questions:

(a). How are international student advisors and administrators across two types of institutions dealing with the "post-9/11 syndrome?"

(b). What, if any, are the differences in international education after $9 / 11$ ?

(c). What have been the institutional priorities in relation to international education before and after $9 / 11$ ?

I sought to understand the perceptions of international education leaders such as student advisors, college counselors, the directors of Study Abroad, International Admissions and International Student and Scholars offices, Vice Presidents/Provosts for Student Affairs and Presidents. I studied how the international-education function has evolved in the post-9/11 period at two universities located in Miami, Florida. 


\section{Purpose of the Study}

Barely 3 years after the 9/11 attacks, a taskforce on international education set up by the Association of Public and Land-Grant Universities (APLU), formerly known as the National Association of State Universities and Land Grant Colleges (NASULGC), concluded in October 2004 that "internationalization is the single most important leadership challenge of the $21^{\text {st }}$ century" (p. 17). Nevertheless, I did not find any studies of how institutional leaders are couching and responding to these challenges. Arguing that internationalization can neither succeed without "deep presidential commitment" nor by "executive fiat" (p. 17), the task force proposed what it called the three "A's" of presidential leadership as the solution to the waning status of U.S. universities and colleges in the international arena. Leaders, they contended, must consistently articulate a vision for internationalization that contributes to the development of globally competent students, faculty, and staff. They must unceasingly advocate for international education at personal, institutional, communal, political, and cultural levels. Finally, they must act to implement transformational change, converting vision to reality by enthroning a regime of accountability that ensures that policy postulations are backed up with verifiable accomplishments.

Although very sparse attention has been given to this in the literature, the vantage position of directors and advisors/counselors responsible for international education as advocates, enablers, strategists, and stakeholders, makes their experiences core to any attempt to discern or re-construct internationalization efforts on campus. They are close to students and scholars as well to the presidential cabinet and the board of trustees that enact the institution's internationalization vision. In essence, they are trusted by the 
college administration to project accurately its vision to the college community while international students and scholars look up to them as veritable advocates for their cause. Despite this vantage position, however, a search of databases like Wilson Web showed that the handful of studies conducted on international education professionals dwelt almost exclusively on the implementation of the Student and Exchange Visitors Information System (SEVIS). None have considered the perspectives of international educators on their roles in the internationalization of campuses before and after 9/11. It is a gap that my study seeks to bridge.

\section{Assumptions and Delimitations of the Study}

Proceeding from the assumption of several landmark studies and reports, including that of the APLU that dwell on the three "As" of presidential leadership in international education, this study assumes that internationalization is a desirable goal of international education. In this regard, it is assumed that acquisition of cross-cultural experiences and skills is an imperative for $21^{\text {st }}$ century survival. It has relevance at the individual, institutional, and national/cross-boundary levels. Consequently, it is assumed that individuals will crave opportunities for education with quality global content and experiences wherever they might find such. It is further assumed that both the hostcountry citizens and foreign sojourners symbiotically benefit from international education and that South Florida, with a 30.4\% foreign-born population, and Miami-Dade, with $51.4 \%$, are well-positioned to benefit from this global trend by presenting a warm and welcoming environment to foreign students, even in the post-9/11 environment.

This study is limited to the perspectives and experiences of international educators and administrators in two Miami-area universities who meet the criteria earlier 
specified. The findings of the study are limited to this context and cannot be generalized to cover other settings. It is, however, hoped that because of thick description, others will find affinity with its conclusions

\section{Summary}

In this chapter, I outlined the seeming precarious position of the internationalization agenda in U.S. colleges and universities that was apparently exacerbated by the September 11, 2001, terror attacks. I identified the research questions that guided this study, which examined the post-9/11 ambience and practices of selected universities in South Florida from the perspective of international education advisors and administrators. In chapter 2, I shall delve into the literature of international education to evoke the historical, theoretical, and research underpinnings of this study. 


\section{CHAPTER II}

\section{REVIEW OF RELATED LITERATURE}

International education administrators, recruiters, and advisors are confronted daily with foreign student and scholar issues, such as programs generation, implementation and assessment, prioritization, resource allocation, college climate, and policy environment scanning. Even though they are on the frontline of any internationalization effort, very few studies have been conducted on their perceptions of their work. This chapter will revisit these issues and provide a rationale for the current study on how these professionals are interpreting and responding to their work as advocates and enablers of internationalization on their campuses, and how this work has been impacted by what I have characterized as the "post-9/11 syndrome."

The research questions guiding my study are (a), How are international student advisors and administrators across two types of institutions dealing with the "post-9/11 syndrome?" (b) What, if any, are the differences in international education after 9/11? (c) What have been the institutional priorities in relation to international education before and after 9/11? I will review the historical evolution of international education, its theories and strategies, as well as its manifestation in the United States before and after the September 11, 2001, terror attacks. As this chapter will show, the U.S. lacks a national policy on international education, and interest in the subject has been slow in developing. Landmark political events such as the launch of Sputnik by the former Soviet Union and the more recent $9 / 11$ attacks often help to spark temporary excitement around the subject. This has, however, not been enough to prevent the U.S. from losing significant number of international students. 


\section{Historical Evolution of International Education}

Scholars have traced the evolution of international education far beyond the middle Ages to Confucius (551-579 BCE), who traveled with his students from Lu Guo in modern-day China to neighboring countries to teach. According to Welch and Denman (1997), the Sophists of 5th Century Greece later emerged as the first professional peripatetic teachers in the West, with a philosophy of education predicated on the assumption that "training, argument and education could take place anywhere dependent only on a master and interested students" (p. 14). The Western medieval era ushered in structural uniformity in the form of peregrenatio academia, the existence (in the West) of Latin as a universal language of scholarship, as well as trivium and quadrivium, a uniform system of study, examination, and colleges.

Incidentally, the Moorish conquest of Spain in 711A.D. and the ensuing civilization (711-1492 A.D) that brought Europe out of the Middle Ages saw the rise of the first modern universities and a belief that Arabic was key to scholarship. According to Karenga (1993), this was not surprising at that time since the Moors gave Spain 17 famous universities and more than 70 public libraries at a time most of Europe was illiterate. Rocker (1937) reported that these universities, which featured an international curricula/pedagogy that included astronomy, philology, geometry, chemistry, geography, trigonometry, botany, and history, attracted students from Africa, the Middle East, and Europe.

In 1232, Pope Gregory IX granted jubisque docendi to the masters of the University of Paris, authorizing them to teach anywhere in the Christian world. The internationalization of education continued in the 18th and 19th centuries with the spread 
of the Oxford and Cambridge models to British colonies like India, and the German model of research-based universities to the U.S. and Japan. Although the Age of Enlightenment had since the 18th century heralded a homespun tradition of research and scholarship, U.S. institutions like Princeton, Harvard, and Columbia still subsidized foreign study for promising graduates (Rudolph, 1962, Thelin, 1947). The establishment of the Johns Hopkins University, a German-styled research university in Baltimore, precipitated an upsurge in the number of U.S. students in German universities (Versey, 1965). From about 1900, however, a combination of apparently "less friendly" policies by the German authorities and the perception that U.S. graduate schools were "rapidly improving" (Versey, 1985 p. 131), led to a steady reversal. By the 1930s German intellectuals began emigrating to nourish the intellectual pastures of Europe and North America.

Similarly, the post-1945 mass migration away from war-torn Europe to the new worlds of North America and Austral-Asia fuelled the development of comparative advantage by educational institutions in those regions, especially in the realm of scientific and technological research (Welch \& Denman, 1997). With de-colonization and the ensuing globalization of international relations came an increased thirst for knowledge and a rising tide of students from the developing nations seeking university education from the more developed countries, especially the United States, the former Soviet Union, and European nations.

According to Heyneman (2003), the U.S. has oscillated between aloofness and knee-jerk, event-based interest in international education. In the 1970s, for instance, this aloofness found expression in a tradition of "localism and educational isolationism" 
(p. 39) such that only one of 3,000 government sponsored research projects in 1974 had anything to do with international education. Even then, the sponsoring agency (the National Institute of Education) made some effort to underplay its existence for fear of being criticized as frivolous. This is despite the fact that the successful launch of the world's first artificial satellite, Sputnik 1 by the Soviet Union in 1957, gave a new fillip to area studies a couple of decades earlier.

Similarly, the 9/11 attacks seemingly stimulated a new interest in terrorism, Islamic studies, and the acquisition of foreign languages as instruments for intelligence gathering. This culminated in the launching of the Foreign Language Initiative by President George Bush at the University Presidents' Summit in January 2006. However, the United States remains without a comprehensive international education policy, and questions about how those in the frontline in the U.S.'s interface with students and scholars from other parts of the world perceive their role after 9/11 remain largely unasked.

Theoretical Foundations of International Education

The international education movement has been broadly influenced by three theoretical traditions: critical theory, post-modernism, and relational theorizing. As Schapiro (2000) indicated, the critical theory tradition insists that higher education commits to "seriously interrogating the world" (p. 23) with a view toward recreating a humane and just planet. Post-modernism rejects the concept of true objectivity as it confronts the dynamics of difference and commonality associated with globalization and the inevitable overlap of local and global knowledge (Back, Davis \& Olson, 1996). Relational theorizing rests in part on a "complex vision of liberation pedagogy that 
validates difference" (Ross, 2002, p. 407), while creating and sustaining relationships between diverse groups with a view toward attaining transformational change. My work synthesizes strands of these traditions.

From the school of thought of relational theorizing, Schlossberg, Waters, and Goodman (1995) outlined four S's as four major factors influencing a person's ability to manage transition: situation, support, self, and strategies. Under this model, a transition could be any event that precipitates changed relationships, roles, and assumptions, such as relocation to a new geographic environment, the $9 / 11$ attacks, or even a non-event such as unfulfilled expectations tied to the inability of an educational institution to enact an inclusive campus environment. Allied with the extensive body of research on student involvement in institutional life and persistence to graduation (e.g., Pascarella \& Terenzini, 2004), the four S's provide a firm grounding for my planned research to the extent that 9/11 represented a significant constitutional event for all stakeholders in higher education.

\section{Strategies and Concepts of International Education}

As a multi-disciplinary subject, international education has traditionally been more practiced than defined. Smart (1971) suggested eight "useful pegs" or conceptual frameworks upon which core theories and concepts associated with international education could be hung. They include the permeation and development of new ideas or transculturation, of a synthesis of value systems and world culture, of national political power, of mutual understanding and cooperation, of basic preparation for life in a global context, of a creative attitude toward diversity, and of the discovery of truth.

Transculturation captures the tendency of cultures to merge and converge as they interact 
with each other. It holds that resolution of conflict situations is the inevitable natural course of events. This also ties the permeation of marginal ideas into the dominant social structure, locally and internationally, as cultures, ethnic groups, and nations feed into each other.

The development of a synthesis of value systems and the ensuing nurturing of people who see themselves basically as world citizens is, however, mediated by the reality that Western culture is assumed by "mainstream" scholarship to be more advanced and probably superior. This spills into the economic arena. Smart (1971) argues that international education is an instrument for the unconscious projection and perpetuation of American power because U.S. universities produce elites whose self-interest are tied to U.S. economic and political interests even after returning to their home countries.

Similarly, other Western universities churn out specialists who are tied to their production techniques, machinery, political systems, and approaches. Other strategies often deployed in international education, such as area studies, language training, and short term exchanges, help create the knowledge and skill base to extract relevant information that enhance the control of other systems and peoples. Such was the case with “Point Four" of President Truman's Inaugural Address in 1949, which pledged technical assistance by the U.S. to developing countries. The policy propelled U.S. colleges and universities into consulting arrangements with foreign governments for agriculture, health, education, and other areas of social and economic development (Sutton, 1998). The growth of international assistance for development not only brought tens of thousands of foreign students to the U.S. for higher education but also promoted the employment abroad, of US educators and expatriates, by countries little known by 
citizens of the U.S. These initiatives were apparently partly propelled by a national needs strategy because the U.S. required well-heeled professionals with multi-lingual and multicultural competencies to project effectively its super-power status.

In line with Smart (1971), educational opportunities also became instruments of cold war politics. The introduction of programs like the Fulbright scholarship in the United States and the Rhodes scholarship in the United Kingdom afforded many bright scholars from all over the world the opportunity to pursue their studies internationally (Welch \& Denman, 1997). Dassin (2005) has suggested, however, that the tendency of many such professionals to remain abroad after their education fosters brain drain in developing nations, whereas a policy of "brain gain" should be pursued as an imperative for a safer and more balanced world.

\section{Internationalization}

According to Boyd (2003), international education should encompass both "international and internationalist elements" (p. 70) by promoting perspectives that transcend national boundaries. In a study of the International Baccalaureate and international schools, he suggests four areas of focus: content (of the curriculum), context, (practical delivery), intention/derivation (sources of, and influences on, content, delivery, intention, and assessment), and currency (extent of acceptability of the ensuing diploma/certificate).

Boyd's internationalization schema is similar to Knight's (1999) four strategic approaches for advancing international education in higher educational institutions: activity, competency, ethos, and process. Under Knight's framework, the activity-based approach includes curriculum development (to incorporate other world views and 
promote cross-cultural appreciation/understanding), student/faculty exchanges, and recruitment/retention of international students. The competency-based approach involves the development of necessary skills, knowledge, values, and attitudes by faculty and staff interested in imparting global competencies to both local and international students. The ethos-driven approach is concerned with engendering a campus climate that promotes and supports intercultural initiatives, while the process-based approach incorporates an international/intercultural dimension to campus activities, policies, and procedures.

\section{Globalization}

Globalization and multiculturalism are two core drivers of today's internationalization efforts. In its simplest characterization, globalization is the creation of a world market in goods, services, currencies, communication, and people, inclusive of, international students and scholars. It has, however, succeeded in creating both winning and losing economies as well as a storm of controversy in its wake. Politically, Hao (2004) holds up the September 11, 2001, attacks in the U.S. as a negative effect of globalization. He argues that it has made world politics more complicated. When viewed from this perspective, globalization encapsulates the decline of states as actors in international relations while non-state actors such as Al Qaeda, multinational companies, and multilateral organizations gained prominence. As Wagner (2004) puts it, conditions of globalization imply "an absence or at least weakness of politics despite a considerable need" (p. 9) for it. Culturally, globalization signals the emergence of a homogenous world culture, often associated with the rise of a universal mass middle-class culture anchored on American values. Ironically, the status of the U.S. as the world's leading immigrant nation has led to the development of diverse and mixed cultures within its 
borders -- a phenomenon now being replicated and referred to as "Americanization" in Europe (Wagner, 2004). When these immigrants find themselves in higher-education institutions and other social settings, some cultural artifacts and orientation might show strands of a common "world culture." However, a single set of cultural values would prove insufficient to describe such settings.

Strategies for going global in orientation are being embedded in the institutional policies and practices of institutions of higher education in Australia and most other OECD countries. The implementation of transnational programs and curricula that equitably facilitates the learning aspirations of all students, irrespective of their national identities is the purported bedrock of the Australian national policy on international education (Haigh 2002). The Australian model seeks to build a curriculum and an environment which values and promotes social inclusion, cultural pluralism, and world citizenship (De Wit, 1999; McBurnie, 2000), helping staff and students develop the skills needed to operate in a culturally diverse environment. It is predicated on the assumption that internationalization, as many authors have noted (e.g., Back, Davis, and Olson 1996), requires national and institutional approaches rather than piecemeal approaches.

International Education in the United States Before the 9/11 Era

An important goal of higher education is to prepare individuals to work effectively with people from different backgrounds (Smith \& Schonfeld, 2000). Common approaches include creating learning environments that promote and value diversity, infusing diversity into university curricula, and intentionally exposing students to multiple and sometimes competing perspectives that challenge previously unexamined assumptions. As several studies have shown, such challenges, when incorporated into 
appropriate pedagogy, can promote high levels of intellectual and personal development (Astin, 1977, 1993; Chickering \& Reisser, 1993; Kuh et al., 1991; Sanford, 1962). In today's interdependent world, diversity on college campuses is not a gratuitous or idealistic goal; it is essential in order for college students to learn how to live and work effectively with others who differ from themselves (Smith \& Schonfeld, 2000).

International students constitute an increasingly relevant and important source of diversity on college campuses. Attending a school enrolling substantial numbers of international students may put American students at an advantage in the marketplace, to the extent that the experience increases their cultural sensitivities and skills in working with people from different backgrounds (Carnevale, 1999).

Despite this, the U.S. still lacks a cohesive international education policy. Many individual institutions maintain student exchange and transnational programs, study abroad programs, and language immersion programs that attract a sizeable number of foreign students. There is, however, still no cohesive national strategy for achieving internationalization despite NAFSA's long-standing advocacy for such a blueprint. Once with more than one third of the world's international student population, the U.S. was considered their choice destination. Although it continues to be the hub of global education, international students and scholars sojourning in the United States have faced important cultural and psychosocial barriers. Several studies have documented that these relate to transition issues such as culture shock, language barriers, marginality and mattering, and wrong placement and advisement (e.g., Cao, Henderson \& Milhouse, 1993; Carden and Feicht, 1991; Kim 1991; Porter \& Samovar, 1994; Proyrazli et al. 2001; Schaefer and Dundes 1995; Schlossberg 1989; Zimmerman 1995). 
Sodowsky and Plake (1992) found that Muslim students reported a greater degree of prejudice from the late 1980s through the early 1990s than did students from other religious backgrounds. Ferdnandez and Sanchez (1993) linked this to the burden of stereotypes carried by international students; they are often presumed to be generally inferior to domestic students, with poorer academic preparation and inadequate language ability. Also, in his unpublished doctoral dissertation, Gonzalez (1990) found that while faculty and staff at Miami Dade College, Miami, Florida, perceived all international students, regardless of immigrant status, as poorly educated, the students self-rated themselves as well-prepared for college. Yet, such perception makes them particularly vulnerable to ethnic and racial discrimination, leading to negative psychological consequences. This situation appears to have been exacerbated with the introduction of NSEERS and its elaborate curbs on the movement and conduct of students from targeted countries in the post-9/11 period. In the light of the contention by Veysey (1965) that "the university in the United States had become largely an agency of social control"' (p. 440), my study examined how the work of international students and advisors has evolved since $9 / 11$.

Dundes and Rajapaksa (2002) contrasted 182 international students with a similar sample of American students to ascertain if students coming from abroad have greater difficulty in adjusting to college. They found that foreign students have a harder time adjusting to college. In a study of 198 Norwegian Fulbright students, Lysgaard (1955) shows that having host friends helps bring international students out of the "U-curve," the emotional slump that follows the initial feelings of euphoria and excitement associated with the immediate post-arrival period. This theory traces the adjustment process of 
sojourners along a time continuum that moves from a honeymoon period to a state of culture shock, followed by an acceptance of reality in the host culture, and ultimately culminating in a mastery stage where the expatriate is effectively immersed in the host culture. It was affirmed in subsequent studies, including Black, Mendenhall, and Oddou (1991). Poyrazli et al. (2001) reached a similar conclusion about Turkish students but linked the initial feeling of depression to the deprivation of familial support and validation, which enhanced international students' self-concept back home.

International students place a higher premium on academic success and professional training (Nicholson, 2001). Achievement of academic competence (Chikering, 1969) is, however, often an unrealizable dream for some international students due to no fault of their own. A comprehensive literature review by Church (1982) found that inadequate prior orientation and poor academic advice for international students transitioning into a new academic environment often leads to confusion and avoidable errors in placement. This negatively impinges on students' academic performance, a characteristic that transcends the pre- and post-9/11 eras.

So far, however, this discussion has focused on students at 4-year institutions, but community colleges should not (and cannot) be ignored. Although not eventually represented in this study, the community college system in the U.S. offers students access to post-secondary education through Associate in Arts degree programs that are approved as equivalent to the first 2 years of a 4 -year university education. They also offer Associate in Science, Associate in Applied Science, and short-term courses focused on training the mid-level work force. The dual role of the community college as a bridge to 
the Bachelor's degree for a few and vocational centers for many inspired Dougherty (1994) to describe it as the contradictory college.

Several studies have been conducted on issues affecting international students in the community college setting in the U.S. In his doctoral dissertation on the personal, academic, and personal characteristics of immigrant and non-immigrant students in an urban community college, Gonzalez (1990) listed the association of U.S.-earned degrees with greater prestige and career opportunities, the highly selective nature of postsecondary educational systems in the source countries, and favoritism in the admissions process, as several of the reasons why foreigners prefer to study in the United States. The influx of international students opened up demand for services geared at meeting the needs of these students in the areas of language acquisition and mastery, academic support services, and social and cultural adjustment. These services were initially provided on a volunteer basis by interested graduate students and faculty, but virtually all higher educational institutions now have full-fledged international student and scholar services and/or international education offices.

In a major departure from the thrust of previous studies, Gonzalez distinguished between the background, needs, and statuses of immigrants (e.g., students on permanent residence, political asylum, etc.) compared with F1, M1 and J1 non-immigrant students in community colleges and other post-secondary institutions in the United States. The F-1 visa is issued for non-immigrant students who wish to study or conduct research at an accredited U.S. college or university. It is exclusively for academic or language training programs. On the other hand, the M1 is a vocational studies temporary visa available to people who want to study or train at a non-academic institution or program in the United 
States. The J1 visa is reserved for non-immigrants who will be engaging in academic studies as exchange visitors. It is the major visa for educational and cultural exchange programs.

Gonzalez (1990) hypothesized that the personal, educational and financial needs, and objectives of immigrant and non-immigrant students are different, so it was imperative for institutions to identify the individual and collective needs of the students and put in place programs to facilitate their adjustment process. To help international students better adjust to the American community college, Gonzalez (1990) proposed a number of solutions. These included ongoing orientation and individual advisement, integration of cultural awareness into the ESL curriculum, and faculty development relating to best pedagogical practices for this population. He also proposed dissemination of information about local apartment rentals, campus activities, the College Level Examinations Program (CLEP), and laws relating to schooling, discrimination, immigration, and employment.

Gonzalez's findings in this study help emphasize the heterogeneity of international students and the need for administrators to design targeted programs to address the needs of sub-sets of this population. Poyrazli and Lopez (2007) arrived at similar conclusions. Unfortunately, however, there was little attempt by Gonzalez (1990) to link recommendations with findings. Furthermore, and more important, there has been little research on international educators and advisors and how their work has changed since $9 / 11$. My study will look at international education after $9 / 11$ from the perspective of international education advisors and administrators. 
International Education in the United States After the 9/11 Era

International services professionals have been saddled with the challenge of grappling with the perceptible slow-down in the flow of international students and scholars into the U.S. after 9/11. Fear of terrorism led to changes that threatened to end some cultural exchange programs. An online survey of 500 international education professionals by the Institute for International Education one year after 9/11 showed that they still regarded such exchanges "as more important or equally as important on their campuses" (p. 11) as before the attacks.

Also, there has been an upsurge in the number of U.S. students participating in study abroad, even though the 2003/2004 academic-year witnessed a drop in foreign student enrollment in the country for the first time in 32 years. Of the top five countries that send students to the United States, China was down by $20 \%$, India by $9 \%$, Japan by $14 \%$, Canada by $3 \%$, and South Korea by $1 \%$. Comparative figures from the predominantly Arab and Muslim Middle East showed a $9 \%$ decrease following a $10 \%$ decline the year before.

This development has been attributed to the apparently harsher regulatory environment for international education after the September 11, 2001, attacks. Regretfully, however, there is a dearth of rigorous studies on the nature of the post-9/11 firmament, a phenomenon I have dubbed the "post-9/11 syndrome" and how it has impacted international education. The existing literature consists mainly of historical studies, such as the final report of the National Commission on Terrorist Attacks Upon the United States (“9/11 Commission”), meta-analytical studies (e.g., Starobin, 2005), and descriptive studies (e.g., Anderson, 2005; Kless, 2005; Johnson, 2003), which 
essentially detail the characteristics of the new legal and policy environment for international education in the aftermath of the attacks. Some other studies take the form of position papers and evaluative reports (e.g., Sigya \& Hayward, 2003; APLU, 2004) that seek to advance or legitimize certain agenda or points of view. A few studies, however, baulk this general trend (e.g., Schmitt, Spears, and Branscombe, 2003; McKeown, 2003; Mpoyi \& Thomas, 2003; Fullerton, 2005; Min-Hua , 2007; Poyrazli and Lopez 2007). In this literature review, I have covered each of these broad swathes, while giving primacy to the meta-analytical and research studies.

\section{Empirical Studies of the Post-9/11 Era}

Starobin (2005) conducted a meta-analysis of studies related to the post-9/11 environment of international education in the United States, with emphasis on policy issues impacting international students' ability to access U.S. colleges and universities. She studied the establishment of the Department of Homeland Security (DHS) and the implementation of SEVIS for online tracking of non-immigrant students (F/M visa holders) and exchange visitors ( $\mathrm{J}$ visa categories). She found that the transition in the 2003/2004 session from manual processing to the SEVIS system, as well as the rigid compliance requirements of the new system, drastically reduced face-time between international students and their advisors, thereby limiting outreach and advocacy efforts for and on behalf of the students.

Starobin blamed SEVIS for "sending unwelcoming messages to the world's academic communities" (p. 63) and largely precipitating the diminishing status of the internationalization effort in the U.S. She catalogued other problems associated with the stringent post-9/11 policy environment, such as the increased rate of visa denials for 
males from Middle Eastern countries, a $14.8 \%$ decline in enrollment in ESL schools, and new complications arising from international students who leave the country temporarily but are prevented from returning to the U.S. to complete their studies. Starobin argued that, with tuition relatively low, and employment policies regarding international students more liberal in Britain, Canada, Australia, and other countries, the U.S. is increasingly at the losing end of the competition for foreign students, Starobin, however, conceded that the economic crisis in Asian countries like Japan, China, and South Korea which, alongside India, amount to $41 \%$ of the international student enrollment in the U.S. could partly account for this downturn.

To redress the situation, Starobin (2005) suggests a change in the prevailing mindset that sees international education as part of a terrorist problem to one that, according to NAFSA's Task Force on International Education Access, can be "part of the solution" (p. 64). Such a paradigm shift in policy thrust would involve recognition that enhancement of international education and national security can be two sides of the same coin. She suggests a more integrated approach to recruitment and retention of international students to the United States, spanning regulatory issues, financial matters, and marketing strategy. At the institutional level, she recommends that multi-institution consortiums should be formed to identify "barriers and areas of improvements for SEVIS and other policy issues" (p. 70). She also advocates innovative recruitment strategies, such as personalized websites for prospective students to track their application status, and affiliate/articulation agreements between U.S. colleges and educational institutions abroad. 
Starobin's argument on the non-contradictory nature of national security and the internationalization of education is in line with the position of NAFSA, which has made this theme its mantra in the post-9/11 era. It strikes at the very core of the ongoing debate on the future course of internationalization in the fear-drenched environment imposed by the traumatic events of September 11, 2001. However, Starobin's study gives excessive attention to SEVIS, which constitutes just an important part of the myriad of challenges being confronted by international education professionals in the post-9/11 era.

In this regard, Matus (2006) attempted to put things in perspective in her study of discourses underlying international students in the post-9/11 policy firmament. She argues that unitary identities are ascribed to all international students, without regard to the complexities of being constituted by the student before and after $9 / 11$, predicated on their individual, national and cultural identities, and predilections. Matus examined some policy documents and position papers from regulatory institutions from the Departments of State, Justice, and Homeland Security, as well as of interest groups like NAFSA.

Based on her analysis, she isolated four discourses as informing attempts to regulate a unitary identity for all international students, particularly in the post-9/11 world: the non-immigrant, threat, control, and benefits, which are the dominant but often conflicting threads of thought in this arena. They underpin an "essentialist and unitary understanding of international students," which erase historical and social differences among them, leaving them stranded "in a space of uncertainty, dislocation and vulnerability" (p. 3). As Matus (2006) posits, the discourse of the non-immigrant lumps international students together with ethnic minorities in the United States as having a history of discrimination and dehumanization but bars them from accessing government- 
sponsored financial aid and other perks associated with that status. The discourse of control assumes that international students and scholars are not responsible enough. As purported sources of potential danger to the society, their daily academic and social life must be controlled through regulations that put them "out of status" and thus subject to deportation should they not pursue a full course of study, work off-campus without USCIS approval, fail to complete their education in a timely manner or contravene some other obscure regulation (s). Their spouses are precluded by Department of Justice regulations from pursuing independent personal development or career plans outside of recreational studies.

Of particular significance in the post-9/11 world is the discourse of threat upon which the discourse of control is predicated. Matus argues that post-9/11 regulations "structure the exclusion, social isolation, and marginalization of international students" (p. 7) by basing the need to monitor international students on the imperative of national security and establishing an alert system to detect failure of the student to report to a litany of regulatory bodies. The three foregoing discourses are only counter-balanced by the discourse of benefits, essentially promoted by NAFSA, which sees international education as cultural capital and international students as mobile commodities that yield enormous economic and diplomatic dividends. NAFSA's narrative serves as some form of validation for the foreign student on an American campus but does not go far enough.

The discourse of benefits is also akin to the chattel narrative advanced by Farnsworth (2005), who proposes an integrated recruitment strategy by community colleges and universities to attract more international students to the United States. Matus criticizes NAFSA for accepting the other three discourses that limit international 
students' subjectivities and the kind of choices they can make, while merely differing on some details. It will be important to see how the subjects of my study (international education professionals) understand the context in which these narratives may take place and the relative impact (if any) they perceive on their institutions.

As Min-Hua (2007) found, international students are particularly sensitive to the negative and often xenophobic attitudes Americans have of their home countries. The tendency of the media to stress the negative aspects of life in non-Western societies and the ensuing negative perception of students from certain countries impinge adversely on their ability to build and nurture healthy relationships with citizens of the host country.

The findings of pre-9/11 studies regarding the adjustment issues faced by international students have been replicated by more recent studies. They are ample indicators of the transcendental transition challenges being faced by international students across both periods. For instance, Min-Hua (2007) conducted a narrative study on why a Chinese female international student kept silent in her American classes. The student not only internalized negative perception of herself as a useless person in group discussions, but a deficient identity was attributed to her by her American counterparts, who valued assertiveness and considered silence an indication of inadequacy. Given that opportunities for second language learners to initiate or contribute to discussions are limited, Min-Hua suggests that the student's silence cannot be attributed solely to her cultural background or personality. The "possible disempowering nature" of American higher educational setting, with its emphasis on success as defined by the dominant White culture, was cited as a plausible explanation (p. 380). 
Disempowerment (and maladjustment) in this regard could also ensue from legal issues relating to the legal status (or lack of it) of international students and/or their spouses. Eligibility for work and immigration problems also have a negative impact on international students economically and psychologically (Solomon \& Nieman, 2003).

These tendencies appear exacerbated in the post-9/11 period. Poyrazli and Lopez (2007) examined group differences in perceived discrimination and homesickness in a sample of 439 college students (198 international and 241 U.S. students) from two campuses of a university. Within the international student group, they also examined homesickness, discrimination, age, English proficiency, and years of residence in the U.S. Results indicated that international students experienced higher levels of discrimination and homesickness than U.S. students. Younger students, those with lower levels of English proficiency, and students with higher levels of perceived discrimination, reported having higher levels of homesickness. Also, years of residence and race or ethnicity predicted international students' level of perceived discrimination. Being a European international student predicted lower levels of perceived discrimination than did being an international student from other regions of the world. These findings indicate that international student advisors and administrators must tailor different services to the different segments and changing profiles of the international student population. They must also engender systems that reproduce non-discriminatory policies, culture, and outcomes, and that offer opportunities for international students and scholars to overcome the deleterious effects of discrimination on their identity development.

Schmitt, Spears, and Branscombe (2003) found through path analysis that international students' perception of discrimination engendered lower self-esteem and 
higher identification with other international students. They also found that identification with other international students led to an increase in self-esteem. This suggests that under the stress of feeling discriminated against, international students seek out identification with other international students to counteract the negative effect of discrimination on their self-esteem. This discussion has focused on 4-year institutions after $9 / 11$ but the community college should also be considered.

For community college administrators and student affairs professionals interested in improving their enrollment numbers while meeting the academic and social needs of their current students, an important study by Farnsworth (2005) offers a pragmatic strategy. His review of the post-9/11 data on international student enrollment in U.S. universities and colleges reveals a decline of $30 \%$ or more in international student enrollment from Muslim and Middle Eastern nations in the immediate aftermath of the attacks (Open Doors, 2003). By the following year, 15 of the 16 Mid-Eastern and predominantly Muslim North African countries registered a steep decline in their student matriculation numbers at U.S. colleges, with Libya the lone exception. While the MidEastern axis is no more than $6 \%$ of the overall student population in the U.S., they have been most affected by the increased difficulties in obtaining student visas during the post9/11 period. Overall, there has been a steady decline in the number of international students to the U.S.

While acknowledging this reality, Farnsworth (2005) suggests that the U.S. can regain its competitive advantage in the international student market by adopting an integrated recruitment strategy that recognizes the increasing preference of the sojourners for community colleges as the starting point of their educational journey in the US. In the 
1990 s, the enrollment of foreign students in community colleges grew by $14 \%$ compared to a $9 \%$ global upsurge for the U.S. higher educational system. In the Fall of 2000, while foreign students in community colleges grew by $5.3 \%$, four-year colleges experienced a $1.6 \%$ upswing in international student enrollment. Farnsworth (2005) attributes this trend, which has been sustained even in the post-9/11 era, to the low tuition base and comparatively lower annual increment of the two-year colleges compared to their fouryear counterparts. The average annual tuition for the community colleges in 2000 was $\$ 5,460$, but four-year colleges cost $\$ 12,992$ (NCES, 2002).

In terms of an overall global strategy to market U.S. higher education to the outside world, Farnsworth (2005) considers the U.S. community college system as an opportunity and strength not available to the competitors for international students (e.g., Australia, Britain, and New Zealand). With 729 community colleges already hosting international students in 49 of the 50 states in the U.S. (AACC, 2005), Farnsworth suggested that what is needed is an integrated "Two Plus Two" model in which every university establishes articulation agreements with one or more community colleges for recruitment and provision of educational services. Holding up the University of Missouri College-University Consortium as a model, he outlined the modalities of such a cooperative enterprise and lists among its advantages reduced costs, greater efficiencies through market segmentation, and the pooling together of consortium resources to achieve mutually beneficial objectives. He also cited the reduced cost of attendance for the international student, residual articulation opportunities for domestic students, and broader social and cultural opportunities for all. 
Although he failed to recognize it, other possible gains from this kind of integrated approach include an increase in the number of international students being granted visas to study in the U.S., even though they would be starting at the community college level. However, the implied treatment of international students as tradable goods or chattel in Farnsworth's analysis reinforces the commercialization of higher education in this era of globalization. Some of the study's recommendations, such as residential housing at community colleges, also appear impracticable given the historical focus and funding pattern of the institutions. Also, this model will require a paradigm shift by consortium members. The idea of not presenting the "Two plus Two" option to prospective international students by the University of Missouri unless they grumble loudly about cost could result in lost opportunities, with the students giving up on international education entirely or opting for the U.S.'s low-cost competitors. Also, an integrated international education policy would be needed to optimize this kind of scheme.

The emergence of some community colleges as baccalaureate-granting institutions in the U.S. and Canada, which Levin (2004) studied, could be one way of benefiting from the "Two Plus Two" system without the attendant bureaucratic gerrymandering. Such forays by otherwise traditional two-year institutions have, however, been marked by identity crises that have somehow escaped the radar of researchers and regulatory authorities. Noting that an institution's identity represents its core and enduring essence that helps to limit and direct its actions, Levin also posed the question of whether the community colleges' statutory obligation of guaranteeing open access and of fashioning and offering a comprehensive curriculum that responds to 
communities' needs are not compromised. In raising this question, it must be noted that Levin did not give any consideration to the possible implications for international student enrollment, recruitment, and satisfaction. Furthermore, absence of a national international education policy in the United States has made the possibility of the kind of integrative model that enhances the discourse of benefits approach to international students and scholars, which is being pushed by community college scholars like Starobin and Levin, as mere academic exercises.

\section{Empirical Studies of the Post 9/11Era}

In fully understanding the post-9/11 syndrome, the public perception of the American persona is an important indicator of the relative difficulty of the work of international education professionals. Drawing from the theory of social construction of reality (See Berger \& Luckmann, 1966), which holds that people develop understanding of the world through communication with others in society, Fullerton (2005) investigated international students' attitude towards the U.S. in relation to the messages they are getting from the mass media. He administered a 13-page likert-scale questionnaire based on two attitude scales (attitude toward America and attitude toward advertising) to 105 international students from 25 countries attending summer classes at Regent's College in London. Seventy percent of the sample was from Europe, $10.4 \%$ from the Middle East/India, $9.5 \%$ from East Asia, $5.7 \%$ from Africa, and $3.8 \%$ from South America.

When SPSS was used to analyze the data, it was found that the item with the highest mean rating was the statement, "Americans like to dominate other people," followed by "I like American music, movie and television." This seems to indicate an ambivalent and somewhat paradoxical perception of the U.S. by the foreign students, 
more so that the item with the lowest mean rating was the statement, "Americans are peaceful people." T-tests and ANOVA showed no significant differences in attitude along demographic categories. An obvious limitation of this study was the setting, which virtually guarantees the domination of its sample by students of European origin.

Duverneuil (2003) examined non-immigrant student visa policy and the impact of the 9/11 attacks on U.S. symbols of economic and political power. A practicum at George Mason University Office of International Programs and Services was completed as part of Duverneuil's study to learn more about the role of international student advisors and USCIS-Designated School Officials responsible for SEVIS reporting. The literature review examined key issues for international student advisors, such as helping students understand how to maintain their immigration status and assisting them to adjust to the American education system and culture. However, even though that study presents a useful taxonomy of the functions of international student advisors, it does not offer a critical analysis of the context in which those duties are carried out.

McKeown (2003) conducted an exploratory study on the relative interest in study abroad of students who underwent such experiences before $9 / 11$ compared to those who did after 9/11. Based on Carlson, Burn, Useem, and Yachimowicz (2000), who posited that study abroad students connect their experience with future career plans and are more disposed to learning about other languages and cultures, McKeon's study of an education-abroad office in a public university sought to understand the effect(s) of the 9/11 attacks on students' perceptions.

For students who studied abroad during Summer 2000 and Fall 2001, 44 out of the 145 questionnaires were returned compared with 77 out of 190 for the Summer 
2002/Fall 2002 group. The overall response rate was $36 \%$. A statistical comparison of the two independent samples showed no significant difference in interest and concern about study abroad between both groups. This showed that the students sampled would not allow fear of terrorism to deter them from pursuing study abroad experiences that could enhance their career aspirations and help them acquire critical cross-cultural skills. Although this is a very important study in our quest to understand the post-9/11 environment of international education, its external validity is limited by its small sample size and failure to test the survey instrument for reliability. Also, it focuses on the perception of students of their study abroad experiences, while my study will focus on international student advisors and administrators' perception of the post-9/11 environment for international education.

A major study conducted by Mpoyi and Thomas (2003) investigated the growing skepticism about the merits of training a workforce that would have the skills to cope with the demands of globalization. They chose the business school of Middle Tennessee State University for an assessment of the effectiveness of the internationalization component of the curriculum. The authors administered a questionnaire to 72 of the 116 students in four of nine business policy classes before and after the students were made to take an international competency exam in the spring of 2002. Results showed that students were neutral about how effectively the curriculum imbued them with international competency but were unanimous that its depth and coverage should be improved. Although male students' perception remained constant during the pre-test and post-test, female students' scores were higher before the exam. However, this study 
neither exhaustively discusses its conclusions nor offers useful suggestions for building a more effective curriculum internationalization effort.

\section{Summary}

Much of post-9/11 research has focused on students or policies, but has not attended to the experiences of educators and advisors who must deal with these students and enforce these policies. These educators and advisors are often the first contacts with the institutions that international students have. The work of educators and advisors, as we know from much of the higher education literature (e.g., Pascarella and Terenzini, 1991), can greatly influence student experiences, and so a study of these educators and advisors is crucial. In this chapter, I have reviewed the international education literature to show that while international students, admissions professionals, and other international education administrators have faced enormous and unusual challenges in the aftermath of the $9 / 11$ attacks, little research work has been done either to capture this critical period from their perspective, or to understand the experiences of educators and advisors who must contend with the effects of $9 / 11$. In chapter 3, I discuss the design of my study, which seeks to bridge this gap and offer useful insights into how international education professionals perceive their work and its environment in the light of the post9/11 syndrome. My study helps to illuminate better the interplay between the 9/11 attacks and the subsisting environment for international education, while offering useful clues to policy makers seeking to promote an internationalization agenda. 


\section{CHAPTER III}

\section{METHODS}

This chapter is focused on the rationale and methods used in conducting this study. My approaches to gathering and analyzing data, site and participant selection, and the reasons for the decisions I made are discussed. The chapter ends with a section on how I preserved the credibility and consistency of the findings. As a reminder, the research questions which guided this study were: (a) How are international student advisors and administrators across two types of institutions dealing with the "post-9/11 syndrome?" (b) What, if any, are the differences in international education after 9/11? (c) What have been the institutional priorities in relation to international education before and after $9 / 11$ ?

\section{The Qualitative Research Tradition}

This study was grounded in the qualitative research tradition and its emphasis on the importance of naturalistic inquiry. It involves looking at things in their natural setting. Instead of one undiluted reality, qualitative research has celebrated the existence of multiple-constructed realities, regarding interaction between variables as important. I proceeded from the perspective that time and context-neutral generalizations are neither desirable nor possible, that research is value-bound, and that it is impossible to differentiate fully between causes and effects. Unlike quantitative research, which is deductive in orientation, qualitative researchers believe that logic flows from the specific to the general: explanations are generated inductively from the data. In its purest form, qualitative research also holds that the knower and the known cannot be separated because the subjective knower is the only source of reality, and the investigator is an 
integral part of any investigation (Guba, 1990). Philosophically, qualitative studies are partly rooted in symbolic interaction, phenomenology, and ethnography, which spun and supported constructivism, relativism, idealism, humanism, hermeneutics, feminism, critical theory, and postmodernism (Burke \& Onwuegbuzie 2004).

Qualitative inquiry has represented a clear departure from the positivist and logical empiricist philosophy of quantitative purists (e.g., Ayer, 1959) who believe that social observations should be treated in much the same way physical scientists treat physical phenomena. Given the complex nature and dimensions of international education and the multiplicity of heritages and perspectives that the $9 / 11$ incident embodies, I found it undesirable and impracticable using positivist lens to effectively capture the essence of this study, given its inevitable nuances and twists. This was the rationale for the qualitative framework that this study adopted. According to Carr and Kemmis (1986), interpretive forms of educational research emanated from the tradition of qualitative research. In interpretive research, education is conceived as a process and the school system a lived experience that invites comprehension through an inductive approach to inquiry. Believing that meaning is embedded in people's experiences, this approach seeks to expose the insider's perspective (emic), not the outsider's perspective (etic). The goal is not to test some existing theory but to "build toward theory from observations and intuitive understandings gained from the field" (Merriam, 1998, p. 7). The findings in the form of themes, categories, typologies, concepts, tentative hypotheses, and theories, emerge from data.

In this regard, Merriam (1988) further identified five types of qualitative studies: basic/generic, ethnography, phenomenology, grounded theory, and case study. In reality, 
these are not discrete categories. The present study drew from the methods of all of them as appropriate. The basic/generic approach seeks to identify recurring patterns in the form of themes, categories, factors, and variables, that cut through data gathered from interviews, observations, or document analysis. My study approached each case study with varied forms of data. Ethnography seeks to understand the beliefs, values, and attitudes that structure the behavioral patterns of a specific group of people, using techniques such as interviewing, document analysis, observations, investigator diaries, and life histories. My study sought to understand the subjective perspectives of international educators at the two institutions studied. Phenomenology is predicated on the assumption that there is an essence to shared experience; core meanings are simultaneously understood through a phenomenon mutually experienced. In this regard, "the experiences of various people are bracketed, analyzed and compared to identify the essences of the phenomenon" (Patton, 1990, p. 70), while the researcher's initial beliefs about the phenomenon of interest are temporarily cast aside. My study investigated the phenomenon that I have couched as "the post-9/11 syndrome." Grounded theory focuses on emergence of substantive theory from data. While I refrained from putting forth grand theoretical claims in this study, I allowed the data generated from my case studies to help me chart the post-9/11 trend of internationalization in the two selected institutions, as articulated by my study participants.

\section{Case Study Design}

Qualitative research provided the larger methodological underpinnings of my study, but the actual research design is predicated on the case study approach. Case studies are detailed investigations of individuals or social units, such as groups, 
institutions, or cultures. In attempting to isolate and analyze the variables under study, the investigator concentrates on learning the details and nuances of a particular case. The qualitative case study approach focuses on bounded systems that can be studied and comprehended under natural conditions in their own habitat (Stake, 2000). It was adopted for this study for two major reasons. First, it allowed for detailed investigation of the post- 9/11 experiences of international educators at the selected institutions with respect to my research questions. Second, while a few authors broadly addressed the policies established after the 9/11 attacks, there had not been detailed consideration of how the post-9/11 environment impacted international education from the perspective of international education leaders and advisors.

According to Stake (2000), case study research could be intrinsic (i.e., the case studied for its own sake), instrumental (i.e., the case studied to illuminate phenomena or issues of interest), or collective (i.e., an intrinsic or instrumental single case is broadened to incorporate many cases). Whichever approach is chosen determines how a case is bounded. I adopted an instrumental approach in my study, with each case bounded by institution. Two mini-case studies, each focused on a separate institution, were the focus of this work. By adopting this approach, I was able to conduct detailed examination of each "natural" setting on its own terms, and to review relevant documents such as brochures, internal memos and departmental websites whenever possible. I conducted interviews with relevant personnel highlighting the specificity and uniqueness of the post-9/11 international education experience at each institution. My objective in pursuing this course was to elicit "a good concentration of information rather than widely scattered pieces" (Bogdan \& Biklen, 2003, p. 51) in each context. 
I employed the case study approach to ascertain how international educators themselves perceive their experiences in the post-9/11 period in each of my selected postsecondary institutions, using the various methods and techniques that conform to qualitative research. Although commonalities and differences between the two cases were ultimately explored, each mini-case was initially studied separately.

\section{My Role as Researcher}

Qualitative research proceeds from the assumption that the researcher cannot be clinically detached from his work. This is the concept of reflexivity: the active acknowledgement that the researcher's social identity, background, actions, and decisions will impact the experience under investigation. However, the researcher must strive to reflect accurately the voice of participants or observe them in their naturalistic environments. Neil (2006) suggests that the research records should be made to reflect the potential impact of the researcher on the data.

In this regard, the credibility of the researcher is an important component. As a 43-year old Yoruba from the South-Western state of Oyo, Nigeria, in the West African region, who migrated to the United States several years ago, I have been exposed to multiple influences. I liken myself to an eclectic painting born to two Christians, one of whom (my father) is a convert from an extended family of pious Muslims but raised partly by an Aunt who religiously subscribed to the Ifa divinity. I am a product of cultural and linguistic syncretism between my Yoruba cultural milieu and language and the acculturation process that is Western education and English, its medium of instruction. Since relocating to the United States, I have been a graduate student as well as an advisor to student groups like International Friendship Club and the African Student Association 
at Western Illinois University as well as the International Club at Broward College. Of late, I have worked as an International Admissions Coordinator and currently as USCISDesignated School Official (DSO) and Counselor at Broward Community College, where I coordinate the ESL program and serve on the college-wide International Education Committee. The active listening, critical thinking, communication, and empathetic skills I possess as a counselor were transferred to this research endeavor. My experience, which covers a 4-year university and a community college, gave me credibility as an international educator able to understand and analyze issues relating to the internationalization of the campuses in the study.

The fact that my identity cannot be defined in "binary terms" (Adams, Bell, and Griffin, 1997) has influenced my approach to research. I do not believe in absolute truth. To me, truth is relative, hence my commitment to including and validating all voices. This has influenced my insistence on allowing an equal story-telling space for all segments of society. I have a passion for fairness, and as a qualitative researcher, I am sensitive to the concept of the "Other" in all its depth and ramifications. These qualities gave me the necessary credibility with my participants. In the course of the study, I relied on my acute sense of self-awareness to identify the tacit theories that guided my behavior. This helped eliminate selective recording and analysis of data while endeavoring to minimize explicit and implicit bias by utilizing phenomenological techniques, such as epoche or bracketing (i.e., withholding of assent or dissent), and imaginative variation (Girden 2001; Moustakas, 1990). Of these, imaginative variation came naturally to me. It involved seeing the object of study (the phenomenon) from several different angles and perspectives. According to Moustakas (1990), this technique 
endeavors to achieve "structural description of an experience, underlying and precipitating factors that account for what is being experienced" (p. 98).

Site and Participant Selection

The participants for this qualitative study were international student advisors and international education administrators at the University of Miami (UM) and Florida International University (FIU) with at least 8 years of experience in the international education function at their institutions. Access to international educators at the University of Miami was partly facilitated by the institution's president, Dr. Donna Shalala, who mandated her vice president for Student Affairs and her Senior Vice-Provost to participate in the study through a December 30, 2009 e-mail after I seemed to have reached a dead-end. Her intervention helped open doors for me to be able to enlist other international educators in the study after a few appeared to have developed cold feet. At Florida International University, all the participants were contacted individually by me. Miami Dade College was initially proposed and approved by the University Graduate School as the third setting for this study but I received on June 24, 2009, a communication from its Director of Institutional Research that its CASSC Research and Testing Committee met and voted not to participate in the research. The committee had expressed concern because I did not promise confidentiality and that those to be interviewed would have to set aside about 90 minutes each to be part of my study.

SEVIS statutorily mandated each college or university to designate officials who act as reporting officers or Designated School Officials (DSOs) for the United States Citizenship and Immigration Services (USCIS) for international students on F1 and M1 visas. It also mandated the institutions to designate Alternative Responsible Officers 
(AROs) who perform similar functions with respect to J1 exchange students and scholars. The practice has been for colleges and universities to designate international student and study abroad advisors/administrators to perform this function so my interviewees were drawn from this pool of professionals who invariably straddle the worlds of advising, administration, programming and advocacy.

The participants were pre-qualified by experience in order to ensure that they worked in the functional area of international education prior to the $9 / 11$ attacks and could thus convey a sense of how their work and its context had evolved since. I took into account the uniqueness of each setting in conducting in-depth interviews with the key administrators and advisors at each of the universities' international education programs. I first sought out those with the required longevity, and organizational authority (e.g., were there before and after $9 / 11$, had positional power, etc.). I sent them a comprehensive e-mail which clearly communicated my research objectives and modus operandi. I identified the rest of the participants via snowball sampling. The rationale for this approach was to ensure that the study participants possessed the necessary work experience to discuss international education in their institutions before and after 9/11.

It was also an acknowledgement of the possibility that international education administrators and advisors with experiences limited to the pre-9/11 or post-9/11 era might not necessarily have the necessary breadth of experience.

The two selected institutions are located in Miami, Florida, a city of 362,470; the $46^{\text {th }}$ most populous in the U.S., and the second most populous in Florida. A 2004 United Nations Development Program (UNDP) report ranked Miami first in the U.S. in terms of the percentage of foreign-born residents (59\%). The 2000 U.S. national census figures 
put the racial make-up of the city as White (66.62\%), African American (22\%), Native American (0.66\%), Asian (0.04\%), Pacific Islander (5.42\%), and other races $(4.72 \%)$. Of this lot, $66 \%$ self-identified as Latino/Hispanic and $11 \%$ as non-Hispanic White. The ethnic make-up of the city is $34.1 \%$ Cuban, $22.3 \%$ African American, 5.6\% Nicaraguan, $5 \%$ Haitian, and $3.3 \%$ Honduran.

Miami is part of the South Florida metropolitan area consisting of Miami Dade, Palm Beach, and Broward counties that are together regarded as the $45^{\text {th }}$ largest metropolitan area in the world. My choice of this area as the setting for this study was based on the diversity of its peoples, its popularity as a world city and tourist destination, and the fact that it has consulates of major foreign embassies. Its Hispanic flavor is accented by a certain historicity predicated on waves of Cuban immigration beginning with the aftermath of the toppling of Fulgencio Batista in the 1959 Cuban revolution. Independent of the 9/11 narrative, therefore, it could be argued that this would be an otherwise relatively comfortable terrain for non-U.S. born residents and students.

UM is one of the nation's leading research universities. Privately supported, the university's current student enrollment is 15,449 , from all states of the United States and at least 110 foreign countries. It is essentially a residential college, with about $20 \%$ of its student body classified as international. In 2000, its international student enrollment stood at 1,632 . By 2004 , the figure dropped to 1,398 but rebounded to 1,630 by 2006 , when it ranked $77^{\text {th }}$ nationwide in international student enrollment. I selected it because it is a private university in the Miami locale, with a diverse student body, big institutional endowment, and large international programs. International education administrators and advisors who met the study's prequalification criteria at this institution were sought for 
interviews. They included the directors of its International Student and Scholar Services, International Education and Exchange Programs, as well as its Vice President of Student Affairs. Other interviewees were identified through snowball sampling.

FIU, the other case study, has touted itself as Miami's public research university. As one of the nation's top urban commuter universities, FIU brought a unique perspective to the study. The long standing PDSO/director of its International Student and Scholar Services at its University Park campus, its Biscayne Bay Campus director/DSO and the director of its Education Abroad program formed the pre-qualified pool of interviewees. As with the other case, additional participants were identified via snowball sampling.

In summary, two universities with graduate programs, one private/residential, the other public/commuter, were selected for this study. The diversity of types of institutions was deliberate. In interrogating the experiences of international education professionals in the pre- and post-9/11 era, I deemed it important to avoid preconceived, one-size-fitsall categories. Bounding each case study as such was an effective way of avoiding such preconceptions. This study proceeded from the perspective that experiences of international educators would differ within and across institutions, although certain commonalities might exist. Considering that the dominant response of policymakers to the 9/11 attacks appeared to have been hostility to the free flow of intellectual capital, in what ways (if any) was this reflected at the institutional level? Would the experience and perspectives of international educators in a private, research university such as the University of Miami intersect or differ significantly from that of their counterparts at a public research university such as Florida international University? The diversity of types of institutions and programs was an important nuance in my study. 


\section{Data Collection}

As earlier stated, a multiple perspective approach was adopted for this study because of its complex nature and the need to explore the two cases in their individuality, richness, and complexity. Data collecting methods primarily revolved round multiple interviews as well as researcher's field journals and interview notes to track reflexivity. Physical documents such as brochures, internal memos, news releases and training manuals were reviewed and analyzed whenever possible in addition to electronic documents such as institutional and departmental vision statements posted on the universities' websites.

Interviews

As Kvale (1996) has noted, the interview is a powerful pathway to the comprehension of other people's experiences and perspectives. It is particularly potent in giving voice to the experiences of those who have literarily and symbolically crossed socio-cultural and geographical borders. Kvale conceived of qualitative research interviews as conversations that strive to unfold the story behind people's lived experiences. They facilitate the pursuit of in-depth information relating to a particular theme or concern, with a view to dissembling complexities and achieving intellectual understanding. Patton (1990) identified three basic types of qualitative interviewing: the informal, conversational interview, the interview guide approach, and the standardized open-ended interview.

The interview guide approach is the most common. The interviewer has an outline of topics or issues to be covered but retains the flexibility to vary the wording and order of the questions. The data elicited from this format is more systematic and comprehensive 
than in the informal, conversational interview, but the tone still remains somewhat casual. However, analysis and comparison of data generated from the informal process is more involving because respondents are responding to different questions. The standardized open-ended interview simplifies data analysis by adhering strictly to a specific wording and order of questions. It is faster, more structured, efficient, and useful for reducing bias, but the interviewer has little flexibility in probing and responding to the unique concerns and perspectives of respondents.

For this study, I developed an interview guide which formed the basis of the interviews but posed follow-up questions as needed while maintaining an informal, conversational tone. My interview guide was predicated on the three-part scheme developed by Schuman (1982). To facilitate story-telling, the first interview consisted of ice-breaking, free-flowing, autobiographical conversation that was exploratory in tenor and focused on engendering trust and disclosure. The second interview balanced the need to allow participants ample narrative space to tell their own stories with the need to elicit research-specific information by adopting a semi-structured interview format. The third interview further delved into the meanings and interpretative frame derived from the experiences of the educators in the pre- and post-9/11 world. This approach also conformed to the format developed by Seidman (1998), which strives to elicit the interpreted meanings of an experience from participants through in-depth interviewing preceded by life history interviewing.

At FIU, personal interviews with six international student advisors and administrators, each with at least 8 years experience in the international education arena constitute the fulcrum of this study. Interviews were conducted with (a) Dr. Ana Sippin, 
long-time director of the Modesto A. Maidique campus ISSS office and Principal Designated School Official (PDSO) by the United States Citizenship and Immigration Services (USCIS) ; (b), her Biscayne Bay campus counterpart, Ms. Nancy Hernandez, who is a Designated School Official (DSO); (c) Ms. Anoush McNamee, assistant director and SEVIS coordinator on the Biscayne Bay campus; (d) Dr. Hillary Landorf, director of the institution's Office of Global Initiative; (e) Ms. Liza Carbajo, Director, Office of Education Abroad; and (f) Dr. Modesto A. Maidique, the immediate past FIU president and current director of its Center for Leadership.

Similarly, formal personal interviews were conducted with five international student advisors and administrators, each with at least 8 years experience in the international education arena. Interviews were conducted with Dr. Patricia Whitely, the Vice President of Student Affairs, Dr. William Scott Green, Senior Vice Provost and Dean of Undergraduate Education, Ms. Elyse Resnick, Assistant Director, International Education and Exchange Programs, Ms. Claudia Zitzmann, Associate Director, International Student and Scholar Services and Mr. Abraham Varghese, Assistant Provost for International Affairs. I also had background discussions in September 2007 with Mark Reid, Teresa de la Guardia and Michele Alvarez, directors of admission, ISSS and the Intensive English program, respectively. Because of time constraints, the participants were unavailable for three separate days of interviews but the three-part format of Schuman's scheme was preserved in sessions, which ranged from 60 to 90 minutes.

The interviews were highly structured, not only to make the most of the time I had, but also to ensure that I minimize the tendency of high-level administrators to deal only with generalities. This three-part format allowed participants to establish the context 
of their experience within the introductory part of the interview. In the second part, they reconstructed and elaborated on the details of their experience. In the concluding part of the interview, they then reflected on what meaning their experiences held for them (Schuman, 1982).

The interview guide in Appendix A was utilized for this study. The interview guide consisted of basic open-ended questions geared at eliciting responses from the participants about the internationalization process in their institutions before and after 9/11. In certain instances, such as when I interviewed FIU's Ana Sippin, I had to exercise flexibility when the interviewee immediately began to reflect on the meaning of her post9/11 experience before I fired off my first question. As much as possible, the interviews at each institution were conducted not more than 2 weeks apart from each other. At FIU, the first four interviews were conducted between April 8, 2009, and June 25, 2009, but I was only able to gain access to the other two interviewees in January 2010. At UM, my first interview was conducted on October 26, 2009. All the other four participants were interviewed between January 21 and 28, 2010, following a prolonged interlude during which some prospective interviewees, who initially agreed to participate in my study, appeared to have developed cold feet. The intervention of the university's president, Donna Shalala, who mandated the senior vice president for undergraduate education and the vice president for student affairs to participate, helped me to regain momentum.

\section{Documents}

For each institution, the interviews were highly informed by a careful review and analysis of institutional documents to ferret out policy trends in the pre- and post-9/11 era. This was in line with the advice of Coffey and Atkinson (1967) on the need for 
qualitative researchers to explore their data from a variety of perspectives or at least be able to "make informed decisions about (the) analytic strategy adopted for a particular project” (p. 4).

The kernel of this aspect of my study was a review of each institution's internationalization policy/objectives, brochures, news releases, internal memos and administrative structures, in the pre- and post-9/11 period. These were used to identify seeming trends and theses that were subjected to further investigation and analysis.

In this regard, for each case study, I reviewed institutional data relating to the recruitment and enrollment of international students for the 5 years prior to $9 / 11$ (19972001) and at least five post-9/11 years (2002-2007). Study Abroad participation trends for the period in question were similarly scoured. The data were analyzed for significant trends to track this important index in the immediate pre-and post-9/11 period. I adopted this approach because of the usefulness of demographic data in suggesting trends. For instance, I was able to ascertain whether the "number of students served has increased or decreased" in each institution and to provide "descriptive information (e.g., region of origin etc.) about the population served by a particular educational program" (Bogdan \& Biklen, 2003, p. 143). As Tesch (1990) has pointed out, qualitative researchers use numbers as they search for patterns in human activity.

In certain cases such as the countdown towards SEVIS at FIU, I was able to review documents to identify or support salient themes and chart trends. This was because documents are non-reactive: they could not alter their nature or behavior to conform to the expectations of an investigation. Included in this category were memoranda, participants' resumes, newsletters, policy documents, proposals, codes of 
ethics, statements of philosophy, news releases, brochures, departmental/institutional websites, pamphlets, and other relevant documents. Some of these documents were either volunteered or identified by the interviewees with others scoured out in the process of my independent research. Such materials were rich sources of information about events, people, decisions, and situations in their context. They revealed what people and the institutions did, what they valued, and how they behaved. To have ignored them would have been to leave a gaping hole in this study.

Therefore, while conscious that some documents were irrelevant, uninformative or self-serving (Guba \& Lincoln, 1981), I tracked and content-analyze documents that seemed relevant to each case, coding and categorizing deciphered meaning based on the interpretive frame of the post-9/11 syndrome and the internationalization agenda at our selected institutions. It must be indicated, though, that there were many instances when I sought access to some documents but met with restrictions and impediments. At the University of Miami, for instance, the participants were not willing to share with me internal memos/documents relating to the pre- and post-9/11 agenda and behavior of the institution, while study abroad participation data that I accessed at FIU was incomplete.

\section{Observations}

While this study did not entail formal observations, interviewing the participants in their offices and familiarizing self with the workings of the institutions entailed observing the participants' behavior and surroundings as well as institution atmospherics. In this regard, I kept pre- and post- interview notes of my observations, a practice which richly enhanced my analytical frame. 


\section{Data Organization and Analysis}

All the interviews were taped. I kept post-interview notes of what transpired in the course of the interviews in terms of the interview's setting, the body language and nonverbal cues of the interviewees and my thoughts as interviewer and researcher. Data collection and analysis for each institution was conducted simultaneously in order to arrive at "parsimonious and illuminating" material and to avoid being saddled with "unfocused, repetitious and overwhelming" data (Merriam, 1988, p. 162). Each mini-case was treated separately, and for the interviews, I followed the advice of Bogdan and Biklen (1992) that subsequent data collection sessions should be used to further narrow the focus of the study and develop leads emanating from previous sessions.

As the researcher, I wrote memos and field journals to myself on my observations

and ideas as they unfold. I tried out ideas and themes on key subjects, solicited ideas from key informants and retreated to reflect on the data, played with metaphors, analogies, and concepts, while continuing to review the literature. I wrote and attached field notes to the transcripts of each interview and arranged them and other materials together for ease of analysis, coding, and interpretation, in order to generate findings.

To create categories and sub-categories, bits of information and units of data were sorted into groupings that had something in common. I organized the data into manageable units (using file folders), coding and synthesizing them based on observable themes, key words, and patterns. The interview transcripts as well as my descriptive and reflective notes were manually sorted out. I created two binders, one for each institution in which I neatly arranged my transcripts, field notes cum parenthetical thoughts and documents. 
Analysis involved organizing my data into manageable units, coding, and synthesizing them, while looking for themes and patterns. I started with the coding ideas identified by Bogdan and Biklen (2004), such as setting/context, perspectives held by participants/subjects, participants/subjects' ways of thinking, process codes, strategy codes, relationships, and social structure codes.

My intent was to interpret my participants' experiences and perspectives using first order concepts. Some of the initial codes I identified during my field work - first at FIU and later at UM - included "forays by happenstance," "accumulation of acronyms: SEVIS, NSEER, IRRIRA, I-20, USA Patriot Act, USCIS," "passion," "new roles," "ambiguity," "contradiction," "cluelessness," "frustration," "disorientation," "caught-inthe-middle," "hands tied," "tensions," "control," "helplessness," "out of status," "phobia," "conversation starter," "flight to safety," "government overreach," "caught flatfooted," "paradigm shift," "advocate," "campus enforcer," "immigration police," "skewed vision," "global vision," "opportunity," "new respect," "more tedium," "resources," "regulations," "stagnation," "profiling," "termination" "middle-east," and "terrorist."

While these codes covered different strata, I took great pains to make coherent meaning out of them, allowing the data and the emerging themes to dictate the direction of the study, collapsing overlapping codes as needed, while bearing in mind that analytical frameworks are never cast in stone in a qualitative study of this nature. Interpretations were constantly reviewed, revisited, recast, and even discarded, in a constant search for transcendental themes. 
The second step in this process involved molding the coded strands into a coherent unit by uncovering how they occur within the experience being investigated. The last step in this analytical process was contextualization. It was during this stage that I strove to situate the constructed process in the respondents' lived experience in the post9/11 world. It involved naming the categories through three possible sources: the researcher's ideas, the participants' quotes, and the literature.

Glaser and Strauss (1967) cautioned against trying to fit data into some prefabricated categories. They noted that "emergent categories usually prove to be the most relevant and best fitted to the data" (p. 37). Miles and Huberman (1994) also recognize loose (less-structured and emergent) and tight (pre-structured and tunneled) qualitative analytical designs but advise inexperienced qualitative researchers to tilt towards the latter. Though an emergent qualitative researcher, I took the middle ground by approaching this study with a clear plan while retaining enough flexibility to accommodate field-induced methodological and substantive changes.

In developing categories, I applied criteria suggested by Guba and Lincoln (1981). These include frequency of occurrence of a concept in the data, number of references by respondents, prioritization of concept by respondents, uniqueness of category, and provision of fresh insight into an otherwise common problem. This approach also helped me to develop more complex and sophisticated over-arching themes as the analytical process advanced. As earlier indicated, each institution (or case) was treated simultaneously as an independent study and as part of a larger study of the post9/11 syndrome. Thus, difference was maintained, but commonalities across the cases were ultimately ferreted out, analyzed, and reported. 


\section{Dependability and Consistency of the Study}

Lincoln and Guba (1985) proposed dependability and consistency in qualitative research as alternative schema to the concepts of validity and reliability traditionally employed in quantitative research. Their approach incorporates an audit trail or peer review mechanism through which results could be confirmed to be consistent with the data collected, triangulation, dense description, reflexivity, and stepwise replication. Qualitative research is defined by the idea that the researcher is the primary instrument for collection and analysis, and so peer de-briefer seems antithetical to this but as my analysis proceeded, I bounced ideas off a colleague who holds a $\mathrm{PhD}$ in Psychology. He was helpful in the code-recoding process, often exposing my blind sides, as I refined categories. His involvement actually helped me in developing the "3Ts" (trajectories) that eventually constituted a significant aspect of my descriptive frame for the post-9/11 syndrome at my two selected institutions.

I have left an audit trail for this study by explaining, in detail, my data collection and analytical methods, including how respondents were chosen, how categories were derived, and how decisions were made throughout the inquiry. Through member checks of interview transcripts and data with participants, I endeavored to ensure that the views of participants were not misrepresented. Transcripts of all interviews were e-mailed to participants for review and validation, and corrections effected as advised.

The Qualitative Analysis Documentation Form developed by Miles and Huberman (1994) was adapted for this study. It facilitated the recording of procedures and outlining of data-gathering and analytical steps, as well as conclusions emanating from each data set. 
As Sandelowski (1986) suggested, this helped promote transparency by leaving a decision trail that empowered the consumer to monitor and verify the research process.

\section{Summary}

In this chapter, I discussed the rationale and methods I used in conducting my

study. My approaches to gathering and analyzing data, site and participant selection, and the reasons for the decisions I made were discussed. The chapter ended with a section on how I enhanced the credibility and consistency of my findings. 


\section{CHAPTER IV}

\section{ANALYSIS AND FINDINGS: FLORIDA INTERNATIONAL UNIVERSITY}

In this chapter, I provide a brief historical overview of Florida International University (FIU) and the evolution of its internationalization function over time. I also give a detailed report and analysis of my interviews with key international student advisors and administrators, an examination of the institutions data base and a review of some documents germane to the theme of this study.

\section{Historical Overview}

FIU was founded in June 1965 as culmination of a vision first outlined to members of the Florida legislature in 1943 by Senator Ernest "Cap" Graham. Its first president, Charles "Chuck" Perry was a mere 32-year old when he was named to the position in 1969, but he was a highly regarded higher education expert and Vice Chancellor of the Florida Board of Regents. He recruited a campus architect, Francis Telesca, and three founding administrators, Butler Waugh, Nick Sileol, and Donald McDowell, who worked to transform the site of the abandoned Tamiami Airport, in South West Miami Dade County into a 344-acre, upper division university. Operating from the disused control tower of the old airport, which he dubbed FIU's "ivory tower" (Riley 2002), Perry was able to open FIU up for classes on September 14, 1972, with the 
highest first-day enrollment in the history of U.S. higher education (5,667 students). The university started with 300 faculty members, in six schools and colleges, including Hotel, Food and Travel Services, Business and Organization Services, Technology, Health and Social Sciences, and Education. Perry understood the importance of international education. He established a Center for International Affairs with the basic mission of promoting international understanding, emphasizing the Americas. He installed a plaque on the frontage of the university's first building proclaiming FIU's intention of becoming a major international education center. His 7-year tenure saw FIU double its student population to 10,000 students pursuing 134 degree programs housed in five major buildings on a $\$ 50$ million campus, with plans for a sixth at an advanced stage (Riley, 2002).

Harold Crosby, who succeeded him in January 1976, was an attorney and founding president of the University of West Florida for 10 years. He previously served as the assistant dean of the University of Florida's College of Law as well as its dean of university relations and development. He presided over FIU at a time of serious economic downtown, which precipitated a temporary hiring freeze within the state university system (Riley 2002). Despite this, he was able to open the 1700-acre North Campus of the university located in Biscayne Bay, establish the Division of Student Affairs, create FIU's first vice presidency for development, and open the School of Public Affairs and Services. He is also credited with reorganizing the university's administrative structure to make it more traditional, insisting on emphasizing the "I" in FIU. This led to the launching of more programs with international focus and the recruitment of additional faculty from the Caribbean and Latin America. 
In February 1978, Gregory Wolfe, a linguist, diplomat, World War II veteran and former president of Oregon State University (1968-1974), assumed the reins of power at the university. Wolfe, a PhD holder from Tuft University's Fletcher School of Law and Diplomacy, won legislative approval and funding for FIU to become a full-fledged university in line with his vision for the institution as the beacon of higher education in Miami (Riley, 2002). Part of Wolfe's tenure coincided with the massive boat-lift of Cuban immigrants to Miami following the May 2, 1980, episode when Fidel Castro opened up Mariel Beach port, allowing 123,000 of his subjects to flee Cuba in an effort to squelch dissent. It also precipitated White flight from Miami at the time Wolfe was articulating his vision of FIU as a truly international, multicultural institution serving the South Florida region and beyond. By the mid-1980s, FIU's enrollment had grown to 16,500 served by about 600 faculty members. The schools of Engineering, Nursing, and Mass Communication were added during his tenure, which also witnessed major expansion of the North Campus known then as the Bay Vista campus. Also, a new student center, a residence hall, an aquatic center, and a library were constructed.

In August 1986, Modesto A. Maidique, a Cuban-American, became FIU's fourth president. Maidique, a PhD holder from the Massachusetts Institute of Technology, is a recognized expert in Executive Leadership and High Technology enterprises. Under his leadership, FIU achieved Carnegie's Doctoral/Research University - Extensive classification, the highest ranking possible, as it grew its enrollment in excess of 38,000 to become one of the 20 largest universities in the United States. With Maidique at the helm for 23 years, FIU witnessed phenomenal infrastructural expansion from 54 buildings and 2 million square feet to 109 buildings covering 7 million square feet. FIU 
surpassed \$100 million each in endowment funds and research expenditure as it graduated more than 100 doctoral graduates in 2008. It has added new colleges of law, medicine, architecture, the new Frost Art Museum, the Green library, and the Wertheim Art Museum, to its academic offerings and physical landscape.

His tenure saw the re-kindling of FIU's internationalization agenda, with the setting up of the Office of Global Learning Initiatives and the School of Public and International Affairs (SIPA).Mark R. Rosenberg, former FIU provost and Chancellor of the Board of Governors of the State University of Florida succeeded him in August 2009. Rosenberg is the author of seven books on Latin America. He has vowed to turn FIU into a "leading student-centered, urban research university that is locally and globally engaged" as enunciated in the institution's Millennium Strategic Plan (2001-2010).

International Student Enrollment Data at FIU: 1996 to 2008

According to figures reported to Open Doors, enrollment of international students in non-immigrant categories (F1, J1, H1, H4) at FIU rose annually from August 1996 through August 2001, just before the September 11, 2001 terrorist attacks on the World Trade Center and the Pentagon. As Table 1 and Figure 3 show, from 1996 to 2001, there was an average annual increase of $8.26 \%$ in international student enrollment. In 2002 (see Table 1 and Figure 4), there was a slight increase to 3,741 students. In subsequent post9/11 years (2003-2008), however, there has been a steady decrease in the number of international students for an aggregate $6.15 \%$ decrease in the seven post-9/11 years (2002-2008).

Although I was unable to access Study Abroad participation data by FIU students from 2001 to 2005 , the available data show clearly that only $1.4 \%$ (550 out of 39,146$)$ of 
FIU students had the opportunity to embark on study abroad in 2008, when the institution, according to Liza Carbajo of its Office of Education Abroad, had its highest level of participation in Study Abroad ever before 2009 when 618 of its students ventured abroad. In 2000, when 233 students representing $0.72 \%$ of its total enrolled population of 32,196 had a study abroad experience, it was the highest tally in the pre-9/11 era.

Table 1

International Student Enrollment at FIU (Fall): 1996-2008

\begin{tabular}{|c|c|c|}
\hline Year & Number Enrolled & Annual \% Change \\
\hline 2008 & 2341 & -17.3 \\
\hline 2007 & 2831 & -13.4 \\
\hline 2006 & 3271 & -0.36 \\
\hline 2005 & 3283 & -1.12 \\
\hline 2004 & 3320 & -2.20 \\
\hline 2003 & 3397 & 9.19 \\
\hline 2002 & 3741 & 0.48 \\
\hline 2001 & 3723 & 3.33 \\
\hline 2000 & 3603 & 22.3 \\
\hline 1999 & 2944 & 1.37 \\
\hline 1997 & 2717 & 7.3 \\
\hline 1996 & 2532 & $\mathrm{~N} / \mathrm{A}$ \\
\hline
\end{tabular}


Source: Open Doors, 1996-2008

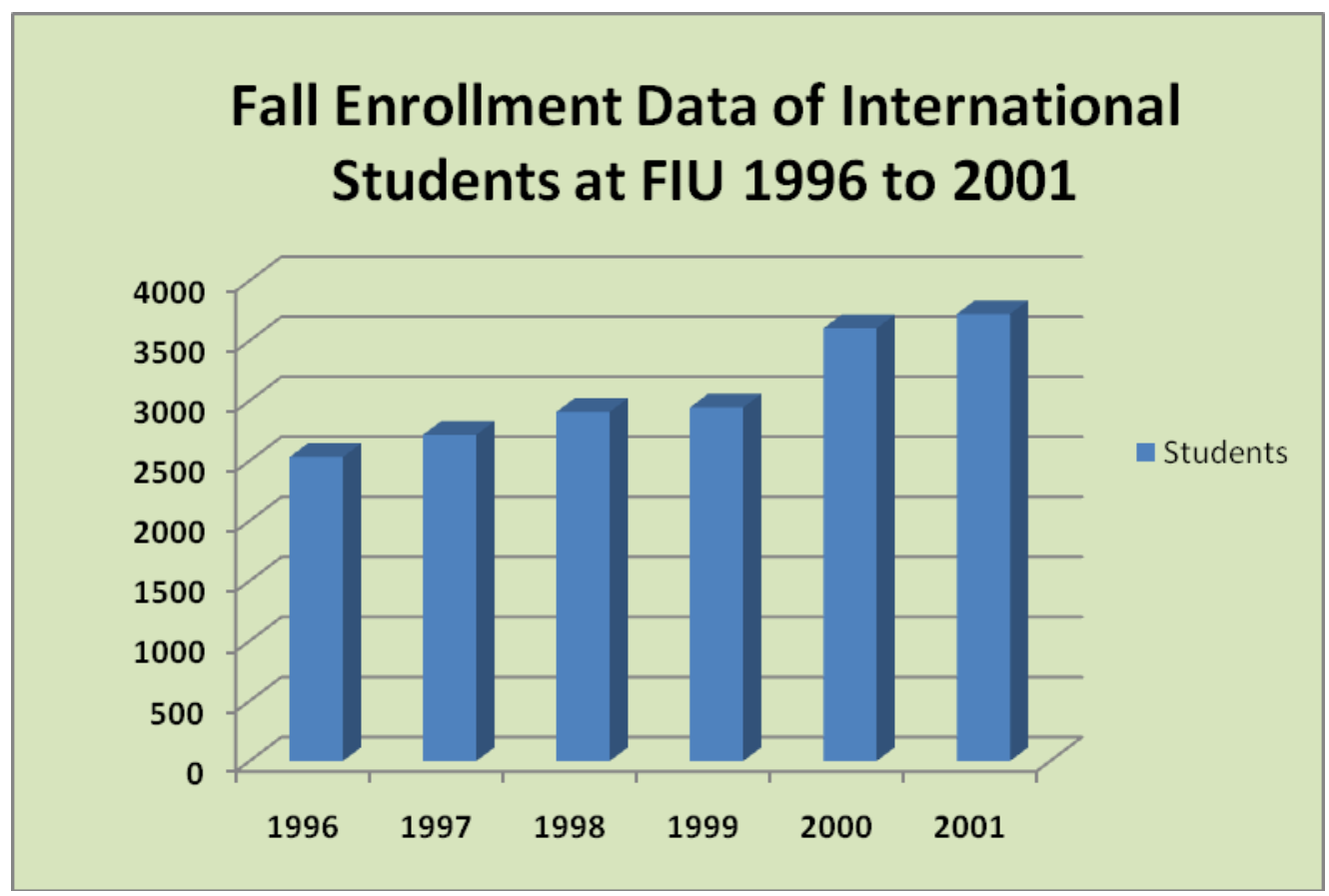

Figure 3. Fall enrollment data of international students at FIU, 1996 to 2001. 


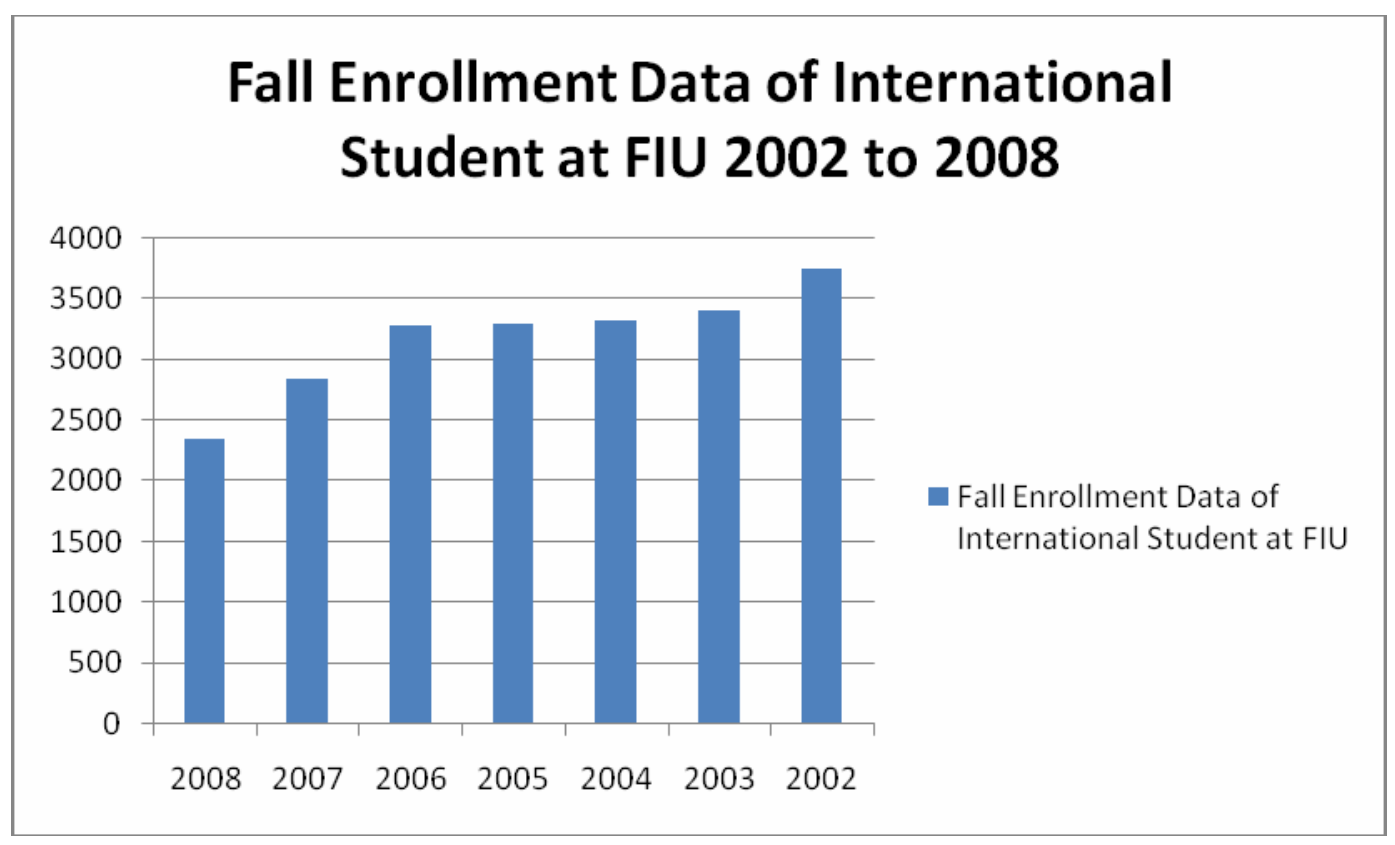

Figure 4. Fall enrollment data of international students at FIU, 2002-2008. 
In effect, the proportion of FIU students exposed to different cultural and education experiences have consistently proven negligible (less than $1.5 \%$ of enrolled students). Also, the top destination countries consistently remained China and the European countries of United Kingdom, Spain, Italy, and France, in the years for which data are available (see Table 2). Regrettably, despite repeated requests, neither the Office of Institutional Planning and Research nor Education Abroad was able to provide me with complete data of FIU students' participation in Study Abroad from 1996 to 2008.

Table 2

Student Participation in Study Abroad at FIU: 1998-2008

\begin{tabular}{lccc}
\hline Year & Participants & Change from previous year & Top destination countries \\
\hline 2009 & 618 & $12.4 \%$ & China, Spain, Italy \\
2008 & 550 & $39.9 \%$ & China, Spain, Italy \\
2007 & 393 & $3.97 \%$ & Spain, Italy, France \\
2006 & 378 & $-5.73 \%$ & China, Spain, Italy \\
2005 & 401 & & \\
2004 & N/A & & \\
2003 & N/A & & \\
2002 & N/A & & \\
2001 & N/A & & \\
2000 & 233 & $-21.28 \%$ & \\
1999 & 296 & $27 \%$ & \\
1998 & 233 & & \\
\hline
\end{tabular}

Source: FIU's Office of Education Abroad 


\section{Organization of the International Education Function}

The international education function at FIU is dispersed throughout the academic and student affairs sides of the institution, with major chunks shared by the Office of Education Abroad (OEA) and the International Student and Scholars (ISSS) office. OEA is directed by Liza Carbajo. She is assisted by an Assistant Director, an Education Abroad Advisor, a student assistant, and an intern. The office coordinates more than 30 semester-long International Student Exchange Programs, over 35 short-term, faculty-led, FIU sponsored programs to five continents as well as non-FIU sponsored programs to countries like China, Ecuador, Belgium, Spain, Brazil, Argentina, United Arab Emirates, and Peru. ISSS has a full complement of staff on the university's two campuses. Ana Sippin is the Director of the Maidique A. Modesto campus as well as the college-wide Principal Designated School Official (PDSO) by the United States Citizenship and Immigration Services (USCIS) for the purpose of SEVIS. She is assisted by an Assistant Director and a Coordinator/Designated School Official. At the Biscayne Bay campus, the ISSS team is led by Nancy Hernandez, complemented by an assistant director/DSO, associate director/DSO, and a Coordinator/DSO.

A latter-day addition to the internationalization bureaucracy at FIU is the Office of Global Learning Initiatives (GLI), directed by Hilary Landorf with an associate director, an assistant director, and a program assistant. GLI was created to drive the Global Learning Quality Enhancement Plan (QEP) for FIU's Southern Association of Colleges and Schools accreditation. According to the GLI website, "the goal of FIU's Global QEP is to ensure that every FIU graduate has the educational opportunity to achieve the knowledge, skills, and attitudes of global citizenship in the $21^{\text {st }}$ Century." 


\section{Themes}

As earlier indicated, interviews were conducted with (a) Ana Sippin, $\mathrm{PhD}$, a longtime director of the Modesto A. Maidique campus ISSS office and Principal Designated School Official (PDSO) by the United States Citizenship and Immigration Services (USCIS) ; (b) her Biscayne Bay campus counterpart, Nancy Hernandez, who is a Designated School Official (DSO); (c) Anoush McNamee, assistant director and SEVIS coordinator on the Biscayne Bay campus; (d), Hilary Landorf, director of the institution's Office of Global Initiative; (e), Liza Carbajo, Director, Office of Education Abroad; and (f), Modesto A. Maidique, PhD, the immediate past FIU president and current director of its Center for Leadership. The perspectives of these key officials are presented and analyzed in this section and reinforced by my observations and analysis of salient documents to chart emerging themes and trends.

\section{Early Beginnings: Passionate Actors, Forays by Happenstance}

One common thread among the international educators I interviewed for this study at FIU is that, except for Hillary Landorf, their foray into the field occurred by happenstance. It was not part of a carefully-crafted career plan but of a spontaneous gravitation towards a profession they would grow to love once presented with the opportunity. Sippin holds a Bachelor's degree in Psychology and a Master's in Student Personnel. She resumed from maternity leave when the opportunity arose for her to work in international education. "I never really thought about it. I had always known people from different countries... I knew a bunch of people from different places but I had not really thought about working with internationals within student affairs [pause] when the opportunity came, I said sure, I'll do it... (personal communication, April 8, 2009). 
Hernandez, a native New Yorker, whose parents are from Puerto Rico, began her career as a Student Affairs Professional (SAP) in the Office of Admissions at Fordham University, her alma mater, where she earned a Bachelor's degree in Spanish Literature and a Master's in Counseling and Personnel Services. At Fordham, she worked first with returning adult students and then with at-risk minority high school students. She said she was quite happy with her job and was already in line to become the director of the program by 1985 when her husband got an irresistible job offer in Florida and she decided to move with him. Within a couple of months, Hernandez got a job to recruit graduate students for Barry University's new School of Podiatric Medicine and was given the task of stitching "the admissions process together" (personal communication, June 5, 2009).

Like Sippin, this opened a door that ultimately led to her emergence as another accidental international educator. The person handling evaluations and international student recruitment asked if he could train her up as a foreign credentials evaluator. At that time, he was planning to quit Barry to pursue an acting career. "I said sure. So he pretty much was the one who taught me how to evaluate foreign credentials and that was how I got into international education...I was at Barry for 3 years until I went on maternity leave for my first child" (personal communication, June 5, 2009). Hernandez resigned to be a stay-at-home mom for 1 year before joining FIU's office of admissions at the Maidique A. Modesto campus as an assistant director recruiting from in-state high schools. Leveraging on her exposure at Barry, she also oversaw foreign credential evaluations university-wide. Incidentally, it took another 3 years on the job and another 6 months of maternity leave for her to be offered the position of Assistant Director of the 
Briscayne Bay Campus of FIU's ISSS office after putting her name in the hat at the last minute for an exhaustive national search. "It was a lateral move, because it was an Assistant Director position, but ...I saw it as an opportunity to work in a different area of international education" (personal communication, June 5, 2009).

Originally from Jamaica, McNamee started her education career in South Florida where she earned an Associate's degree at Broward College. She then gave in to the allure of New York, pursuing a course of study in fashion before returning to South Florida to earn Bachelor's (Marketing/International Business) and Master's (Education/Higher Learning) degrees at Florida International University. Prior to 9/11, McNamee was a coordinator in the Multicultural Programs office at FIU. Like other international educators on the frontline at FIU, her foray into international education was by happenstance. Based on her background, she was approached by Hernandez to handle international programming immediately after the 9/11 attacks. Incidentally, she admitted not being particularly interested in international education before then. Although she came to the United States as an international student, she never planned on becoming an international educator. "My whole intention was to go to corporate America but then I decided that was not where I wanted to be. The opportunity came and I gladly took it... and it turns out that it is something I really enjoyed and still enjoy," recalled McNamee, who resumed at ISSS on November 5, 2001. She added: "I really love to work with students in programming, in finding resources for students, educating students, so 8 years later, I'm still here" (personal communication, June 5, 2009).

Like McNamee and Hernandez, the trajectory of Hilary Landorf's involvement in international education has a New York tinge to it. On September 11, 2001, as the 
infamous commercial airliners were crashing into the World Trade Center's twin towers, Landorf was to teach her first class as a visiting assistant professor of international education at New York University. The class was a non-event for obvious reasons but it afforded Dr. Landorf the opportunity to observe the 9/11 attacks first-hand. "At NYU, the buildings were less than a mile from the World Trade Center," she recalled. "So I saw the effects ...physically....and emotionally, the students experienced those effects on the whole campus" (personal communication, June 25, 2009).

Unlike her other counterparts at FIU, however, her entry into international education was not accidental. Having been involved in international education all her life, Landorf's life history is a study in the multi-dimensional elements of internationalization. She was the only American student who chose to live in International House while she was at Stanford University. She then proceeded on abroad during her junior year, eventually joining the Peace Corps. "I went to the Peace Corps in Morocco and liked it so much that I stayed another year and then went for another year to Mauritania and stayed abroad for several years, taught in Mauritania, Martinique, and Morocco" (personal communication, June 25, 2009). After the stint in Morocco, she returned to the United States to earn a Master's degree in English literature with the intent of returning overseas to be an itinerant university teacher. Instead, she found herself teaching English as a Second Language, and eventually heading for New York University, where she earned a $\mathrm{PhD}$ in International Education. What attracted her to FIU was its rare distinction of having a discrete program in international education, unlike NYU which had a combined social studies/international education program. She joined FIU in 2004 as program leader of the College of Education's International Education program at a time when FIU began 
serving as the seat for the Comparative and International Education Society which pretty much acts as the profession's custodian in the United States.

Pride in their work and deep passion for the profession was interlocked with the manner of entry of these professionals' into, and eventual immersion in the ambience of international education. Sippin said she grew to love her new area of specialization even as she became a recognized expert within NAFSA. "It was funny because when I started working it was like I didn't know these different rules...you had to do OPT, CPT and other things but I eventually loved working within the regulations and seeing what you can and can't do with it" (personal communication, April 5, 2009).

Sippin has also found working with international students with diverse background exciting. She recalled working with a student from a Moslem country who indicated she was perfectly fine with an arranged marriage in which the groom was a stranger until their wedding night. Such engagement with the concept of the other was what made Sippin secure a grant to organize orientation for in-coming Fulbright students for three consecutive years, leading to even more cultural awareness and education. She said she loved "just meeting ... really bright students from all over the world" and to see them graduate, giving the example of a paraplegic international student who still managed to earn a PhD. "It's just a really nice feeling to see that he was able to overcome all the adversities and really make it through and he invited (me)... to when he defended his dissertation and his little get-together. And it was just so nice to see that happening" (personal communication, April 5, 2009).

The same love for students and scholars was the major motivation for Hernandez's foray into student affairs. She started as a work-study student/secretary in 
the financial aid/admissions office of Fordham University's law school. Upon graduating, she went into the corporate world, working for a nursing company but she soon found out she was too wedded to the university environment. She did not feel fulfilled in the Admissions department because it involved more paper-shuffling than student contact. I like working with students. For me it was very fulfilling to help students and see them succeed and help them through that process. So that was why I decided to come back to education... when I took this job it was not a promotion it was just a lateral move but I saw it as an opportunity to be able to create a job that will not only be fulfilling to me but help the international students (personal communication, June 5, 2009).

She really savored the opportunity to design programs that positively affect students. Liza Carbajo, Director, Office of Education Abroad, did study international relations at FIU, ultimately earning an MS in Global Studies but that did not necessarily guarantee that she would work in international education. She found herself increasingly drawn to the field once she talked her boss in FIU's admissions office into allowing her to try her hand at international student recruitment. "I enjoyed it so much that I really wanted to look at it as a career and I wanted to explore it from different perspectives" (personal communication, January 26, 2010).

Her 16 years at FIU has seen her traverse the entire universe of international education. She worked with in-bound and outbound students as an international admissions recruiter, an operative at the Latin American Center, and an advisor/DSO in the International Student and Scholars (ISSS) before being tapped in 2007 to head the Office of Education Abroad. She finds dealing with U.S. nationals and permanent 
residents who travel aboard rewarding because of the life-changing impact the experience almost always has on the students. "It's amazing ... when they come back. They are just completely changed. They live their lives a little slower, especially at the beginning. They'll take 3 hours to have lunch, whereas here you are on the go. They'll speak a little slower and they take their time" (personal communication, January 26, 2010). Similarly, Landorf described her involvement in international education as "a transforming life experience," citing how her colorful and far-reaching work-history has shaped her perspective and career. "My life has been colored by the experience of living and working in a culture very different than my own culture," she stated (personal communication, June 25, 2009). According to her, what she learned most as a Peace Corps member teaching English as a Second Language in Morocco is that "the more you know a culture other than your own, the less you know; the more familiar you become with the culture, the more you realize how much you don't know about yourself, and about the other culture. She does not, however, see the utility in "going native," attaining "some sort of state where you walk in someone else's shoes."You can understand that someone else's shoes are different than your shoes and learn to empathize with someone else's position. I don't believe that you can ever get into their skin. Passion, empathy is it!" (personal communication, June 25, 2009). She was enthusiastic about her work as the Director of the Office of Global Learning Initiatives. "This is a school of 38,000 students, 30,000 of whom are undergraduates. And again it is a real honor and I am lucky that I have been steeped in international education since college. It's in my research, it's in my pedagogy, it's in how I teach, it's in what I teach and really who I am," she emphasized, with an unmistakable glint in her eyes (personal communication, June 25, 2009). 
McNamee also professed her love for international education, and as testament to her commitment, I observed that her office, like that of Sippin, is a kaleidoscope of flags and artifacts from various countries. Another backdrop in Dr. Sippin's office is a book shelf of gripping pictures and bound volumes of NAFSA Adviser's Manuals.

The lobby of the ISSS office of the Biscayne Bay campus is adorned with several backto-back trophies McNamee won with the International Student Club as an advisor. Changing Roles: SEVIS as "Main Outgrowth" of the September 11, 2001, Attacks

SEVIS came into effect in the fall of 2003, but involved a lot of groundwork dating back to 2002. Prior to SEVIS, security concerns after the first attempt on the World Trade Center in 1993 led to the establishment of the Coordinated Inter-Agency Partnership Regulating International Students (CIPRIS) in 1997 as a pilot program involving some select universities as mandated by the Illegal Immigration Reform and Immigrant Responsibility Act (IIRIRA). It was a much smaller program, however, involving some Southeast schools when compared with SEVIS. The appropriation of \$36.5 million in start-up fund for SEVIS under the USA PATRIOT Act enacted in November, 2001 with a clear mandate for implementation by USCIS not later than January 1, 2003, was a culmination of this process. SEVIS was considered the most visible legacy of the September 11 attacks by study participants. Sippin characterized SEVIS as the immediate outgrowth of the incident. According to her, the process of complying with SEVIS, an Internet-based tracking system for international students and exchange visitors in non-immigrant visa categories, was tedious and time-consuming:

We went through all the files, made sure the information was correct, made sure everything was in there; we also had mandatory workshops for all our students in 
2002 when we went through SEVIS and all the changes in the regulation, the consequences and things like that. SEVIS didn't start until the Fall. So, we started it in the Spring and just did a whole bunch of workshops and even recorded them for those who would not show up (personal communication, April 8, 2009). An analysis of a two-page Microsoft Project Exported Information Task Data, titled SEVIS Implementation, which I obtained from Sippin, showed the involving and time-sapping nature of the process. The document lists, in tabular form, 30 discrete tasks related to the integration of FIU's data-base into that of the former Immigration and Naturalization Services (INS) now USCIS; duration of the tasks; their start and finish dates, and the FIU personnel involved. The process which began on May 2, 2002 ended on Thursday, January, 30, 2003, the SEVIS compliance deadline. It involved 3 of the current study's participants - Ana Sippin, Anoush McNamee and Nancy Hernandez and 11 other FIU employees in activities such as conference attendance, meetings with the SEVIS team and participating in demos of Windstar, FSA Atlas and PeopleSoft software. It scheduled 4,057.76 labor-hours for the institution to deal with just this aspect of the post-9/11 regulatory environment alone. This document signaled that some technology savvy, attention to detail and adaptability became part of the implicit job descriptions of international student advisors/administrators and their colleagues in Information Technology in the aftermath of the 9/11 attacks.

Preparing for SEVIS also meant that international educators worked well beyond regular work days. They "burned the midnight oil" as they sought to "put all their ducks in a row" prior to the launch date. "We spent many nights together in my living room, digesting those regulations and putting together the business practices for the office. We 
created the forms that we used for our reduced course load... We also put together a policy and procedures manual," Hernandez of the Biscayne Bay Campus recalled (personal communication, June 5, 2009).

Over time, international student advisors found that their roles changed in terms of the quantum of secretarial work they had to undertake and how proactive they had to be with the students, their academic counselors, and their teaching faculty. Biscayne Bay director, Hernandez, noted that international student advising and scholars services evolved beyond core programs for the integration of internationals into campus academic and cultural life such as peer mentoring, welcome back receptions, club advising, and celebration of cultures after September 11, 2009.

While some of the traditional programs are adaptable to the post-9/11 ambience, she argues that the new regulatory framework imposes greater burden on FIU's ISSS to be more proactive. She spoke about having to do more data entry, meet regularly with academic advisors to ensure that students are properly advised, and stay proactive and engaged with any immigration issues that might compromise students' legal status. “Though ultimately it's the students' responsibility, we try to do the best we can to contact them so they do not fall out of status," Hernandez stated. The process she described was monotonous and tedious even though she made light of it:

We e-mail the student, we call them, we even send them a hard copy of the emails [laughter]. Sometime as a last resort if they have not given us a U.S. address ...we call the academic advisor and that is why it is important to have that rapport. Is there any way you could contact the student, pull them out of class? (personal communication, June 5, 2009). 
In this regard, Hernandez said she had to develop relationships with the academic units on campus, meeting with advisors to update them on how immigration regulations impact international students' enrollment behavior. A yearly advisors' meeting and several workshops were also put together for capacity-building in this area, "making sure they advised students properly in terms of enrollment ...educating them on student rights and responsibilities and what students have to comply with" (personal communication, June 5, 2009).

According to Sippin, SEVIS also heralded a new role for international student advisors as teachers and enforcement agents. International students could not register unless they attended mandatory immigration workshops or watched video versions of them. Those who chose neither were made to sign release letters absolving FIU of any liabilities. "We tried as much as we could because we knew there would be major consequences. How that has changed is that we became more of enforcers than we ever had to... So, the main outgrowth of September 11 was SEVIS, making us more diligent in reporting students. We just had to report everything!" (personal communication, April $8,2009)$.

Reflecting on this new role of international student advisors in their capacity as DSOs McNamee hit on the same theme: "I call. I e-mail, I write. We do initial e-mail, we do second e-mail, we do final e-mail. We do phone calls, we do letters after letters so we put in ... much effort ... to prevent students from falling out of status. Don't withdraw from a class; you can't take more than one online class," she said. McNamee narrated the story of a student who was dismissed from FIU by the college authorities. The student needed to appeal the dismissal or leave the United States within 10 days or be terminated 
according to immigration regulations. "After a month, they still had not appealed the dismissal. It was now the $38^{\text {th }}$ day. You do not have a choice, you have to terminate. That is something our nation takes seriously. We love our students but at the same time we have to uphold the regulations (personal communication, June 5, 2009), noted McNamee, who eventually earned the nickname of "The Terminator" from her students.

One associated outgrowth of the post-9/11 firmament in this regard is the new level of recognition cum respect accorded international educators by institutional leaders. Hernandez said she was able to get funding to transform her one-person operation at the Biscayne Bay campus to a full-fledged operation with a secretary, additional professional staff and graduate assistant. This was a far cry from the pre-9/11 era when she shared a suite and two secretaries with disability services and multicultural programs. Also, the ISSS office became a clearing house of sorts for FIU's human resource department and departmental heads interested in hiring non-immigrant students.

The ever-changing regulations also meant continuous training for international student advisors to keep abreast of developments pertaining to SEVIS, NSEER and other issues affecting F1, J1 and other non-immigrant students. While 9/11 initially heralded greater resource flow into FIU's International Scholars and Student Services, Sippin regretted that recent budget cuts have reversed much of those gains. Landorf also conceded that international education and its practitioners appeared to have achieved a new level of respect and an "influx of new funding" after 9/11, but she described the new ambience as a "knee-jerk response" (interview, June 25, 2009) by a nation still desperate to understand the ides of September 11. She said the funds soon dried up as the age-old tension between unity and diversity or multiculturalism was, again, re-kindled. 
I recall personal experiences of people saying why are you in this field; what is international education anyway? And what does it mean to us? We are fighting the war on terrorists and institutionally, there seems to be very marginal interest in things international education. Maybe I need to qualify it. I know at the College of Education, for instance, there was marginal interest in international education as a program. No funding... Well, first after $9 / 11$ there was an influx of funding but that went away and then the feeling was what is international education anyway and why do we need it? (personal communication, June 25, 2009).

Maidique, however, said the post-9/11 regulatory framework increased the pressure on universities to do more with less. "It was a cost to us," he stated, noting that the establishment of the School of International Studies and Public Affairs (SIPA) in 2006 was partly motivated by $9 / 11$.

Carbajo reinforced this theme when she noted that the university failed to develop a student exchange partnership or study abroad program with the Middle East before 9/11. Although some faculty focused their research work on the area, it was not until December 2008 that the university formed its first Middle-Eastern partnership, signing two exchange agreements in Hospitality Management and Middle East Studies with the University of Dubai. Carbajo also noted the establishment of the Middle Eastern Center, "with Mohiaddin Mesbahi as director," at the Modesto A. Maidique campus and the coming into being of SIPA. "That is a big thing with the university. I think that would be an outcome of September 11, she said. "I think as SIPA grows, there will be more and more interest in the Middle East" (personal communication, January 26, 2009). 


\section{Dueling Roles and Tensions}

This new regime precipitated tensions at various levels. These tensions played out between international student advisors and agents of the Immigration and Customs Enforcement (ICE) unit of the Department of Homeland Security (DHS); the incipient regulatory environment and the need of students for continued confidentiality and autonomy; the dilemma of international educators caught in the middle between personal desires and professional obligations to help their students and scholars and the legal framework that makes it obligatory for them to report contraventions and enforce immigration regulations; and the push-pull dynamic between nationalism and internationalism for all the stakeholders.

ICE agents versus advisors. FIU saw several visits from ICE agents checking up on students who withdrew from classes thereby falling below the threshold required of 12 semester credits course load for undergraduate students and 9 credits for graduate students. Sippin said some of those visits proved to be cataclysmic for a few F1 students. "A poor soul was picked for dropping classes; so was a couple who got dismissed [from the university], but stayed in the country even though their I-20s had been terminated" (personal communication, April 8, 2009). Overall, Sippin considered many of the agents who visited her office quite polite. She, however, described a few as being "very forceful." She related her experience with some agents in 2009. They wanted to know a student's class schedule in order to fish her out of the classroom. Sippin made it clear to the agents that DSOs are only required to report, if students are not attending full-time, but she said they wouldn't budge because they had been unsuccessful in tracking the student down in her apartment. 
Well they were sort of threatening me [laughter] like "you know this student is attending class." I said, "Well, they are enrolled in class." "You have to know if they are attending or not." I said, "I'm sorry but we don't get that information" "you know the requirements." "Sorry, we have like 3,000 students. You think we'll know every time where everyone is? That's so unreasonable." Then he said, "I'll just have to audit you" and I said, "Well, do what you need to do" (personal communication, April 8. 2009).

This incident epitomized the tension experienced by international educators, post$9 / 11$, as a result of their dueling responsibilities to government, the university, the community and their student/scholars. Sippin stated that each of these layers had a different response to the challenges posed by the post-9/11 environment. "The university was still very interested in dealing with international students so ...the university was supportive in that. I think people [in the community] were suspicious of things," even as the students seemed to take things in their stride. Hernandez touched on this polarity in the treatment of international students and scholars at the institutional [FIU] and governmental/regulatory contexts. "We don't mark anyone as a potential terrorist. Maybe the government does, but as far as we are concerned admission is open to everyone whether you are documented or undocumented," she stated.

Autonomy and regulation. Student autonomy and the imperatives of regulation in an otherwise free-wheeling academic environment represented a related level of tension. Students do not necessarily have to listen to advisors since they are adults responsible for their own decisions. "If you tell me, 'I don't care,' that's your choice and you'll face the 
consequences" Sippin stated.

McNamee remembered feeling frustrated by students who choose not to respond to entreaties of advisors until they are ultimately terminated in SEVIS but are quick to complain bitterly after the fact. According to McNamee, some of them pressure advisors to bend the rules. "My students know that I love them but I also know that we do have responsibilities. I don't lie for students. I've been asked several times. I tell them no; I can't lie for them" (personal communication, June 5, 2009).

\section{Advocate versus enforcer: "I tell my students I love you, but I have to terminate} you!" The emergence of international student advisors as Designated School Officials (DSOs) charged by the United States Citizenship and Immigration Services (USCIS) with relaying timely information on the enrollment and living status of students put the professionals in an ambiguous position with students. "I think at the beginning it was hard because they saw us as the enforcers and even though we held the workshops they had to understand that these were not our rules and regulations. We have to comply in order for us to be able to bring students here," Hernandez stated (personal communication, June 5, 2009).

They wore often contradictory hats as international student advisors/DSOs. They became advocates for students as well as enforcers of the very strict regulatory regiment ushered in by the PATRIOT ACT in the aftermath of September 11, 2001. Skirting this divide is a major undercurrent of the post-9/11 syndrome. Describing SEVIS as somewhat adversarial in nature, Sippin said it was difficult for the students not to conclude that international educators were only working for the government especially at the initial stage. "Everything was being monitored...," she recalled. "If they violated their 
status, we would tell them right then. So I think the students were feeling like, you know, you are only working for the government. But it was kind of a transition that we had to go through to get everything in order and that I think really sort of affected the staff. It affected everybody. It put everybody on edge (personal communication, April 8, 2009).

Hernandez said a balancing act is hard but she tries to be a teacher, counselor, mentor and enforcer, all rolled into one. She explained:

I advocate for them in terms of trying to get programs that helps them in their process of cultural adjustment to the United States. We advocate for them when it comes to the international insurance plan. Again, we work with Ana [Sippin] on that...to make sure that they get the best plan... And we usually tell them even if you are outside the university, you represent the university, you are on I-20, you always have to be careful, carry your documents with you so if you are charged with a violation or something, you should have your documents with you (personal communication, June 5, 2009).

In the course of this study, I observed that the International Student and Scholars Services (ISSS) website is replete with helpful pre-arrival, post-arrival, pre-graduation and post-graduation information for students. During visits to the ISSS website in April, June an December 2009 as well as March 2010, I noticed that several programs including the Welcome Reception, Immigration and Tax/Employment workshops, Walk-In Wednesdays, Coffee House, Thanksgiving Dinner, Miami Area Tour, One World celebration, International Student Newsletter and the International Photo Contest, have been put together to facilitate seamless integration of the students into campus social and academic life. These programs were also well advertised with posters on both the 
Modesto Maidique and Biscayne Bay campuses.

Despite these efforts, McNamee, who touts the culture-shock experience she had as a Jamaican attending college in the United States, the post-9/11 environment of international education represented another shock. "It was pretty tough with declaration of the war on terrorism. I didn't know what to expect," she stated. The challenge for international educators was to assume the new responsibilities of this new securityconscious environment while at the same time not falling into the mindset of stereotyping students on account of their religion or geographic roots. "We were all in patriotic fervor while at the same time understanding that not everyone was a terrorist... Coming in to this field, you must be open-minded," (personal communication, June 5, 2009) she stated, while admitting it was difficult convincing international students and scholars that this was the case.

Because of this lack of understanding, many of the students could not comprehend the enormity or complexity of the work of an international student advisor/DSO, who is both called upon to be an enforcer of rules as well as an advocate for students, for scholars, and for the entire concept/process of internationalization. Neither did international student advisors and educators smoothly navigate that minefield. Sippin stated:

That is difficult. Well, I think that as an advocate... I can assist the students if they are having problems getting a regular class if they can access only online classes. I can advocate for them, go to the department and things like that but then if the student actually falls out of status, I have to report it so in a way working with them is letting them know, giving them the options...you drop a class then you need to 
get back on. Okay you're gonna pay by tomorrow, your classes are going to get reinstated. You know, I'd write it down. Make sure you come and let me know. You know it's kind of working with the students...empowering them (personal communication, April 5, 2009).

Sippin cited her intervention for the students with Student Government to fund orientation and provide computers for the student lounge in the ISSS office on the Modesto A. Maidique so that they can have "a nice place that they can come to," as examples of such advocacy. She added that all the DSOs diligently explore legitimate ways for fixing any problems that students might have with immigration. There is a limit, however, as the three international student advisors indicated. "It's a fine balance and you know I don't think you can be so much like I am here for the students and forget your responsibilities. Then that's not it: you are also representing the university and that could be jeopardized by not doing the right thing- jeopardizing your whole F1 program" (personal communication, April 8, 2009).

Hernandez struck the same chord when she said if the students contravene regulations and fall out of status there is nothing international student advisors would be able to do to remedy situation. "It's federal regulations. There is not much we can do. Our hands are tied," She declared. Sippin, however, noted that students have generally navigated the post-9/11 environment with disarming grace and humor. She related the story of a Kuwaiti student who visited with her in the office. "I said how are things, are you having any problems at all? He said that's what I came to find out ... (laughter). So I think it's easy for students to blend in" (personal communication, April 8, 2009). 
This humor was also evident not only in the way the students waged a successful whisper campaign that saw McNamee nicknamed "The Terminator!", but the way the professionals in the office were able to engage in some level of self-deprecation in recognizing the fun of it all. Hernandez joked that McNamee was the office's best hand in the termination business while the "terminator" herself served notice that her alias would be mutating to "the ender" under the SEVIS 2 system now in the works. McNamee had a memorable line to share in this regard, "I tell my students 'I love you but I have to terminate you!'” (personal communication, June 5, 2009). She explains how she earned the nickname: "I am the one that registers the students, I am the one that terminates them if they contravene the regulations...It is a responsibility that I take very seriously...It really weighs on you sometimes" (personal communication, June 5, 2009).

This somewhat fatalistic feeling of inevitability and helplessness has birthed a new culture of detailed documentation of student contacts not only to satisfy ICE requirements but to achieve some sort of advisor justification or/and vindication. Hernandez recalled:

We document everything .... in their files...especially if it is a situation where a student would get terminated. We send them an e-mail; we put it in writing. They are really supposed to be using the FIU e-mail account, but if they have several accounts we send it to all the accounts...Anoush is very good at that! (personal communication, June 5, 2009).

In effect, she found herself spending time constructing an elaborate paper-trail for selfvindication; time that would otherwise have been dedicated to face-time with her students and scholars, organizing programs or advocating the cause of international education. 


\section{Nationalism Versus Internationalism}

Another emerging post-9/11 trend, according to Hilary Landorf is that international students appear to have become "more ethnically and nationally-oriented, more conscious of their own ethnic and national background" while Americans have become both "more nationalistic and ... aware of international affairs." She said U.S. students are more aware of the fact that the world is an interconnected place, "that what they do affects others and what others do affect them" (personal communication, June 25, 2009).

Sippin touched on the same theme when she stated that, in the post-9/11 firmament, many international students liked their countries to be recognized in a positive way, even as flag-waving became more rampant among U.S. students. Carbajo, however, argued that it is natural for nationals of a country to feel defensive in the face of a perceived external threat like 9/11. "I don't think that our students - well, maybe right after 9/11 completely clammed up after $9 / 11 \ldots$ I think our students are pretty savvy.... They are proud of their country" (personal communication, January 26, 2009), she stated while conceding that the somewhat bellicose response by the U.S. federal government did create animosity with some nations. Liza Carbajo agreed:

When you look at any country, I think any country is nationalistic. They are proud of their country. I think what happened with the U.S. is the government perception of things. That's what people don't like about the U.S. When a country that you are raised in becomes threatened, obviously you become more patriotic or more nationalistic but I don't think that our students - well, maybe right after 9/11 - but I think our students are proud of the U.S. and our way of doing things but I don't 
think they've completely clammed up after 9/11 (personal communication, January 26, 2010).

Indeed, for FIU, which pursued an internationalization agenda right from inception, there was a concerted effort to encourage students to co-mingle through programming. Dr. Sippin stated: "We always tell them that if you are going to flock around with only people from your own country, then why are you here?" Carbajo, who co-led an exchange program to Dubai in December 2009, said she observed that while people from UAE generally have a low opinion of the U.S., they still want to come to the U.S. to get an education. "We currently have a student from Dubai. She was obviously sheltered with her family. She came here, and she is like, 'I just enjoy my freedom. This is what I've been waiting for; to be independent.' I think, again, they may not agree with everything; they still want to come to the U.S." (personal communication, January 26, 2009), Carbajo concluded.

While Landorf said the immediate response of society to $9 / 11$ tended towards insularity, she suggests that the environment eventually became more open towards international education. She argued that the initial "closing-in" period was characterized by an intense feeling of nationalism, the typecasting of everything international as negative and the embrace of everything insular as positive. Landorf said the antiinternationalization tide changed from around 2007 when there was a " "knock-your head against the wall' realization that ... as an institution, as a society, that what we do depends on the rest of the world and vice-versa... People realized that our initial reaction to $9 / 11$ got us into a lot of trouble and cost a lot of money, we lost a lot of lives, and was the wrong response, so let's try another way" (personal communication, June 25, 2009). 
The initial clamming-up was, however, not necessarily a reflection on students who tended to be more of free-wheeling risk-takers. Noting that a recent vice president of Student Government was an F1 student, Sippin characterized the new generation of students pre- and post-9/11 as essentially interest-driven. They make friends regardless of national or cultural barriers:

It's funny how ... an American friend ... will accompany them [international students] to my office and say; "Why can't my friend work off -campus?" [laughter]. What do you mean he can't work? They can't understand... since they can work 40 hours off-campus without any problem, and they can drop a class whenever they feel like... They don't really understand how immigration works [more laughter] (personal communication, April 8, 2009).

As one international educator who worked closely with students and could claim to substantially understand their issues and concerns, McNamee argued that there was no overt sign of animosity by domestic students at FIU towards their international counterparts. Instead both the students and professional staff showed empathy:

As a campus we had a memorial for victims of 9/11 organized by Student Life and the international department participated. As far as the relationship between students, I did not really see anyone being irate; I think the community embraced them... Our office was more sympathetic to students from those countries who were trying to distance themselves from the perpetrators...

If there is a post-9/11 syndrome at FIU, I would say it is reflective in nature. We even have a peace pole with inscriptions written in various languages, you know dedicated to remember $9 / 11$. I think the university through the office of campus life 
tries to remember those who died in September $11^{\text {th }}$, not in a negative way to isolate international students. It is just to remember those students who were the victims and also help their families to adjust while reflecting on how we can move on (personal communication, June 5, 2009).

By implication, the FIU community appeared to have demonstrated a certain level of sophistication in interrogating the aftermath of the 9/11 terrorist attacks, setting it up as a conversation starter.

Fear, Agitation, and Stagnating Enrollment

Sippin contended that a new ambience of fear permeated the nation post-9/11 with "everyone very much on alert, a little bit suspicious" and "a little bit more agitated" with each succeeding bomb threat or change in terror alert levels. People were more edgy about things. "I remember a student telling me that her mother wanted her to go home because she didn't feel safe in the U.S. anymore," Sippin recalled (personal communication, April 9, 2009).

Maidique echoed the same theme, saying that the FIU community became more keenly aware of security issues and "more intolerant of security breaches" (personal communication, January 14, 2010). He related several incidences of bomb threats which threatened to shut down FIU in the aftermath of 9/11, but for his conscious decision to baulk the prevailing culture of fear. The post-9/11 period also heralded the NSEERS program and its special registration requirements for students from certain parts of the world. Hernandez said she thought that "has worked adversely in a way," leading to declining enrollment. She added:

After 9/11, a lot of students from those areas went to school in England or in 
Canada. I would say our enrollment started to dwindle after 9/11 because it was very difficult for the students to be able to obtain an F1 visa, and they were getting better offers from other colleges and universities where they didn't have to go through the rigorous rules and regulations that are put on our international students here. I can tell you that our numbers did go down but they've started to pick up again (personal communication, June 5, 2009).

Indeed, both Sippin and Hernandez told touching anecdotes about students who went back home because they feared for their lives in the immediate aftermath of 9/11, leading to non-representation of some countries such as Turkey and Kuwait in the FIU student body. "I remember having a PhD student from Saudi Arabia who came to my office. He was very apologetic. He had to return home. Given the way things were portrayed, in the media and society, he was afraid... he decided to finish his $\mathrm{PhD}$ in England," Hernandez said.

The apparent calm and sophistication of FIU's institutional response did not, however, appear to have really helped to dispel the post-9/11 unease of many international students. Stated McNamee: "International students felt they were under a microscope: They had to undergo so many hurdles to obtain or renew their visas especially because it was still fresh in our minds compared to now when numbers have gone up. It was, with everything, a defensive mechanism" (personal communication, June 5, 2009). To her, the post-9/11 syndrome could be characterized as "reflective in nature" at the institutional and psychological level, a string of remembrance activities for victims and a coping mechanism for their families. McNamee believes things are easing up with the reduction in the number of countries covered by NSEERS and the re-enabling of FI 
students not subject to NSEERS to go across the border to Mexico and Canada to renew F1 visas. NSEERS initially covered all nonimmigrant males from Iran, Iraq, Libya, Sudan and Syria, Afghanistan, Algeria, Bahrain, Eritrea, Lebanon, Morocco, North Korea, Oman, Qatar, Somalia, Tunisia, United Arab Emirates and Yemen. This list was revised to subject only certain nonimmigrant alien visitors from Iran, Iraq, Libya, Sudan, Syria, Pakistan, Saudi Arabia and Yemen to NSEERS registration at the port of entry, subject to exercise of administrative discretion, upon the introduction of the U.S. Visitor and Immigrant Status Indicator Technology (US VISIT) program. The US VISIT Program requires non-immigrants to provide fingerprints, photographs and other biometric identifiers when arriving in, or departing from, the United States.

Sippin also noted that the university strived to keep its interface with Middle Eastern students and scholars at pre-9/11 levels despite bureaucratic and regulatory hurdles. She did hint that the university might have been partly encouraged by economic self interest:

We do get students from those countries and I think that is good from the university's perspective. They are fully funded for the most part, especially students from Kuwait, Saudi Arabia and the rest of the Middle East. ..and it is a good area for the university to do more recruiting. So I haven't really seen a difference (personal communication, April 8, 2009).

A related spin-off of the $9 / 11$ attacks in this regard was the abandonment of the tools of diplomacy and other elements that could be used to project soft power, a development, which Landorf said was exacerbated when Karen Hughes, an advertising expert, was appointed to lead the U.S.'s post-9/11 public diplomacy with the Arab and 
Moslem world.

What we saw was that that they were making a mockery of their soft power. You could see that through history again what the political winds of the time were... and their goal for their soft power for the United States is really propaganda...naked propaganda. And now we see it that everyone now knows what soft power is. You see it in various newspapers; we see that Obama is taking a different tack. So I see it just in a small span of time how things have changed post-9/11! (personal communication, June 25, 2009).

One interesting but ironic twist exposed in my interviews with international educators at FIU is that despite all the new regulations, extensive paper trail, intrusive Internet-based reporting and monitoring and other strictures associated with the 9/11 attack and its aftermath, neither the institution nor the country was considered better protected against terrorism. Hernandez bluntly asserted that not much has been achieved in terms of guaranteeing safety. "I don't believe anyone is safer" (personal communication, June 5, 2009), she stated, matter-of-factly.

McNamee attributed this partly to the tendency of Americans to forget easily, pointing to various incidences where students have been able to enter the United States on terminated I-20s, including through New York! "I think it's somewhat part of American culture. Countries like Germany, other countries. they remember their history but we have a tendency to forget... I don't think people are focusing too much on it now," she stated (personal communication, June 5, 2009).

Similarly, Sippin did not feel that the university or country is necessarily safer 
except that incidence of fraudulent I-20s which she said was prevalent pre-9/11 have been curbed:

Students ... go out and come back in even though their records have been terminated or the record has been cancelled and things like that. We've also had calls from port-of-entry people call that we have so and so students, can we see if they are enrolled? And we'll be like we haven't seen them in 2 or 5 years, send them back! So in some ways the timing of the regulations has helped but there is still a lot to be done. Do I feel safer with our students now...the fact that I terminate them when they drop a class...I mean that doesn't make us safer (personal communication, April 8, 2009).

This undercurrent of pointlessness and futility is especially poignant given all the time and efforts directed at tightening regulations, training personnel and instituting a more security-conscious environment in the wake of the attacks.

Internationalization Vision and Identity Crisis

Although an internationalization agenda had always been part of the original vision of FIU with the recruitment of a diverse faculty and the creation of the Caribbean, European and other institutes, Sippin argued that it was more confined to academics and there was no aggressive recruitment effort to attract a critical mass of international students because only "a certain percentage of the student population could be out-ofstate, which includes international." This is despite the fact that F1 students are compelled to pay the full cost of tuition. This situation was exacerbated after $9 / 11$ when the mood in Tallahassee was to block international students from accessing financial aid. The financial debacle also affects domestic students at FIU who do not have the 
wherewithal to embark on Study Abroad trips.

When students don't have money, they can't go. In some of the private universities, students are wealthy and they can afford to go on a whole year study abroad, but here students cannot. I think it's getting students to become more internationalized. We've been bringing in more of Visiting (J) scholars although we probably should be doing more of that, but I think as we become more of a research institution, the researchers bringing in people, the medical school bringing in people... That's a good internationalization tool (personal communication, April 9, 2009).

Also, unlike ISSS, the Office of Education Abroad at FIU did not experience new influx or re-allocation of funds, according to its director, Liza Carbajo. "As a matter of fact, we've had to move all our programs into self-supporting programs, where salaries have to come from the program fee. The programs have become a little bit more costly that way... there is a level of frustration that we don't have more aid" (personal communication, January 26, 2010), she stated. To compound the department's dilemma, the Office of the Vice Provost of International Affairs to which it reported, was eliminated and its responsibility for developing and managing the university's exchange programs transferred to the Office of Education Abroad, which did not get additional personnel help. Carbajo said the result is that the department's vision of sending more students abroad is not being adequately resourced.

The perceived contradiction between being a global university and a Research 1 intensive university embroiled the university in a festering crisis of identity which is only now being resolved. Hitherto, fewer and fewer resources were being devoted to FIU's international programs like the Education Abroad office, which had its outreach efforts 
downsized for budgetary reasons.

I think the university needs to decide what to do... not just talk the talk because I think that happened for a while here. There was this double-talk: we are international but we don't really want to be seen as international. You know we want to be just a regular institution; we want to be the research institution and I think now FIU is coming to terms with all that. Being international is good; we are there in many ways. (Sippin, personal communication, April 8, 2009) An analysis of FIU's Millennium Strategic Plan (2001-2010) seems to confirm Sippin's observations in this regard. Crafted by a university-wide council chaired by its current president, Mark B. Rosenberg, the 33-page document made no mention of the word, international, that had been aggressively promoted as the university's middle name in the past. Instead, the vision document came up with the tagline, "A history of Forward Thinking," and the following mission statement retrieved from the FIU website on April 7, 2009:

FIU is an urban, multi-campus research university serving South Florida, the state, the nation, and the international community. It fulfills its mission by imparting knowledge through excellent teaching, promoting public service, discovering new knowledge, solving problems through research, and fostering creativity

An almost grudging recognition of diversity as one of the institution's seven operational philosophies was the closest this document came to acknowledging FIU's international legacy. Interestingly, the document was put together after intensive dialogue and brainstorming among stakeholders of the university. It was a dialogue that took place 
before the $9 / 11$ terror attacks.

Following the 9/11 attacks and with the Office of Global Learning Initiatives (GLI) as the driver, FIU has outlined an aggressive internationalization agenda. It is anchored on the Quality Enhancement Plan (QEP), an element of the Southern Association of Colleges and Schools' (SACS) requirements for institutional accreditation. Modesto A. Maidique, who was the FIU president when this initiative was adopted, suggested that the 9/11 attacks somehow helped imbue FIU's age-long internationalization agenda with more urgency and credibility. According to him, it allowed the university community to see that "the world may be more interconnected" (personal communication, January 14, 2010) than hitherto imagined.

Landorf said the university came up with an improvement plan to facilitate student development through global learning. At the lower division level, courses with global learning outcomes are being developed and will be made mandatory for all students effective Fall of 2011. For juniors and seniors, every major will compel students to take a minimum of one class in their discipline with global learning outcomes. Three goals were identified for this process: perspective consciousness, knowledge of global dynamics, and global citizenship. "The first one is a skill, the second a knowledge goal and the third one is an attitude goal. Each of them have measurable outcomes," Landorf explained (personal communication, June 25, 2009).

About 1.5\% of FIU's student population (618 out of about 40,455 students, according to the Office of Planning and Institutional Research) ventured abroad in 2009. Carbajo indicated that this figure represents one of the highest participation rates ever for the institution but it still leaves $98.5 \%$ of its students in limbo if there is no systems and 
campus-based approach to internationalization. She added that with FIU being a commuter-serving institution coupled with the economic recession, most of its students are too busy working to pay bills to take the time or eke out the resources to embark on Study Abroad. She believes the adoption of global learning as FIU's QEP for SACs reaccreditation will help but it is potentially not enough:

At first, I thought: how are two globalized classes going to teach them how to be global citizens. I think that it's just a step. You can't become global by just reading a few books or taking a few classes because that is not realistic but I think that we are in the right direction. I wish we had all the money in the world, we could have all this aid and we could require the students to go abroad, having it as a mandatory requirement because that's when they are going to understand. Taking the mandatory classes at the beginning can prepare them but there is nothing that can prepare them more than to go and be integrated into a community outside of their own.

Like 'Oh, my God, I'm lost!' Wondering how to ask directions in another language in a foreign culture, understanding how people live, how people work and function differently, that's how they are going to become global citizens. I know that the QEP is supposed to be for 10 years until SACS and you go on to another project entirely. I hope this is not just a 10 -year project (personal communication, January 28, 2010).

Incidentally, Carbajo was on the panel that came up with the QEP. She said she liked the first initiative of the new office, which was an annual common reading with global content for all incoming freshmen, She said the first such read, Funny in Farsi by 
Firoozeh Dumas, an Iranian-American author which dealt with issues pertaining to hyphenated identities, was a success more so as the author visited both campuses. "The kids enjoyed reading and having that experience of reading the book and having her here, that made it much more concrete in terms of the experience."

Eventually, the goal is for FIU to transition from making students take at least two courses infused with global content to having the entire FIU curriculum globalized, regardless of discipline. To achieve this, Landorf contended that much effort would need to be invested in faculty development. "The students will be okay, the curriculum will be okay but there is a great need for faculty development so that we can take care of the course delivery aspect, in global learning, in techniques, in pedagogy, assessment etc. and that is where I see my future," she said. Landorf said some of the courses are already being piloted with August 2011 slated for the full implementation.

With the current SACS accreditation cycle running through 2014, she signaled that FIU is using the accreditation body's QEP mandate to have this focus on global learning as the impetus to take FIU back to what it originally started with. According to her, the post-9/11 ambience has been largely responsible for this re-kindling of FIU's original internationalization agenda. She stated:

One of the original goals for FIU in 1972 was greater international understanding and that goal has been sort of waxing and waning... You see it really prominent in some years depending on who the president is and depending on what political winds are blowing up in Tallahassee and down here in Miami. And luckily we have a favorable environment post-9/11 ... and ironically that has a lot to do with why the environment has become favorable again for internationalization and 
international education (personal communication, June 25, 2009).

The original intentions of FIU's founding fathers in this regard appeared to have been clarified by a January 1974 position document titled "International...It's Our Middle Name" exhumed from the library archives by GLI. The document articulated the university's resolve to build an inclusive learning center that is global in outlook, inclusive in character and cosmopolitan in orientation. It linked the United States' fate to "the standard of living experienced by the man who works on an oil-drilling rig in the Middle East, the peasants who pick coffee beans in the Caribbean and Latin America, and the workers on the rubber plantations of Southeast Asia" because "solutions to the problems of urbanization, and population growth which beset us can only be approached by a consciousness of their relation to the global environment." The document eloquently spoke to FIU's desire to “develop instructional programs which impart deeper understanding of the peoples of the world," an unfinished business which the Office of Global Learning Initiatives apparently inherited.

This historic mandate as well as the identification by study participants of truculent advocates of international education such as FIU's Provost Ron Berkman who was one of the key initiators of the global learning initiative, current President Mark Rosenberg, Student Affairs Vice President, Dr. Rosa Jones, and several other stakeholders top-down and bottom-up are crucial to the pursuit of a genuine internationalization agenda. Carbajo trusts President Rosenberg's leadership instincts:

If anyone could be Mr. FIU, it will have to be him. He loves this institution...that's why we're all so happy for him. He started here in 1974 right after earning his PhD. Mark Rosenberg has always been very student- 
centered...He is very passionate about the university, the students, globalization and the community that we serve. He is a Latinist. He established the Latin American and Caribbean Center on our campus. International is all he's done and he's very passionate about it (personal communication, January 26, 2010). Similarly, Rosenberg's predecessor, Maidique, indicated that the university's decision to collaborate with Tianjin University of Commerce in China was one of the most significant decisions in FIU's internationalization process. It positioned the institution as China's principal partner as it seeks to produce enough hotel and tourism professionals to manage what it hopes will be the world's foremost tourist destination. Fully-funded by the Chinese government, the $\$ 50$ million U.S. School of Hospitality and Tourism sits on 80 acres of land in Tiajin, China and includes a 1,000-student capacity residence hall tower. FIU was able to leverage one of its top-notch programs to achieve this collaborative enterprise with the Chinese government.

Because the international education function is widely dispersed throughout FIU, however, tension often develops between the student affairs and academic sides of the house with either often feeling marginalized. Sippin alluded to this in discussing the QEP, which she sees as largely driven by faculty, although she indicated that student affairs remains supportive. Landorf firmly identifies the opposition to internationalize the curriculum and make it more inclusive as essentially academic affairs driven, and notably led by "positivists ...by and large reside in the hard sciences."

There are two major reasons. They see it as something that is an intrusion on their curriculum. There is resistance in the hard sciences to this notion of multiple perspectives. There is this notion in the hard sciences that there is only one 
perspective. That perspective has to be learned. And that it is dangerous to convey to students the idea of multiple perspectives. We'll get comments like Math is Math; Physics is Physics (personal communication, June 25, 2009).

Positivists assert that the only authentic knowledge is that based on sense experience and positive or empirical verification. Most modern scientists, including many at FIU, regard themselves as post-positivists. While post-positivists accept probabilistic statements and allow multiple stakeholders' views, disdain for multiple perspectives as advanced by hard core positivists could be a proxy argument against the twin concepts of multiculturalism and internationalization. Dr. Landorf said the Office of Global Learning Initiatives is skirting this divide by crafting compromises with faculty and affected academic departments, using a multi-pronged strategy. She added:

One way, they don't have to play. The Math department does not have to deal with that in their curriculum. Their students can take the global learning course in another area: they don't have to globalize the Math course. Health and sciences were also told that they do not have to globalize their curriculum as long as they have enough leeway in their system for their students to be able to take electives. In engineering on the other hand, engineering is very tightly controlled, so there is no leeway for electives. We are drawing on the early adapters to convince the rest of their faculty - at least some of their faculty - that this is a worthwhile endeavor. Even MIT (Massachusetts Institute of Technology), which is a leader in engineering in the world, is also a leader in globalizing curriculum (personal communication, June 25, 2009).

Incidentally, Modesto A. Maidique, who stepped down as FIU's president in late 
2009 after 23 years in the saddle, holds a PhD in electrical engineering. Having served as a faculty member at MIT, Harvard University, and Stanford University between 1976 and 1986, he had a unique perspective on this. While saying that the substance of the science curriculum cannot be changed in an effort to infuse diversity, he argued that "certain cultural elements to the learning process" such as the pedagogical approach and illustrative paradigms could be made more relevant and inclusive. "Certainly, there can be no Chinese chemistry or Angolan physics but we can teach in a way that reflects different cultures through the examples we cite and the concepts we emphasize," (personal communication, January 14, 2010), he said.

Amid this age-long contestation between positivists and relativists, one overarching tension specific to the theme of this study remains unresolved though: the unmistakable promise of the QEP as a catalyst for the acceleration of FIU's internationalization agenda, and the stubborn imperviousness of the insular regulatory framework imposed on international education and its participants in the aftermath of September 11, 2001.

\section{Summary}

In this chapter, I provided a brief historical overview of Florida International University (FIU) and the evolution of its internationalization function over time. I also gave a detailed report and analysis of my interviews with key international student advisors and administrators, of an examination of the institutions data base and of a review of some documents germane to the focus of this study. In summary, I found that, despite the accidental nature of their forays into the profession, the passion of international educators at FIU for their work with students has remained largely 
unaffected by the tedium and additional responsibilities associated with the post-9/11 era.

Other key themes include the dominant nature of SEVIS as an outgrowth of 9/11, the onset of fear, agitation, and unease as a subtext, stagnating international student enrollment, and a crisis of identity as FIU sought to pivot from its Millennium Vision Document, which consciously and almost exclusively, projected it as a research university, as it sought to rediscover its international roots. Also central to the institution's desire to pivot away from its seeming flight from the definitive internationalism of its formative years are dueling roles and tensions at various levels that are linked to the 9/11 attacks and its regulatory, socio-political and psychological aftermath. These include the contradiction between the traditional role of international student advisors and administrators as student advocates and their new roles as DSOs, expected to report every violation of immigration rules and regulations through SEVIS; tension between wanting to help students by furnishing them with the necessary information, and the prerogative of students as autonomous beings; unease between international student advisors and agents of Immigration and Customs Enforcement (ICE) regarding limits of information disclosure; and ambiguity cum contradiction in the comparative responses of government and FIU to the $9 / 11$ terrorist attacks. In the next chapter, my study focuses on the University of Miami, a private, research-intensive university, located in Coral Gables, a suburb of Miami. 


\section{CHAPTER V}

\section{ANALYSIS AND FINDINGS: UNIVERSITY OF MIAMI}

In this chapter, I provide a brief historical overview of the University of Miami and the evolution of its internationalization function over time. I also give a detailed report on my interviews with key international student advisors and administrators, examination of the institution's data base and examine some documents relevant to the theme of this study.

\section{Historical Overview}

The University of Miami (UM) was chartered in 1925 by some citizens who felt a need in the community. Inter-American studies, the creative arts and teaching/research programs in tropical studies, constituted the core areas of development in the fledgling years of the university. At UM's inception, the South Florida land boom was at its peak, leading to overly optimistic projections on its financial sustenance. In 1926, the university opened its doors to a pioneering class of 560 students. They were dispersed into the College of Liberal Arts, the School of Music, and the Evening Division. By this time, however, a land burst and a major hurricane meant the institution barely stayed afloat for the next 15 years as the nation riled in the throes of the depression.

Tebeau (1976) credited the vision and doggedness of Dr. Bowman F. Ashe, its first president (1926-52) for the survival of the university during this trying period. Ashe's tenure saw UM skirt a bankruptcy, overhaul its administrative structures, survive World War II and its aftermath to usher in an era of rapid development. At inception, the university consisted of the College of Liberal Arts, the School of Music, and the Evening Division. These were followed by The School of Law (1928), the School of Business 
Administration (1929), the School of Education (1929), the Graduate School (1941), the Marine Laboratory, later renamed the Rosenstiel School of Marine and Atmospheric Science (1942), the School of Engineering (1947), and the School of Medicine (1952).

President Ashe's erstwhile assistant, Dr. Jay F. W. Pearson, a marine biologist, assumed UM's presidency in 1953. His tenure heralded ten years of continuous growth with total enrollment increasing by 4,000 by the end of his presidency in 1962 . The university added an undergraduate honors program, expanded the graduate programs to the doctoral level in 12 discipline areas, established a core curriculum for undergraduates, and vastly increased its research activity. Research activity was further intensified under the presidency of Dr. Henry King Stanford (1962-81) who established several research centers and institutes. These included the Center for Advanced International Studies (1964), later renamed the Graduate School of International Studies, the Institute of Molecular and Cellular Evolution (1964), the Center for Theoretical Studies (1965), and the Institute for the Study of Aging (1975). Although UM dropped its policy of racial segregation and began to admit African-American students in 1961, it was not until December 1966 that UM signed on an African-American athlete, Ray Bellamy - a football player. Bellamy made UM the first major college in the Deep South with an African-American football player on scholarship. The university established an Office of Minority Affairs to promote diversity in both undergraduate and professional school admissions. Currently, with an undergraduate enrollment that is $53 \%$ female, $28 \%$ Hispanic and $10 \%$ African-American, UM is a diverse institution.

Edward T. Foote II became UM's fourth president in 1981. During his tenure, the colleges of Architecture, Communication as well as the Graduate School of International 
Studies and its research component, the North-South Center, were created. The university was elected to membership in Phi Beta Kappa, the nation's premier and arguably most prestigious honor society; average SAT scores of incoming freshmen increased by almost 100 points; and the university initiated and concluded renovation/re-modeling works that converted standard student dormitories into a system of residential colleges. Foote facilitated the creation of the university's strategic plan which detailed a blueprint for the acceleration of its vision of excellence. In 1984, he launched a 5-year, \$400 million Endowment Campaign for the University of Miami, which, by 1988, had raised $\$ 517.5$ million.

Donna Shalala, an Arab-American, succeeded Foote in 2001. She was the Secretary of Health and Human Services under former President Bill Clinton and previously served as President of Hunter College of the City University of New York system for 7 years and as Chancellor of the University of Wisconsin for another 6 years. In 2003, she launched Momentum, a one billion dollar, 4-year endowment campaign to sustain Foote's legacy in the area of fundraising. The campaign exceeded its target 18 months ahead of schedule. The university set an additional \$250 million target through December 2007, the original end-date of the campaign by which time it had attracted $\$ 1.4$ billion in private funds.

A former Peace Corps volunteer in Iran from 1962 to 1964, Shalala holds a doctorate degree in Public Affairs from Syracuse University, New York. Her tenure as president has seen UM climb by 16 steps in the US News and World Report ranking of the country's best colleges from 66th position in 2001 to 50th in 2010, even as the institution consolidated its status in Carnegie's top research-intensive hierarchy. There 
has also been a great deal of physical development with new libraries, residence halls, symphony rehearsal halls and classroom buildings. Its student body currently consists of 15,670 in approximately 120 undergraduate, 108 Master's, 49 doctoral, and two professional areas of study. The Academic Ranking of Academic of World Universities ranks UM among the foremost 200 academic institutions while The Princeton Review (Best 371 College, 2009) rates the university first in the "lots of race/class interaction" category, an irony given UM's origins as a White-only institution.

International Student Enrollment Data at UM: 1996 to 2009

A review and analysis of UM's international student enrollment data from 1996 to 2009, sourced from the institution's annual fact book, its enrollment management system as well as its Office of Planning and Institutional Research revealed interesting trends. In the pre-9/11 years (1996 to 2001), there was a $10.2 \%$ increase in the number of freshmen in non-immigrant visa categories from a base of 98 students in 1996 to 108 in the fall of 2001. This was barely one month before the September 11, 2001 attacks.

In the intervening period, there was some modest fluctuation in the annual intake of international students. In 1997, for instance, there was a 45.9\% increase to 143 students only for there to be a $24.4 \%$ plunge in 1998 when only 108 new international students, the same number as in 2001, enrolled. Save for 1997, which seemed to be an outlier, the global picture appeared to be that of steady growth and stability. Also, during the pre-9/11 years, there was a 100\% increase in the number of new Middle Eastern students in 2001 to 20 students compared with only 10 in 1996 . This constituted the biggest change in the number of new international students attracted by UM from any other region of the world before 9/11 (See Table 3 for details). 
Table 3

New Freshmen (International) by World Region Headcounts: UM (Pre-9/11)

\begin{tabular}{lccccccc}
\hline Region & 1996 & 1997 & 1998 & 1999 & 2000 & 2001 & 6-yr. diff (\%) \\
\hline Caribbean & 9 & 19 & 16 & 17 & 15 & 9 & 0 \\
Central America & 4 & 5 & 6 & 3 & 3 & 2 & -50 \\
South America & 33 & 42 & 34 & 34 & 40 & 39 & 18.1 \\
Europe & 23 & 25 & 19 & 19 & 25 & 21 & -8.6 \\
Middle East & 10 & 14 & 12 & 11 & 14 & 20 & 100 \\
Africa & 4 & 8 & 8 & 4 & 0 & 5 & 20 \\
Southeast Asia & 5 & 1 & 4 & 2 & 0 & 1 & -80 \\
Asia & 10 & 8 & 9 & 15 & 15 & 11 & 10 \\
Australia/New Zealand & 0 & 1 & 0 & 0 & 0 & 0 & 0 \\
Total & 98 & 123 & 108 & 105 & 112 & 108 & 10.2 \\
\hline
\end{tabular}

Source: Enrollment Management System/FACT BOOK/University of Miami Planning and Institutional Research

When fall semester data of all international students (undergraduates, graduates, freshmen, sophomores, juniors and seniors) in non-immigrant visa categories in each of the 6 years preceding 9/11 were aggregated, however, there was just a slight $2.3 \%$ increase in enrollment from 1429 students in 1996 to 1462 students in 2001. Also, there was negative growth (-16.4\%) in the overall number of students from the Middle East enrolled at the University of Miami in the Fall of 2001 (152) compared with the 1996 figure of 182 students (see Table 4 and Figure 5 for details). 
Table 4

All International Students by World Region Headcounts: UM (Pre-9/11)

\begin{tabular}{lccccccc}
\hline Region & 1996 & 1997 & 1998 & 1999 & 2000 & 2001 & 6-yr. diff. (\%) \\
\hline Caribbean & 144 & 143 & 133 & 130 & 129 & 185 & 28.4 \\
Central America & 61 & 52 & 52 & 47 & 48 & 51 & 16.4 \\
South America & 347 & 337 & 338 & 390 & 408 & 442 & 27 \\
Europe & 310 & 298 & 289 & 325 & 299 & 300 & -3.22 \\
Middle East & 182 & 166 & 154 & 169 & 159 & 152 & -16.4 \\
Africa & 31 & 35 & 32 & 54 & 42 & 38 & 22.5 \\
Southeast Asia & 76 & 74 & 55 & 51 & 34 & 23 & -69.7 \\
Asia & 271 & 273 & 268 & 275 & 279 & 264 & 2.5 \\
Australia/New Zealand & 7 & 5 & 10 & 8 & 17 & 6 & 14.28 \\
Pacific Islands & 0 & 0 & 0 & 0 & 0 & 1 & 100 \\
Total & 1429 & 1374 & 1323 & 1429 & 1415 & 1462 & 2.30 \\
\hline
\end{tabular}

Source: Enrollment Management System/FACT BOOK/University of Miami Planning and Institutional Research

In the 5 years succeeding the $9 / 11$ attacks (i.e., 2002 to 2006), UM did not reach the 2001 level in the number of new international students attracted annually to the institution.

Only 9 students from the Middle East enrolled in 2002, 15 in 2003 (before SEVIS was fully activated), 7 in 2004, 17 in 2005 and 14 in 2006. There was, however a 78\% increase in 2007 to 25 students although only 18 new Middle Eastern students registered for the 2009/2010 academic session, a 21.7\% decrease from the 23 freshmen welcomed by UM in 2008 (see Table 5 for details). The figures tell a similar story when Fall-to-Fall 
total enrollment of international students in the post-9/11 period is considered.

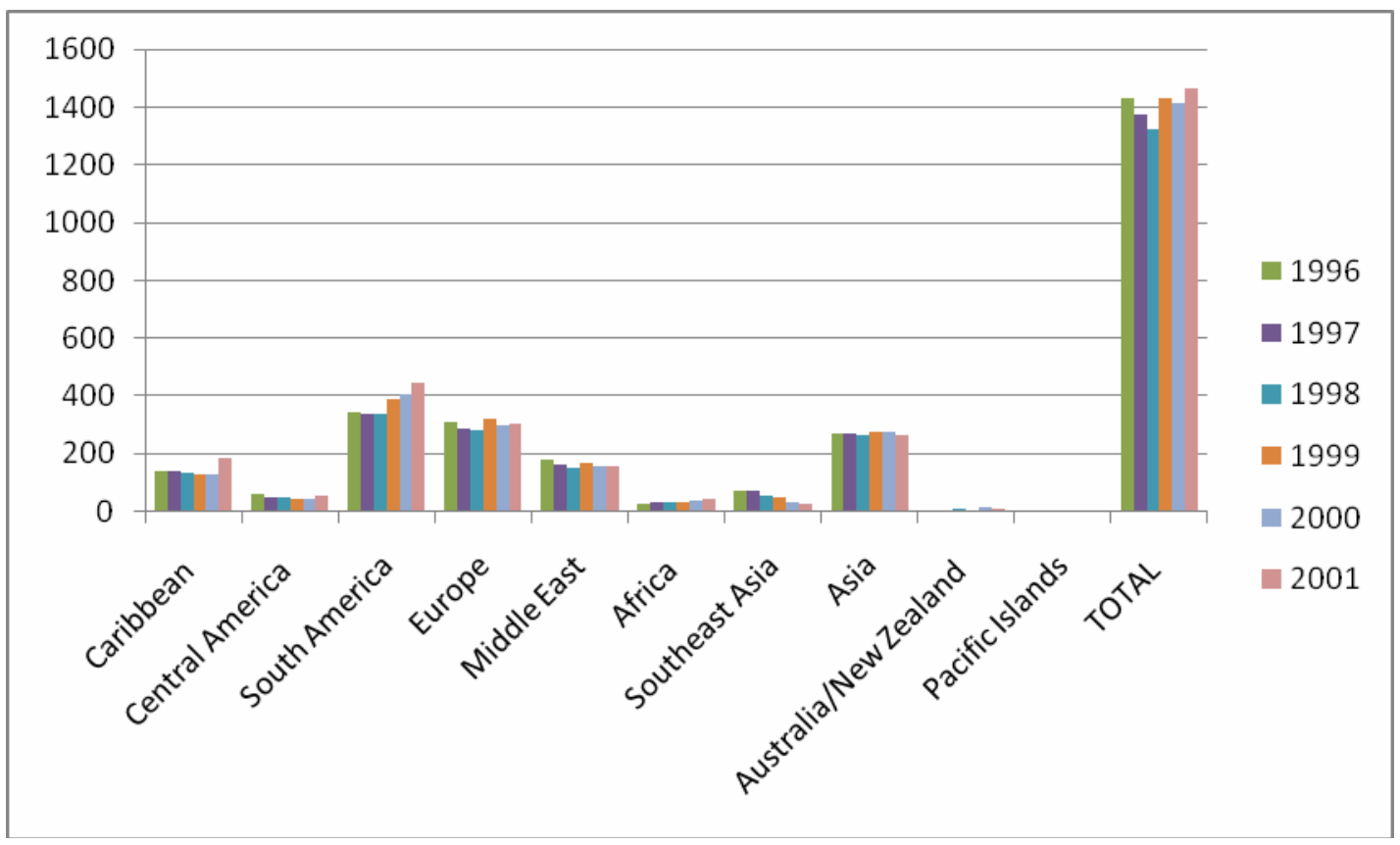

Source: Enrollment Management System/FACT BOOK/University of Miami Planning and Institutional Research

Figure 5. UM international students by world region headcounts (Pre-9/11).

Between 2002 and 2006, UM was unable to attain the level it attained on the eve of 9/11 (1,462 students). The figures indicated a $13.05 \%$ progressive decline in the 5 years after $9 / 11$. 
Table 5

New Freshmen (International) by World Region Headcounts -UM (Post-9/11)

\begin{tabular}{lccccccccc}
\hline & & & & & & & & & 8-yr. diff \\
Region & 2002 & 2003 & 2004 & 2005 & 2006 & 2007 & 2008 & 2009 & $(\%)$ \\
\hline Caribbean & 7 & 15 & 10 & 17 & 13 & 22 & 14 & 11 & 57.1 \\
Central America & 4 & 3 & 0 & 2 & 3 & 2 & 0 & 2 & 50 \\
South America & 32 & 27 & 20 & 19 & 16 & 34 & 32 & 21 & 34.3 \\
Europe & 19 & 21 & 15 & 18 & 25 & 24 & 35 & 30 & 57.9 \\
Middle East & 9 & 15 & 7 & 17 & 14 & 25 & 23 & 18 & 50 \\
Africa & 3 & 4 & 1 & 4 & 1 & 5 & 4 & 5 & 66.6 \\
Asia & 9 & 9 & 9 & 7 & 16 & 18 & 47 & 146 & 152.2 \\
Australia/New Zealand & 0 & 2 & 0 & 3 & 0 & 1 & 0 & 2 & 200 \\
Total & 85 & 96 & 64 & 87 & 90 & 133 & 157 & 237 & 220 \\
\hline
\end{tabular}

However, international student enrollment has been on the upswing since 2007 with 2009 showing an impressive 17\% increment over 2008 figures. UM's Middle East student population was able to skirt a sharp drop in its population in the 3 years after the full implementation of SEVIS (2004-2006) to achieve a semblance of stability and post a positive 8 -year change of $8.5 \%$ (see Table 6 and Figure 6 for details). 
Table 6

All International Students by World Region Headcounts -UM (Post-9/11)

$\begin{array}{llllllllll}\text { Region } & 2002 & 2003 & 2004 & 2005 & 2006 & 2007 & 2008 & 2009 & 8 \text {-year }\end{array}$

Diff.

$(\%)$

\begin{tabular}{llllllllll}
\hline Caribbean & 145 & 117 & 104 & 95 & 101 & 110 & 104 & 95 & 106
\end{tabular}

Central

$\begin{array}{llllllllll}\text { America } & 47 & 41 & 31 & 33 & 31 & 33 & 26 & 26 & 37.8\end{array}$

South

\begin{tabular}{|c|c|c|c|c|c|c|c|c|c|}
\hline America & 37 & 26 & 27 & 27 & 17 & 24 & 28 & 23 & 37.8 \\
\hline Europe & 296 & 273 & 283 & 292 & 300 & 314 & 344 & 347 & 16.3 \\
\hline Middle East & 153 & 166 & 149 & 146 & 145 & 165 & 161 & 166 & 8.5 \\
\hline S. E. Asia & 23 & 18 & 25 & 27 & 28 & 32 & 31 & 33 & 43.4 \\
\hline Asia & 281 & 311 & 294 & 309 & 334 & 360 & 411 & 598 & 112.8 \\
\hline Australia & 9 & 14 & 27 & 23 & 22 & 21 & 33 & 29 & 222.2 \\
\hline \multicolumn{10}{|l|}{ Pacific } \\
\hline Islands & 0 & 0 & 1 & 0 & 0 & 0 & 0 & 0 & 0 \\
\hline Africa & 37 & 26 & 27 & 27 & 28 & 32 & 31 & 33 & 43.4 \\
\hline Total & 1402 & 1306 & 1241 & 1225 & 1219 & 1566 & 1718 & 2071 & 47.71 \\
\hline TOTAL & 1497 & 1524 & 1525 & 1567 & 1567 & 1544 & 1532 & 1562 & 4.34 \\
\hline (ALL) & 8 & 8 & 0 & 4 & 0 & 9 & 3 & 9 & \\
\hline
\end{tabular}

Note: Source: Enrollment Management System/FACT BOOK/University of Miami Planning and Institutional Research 


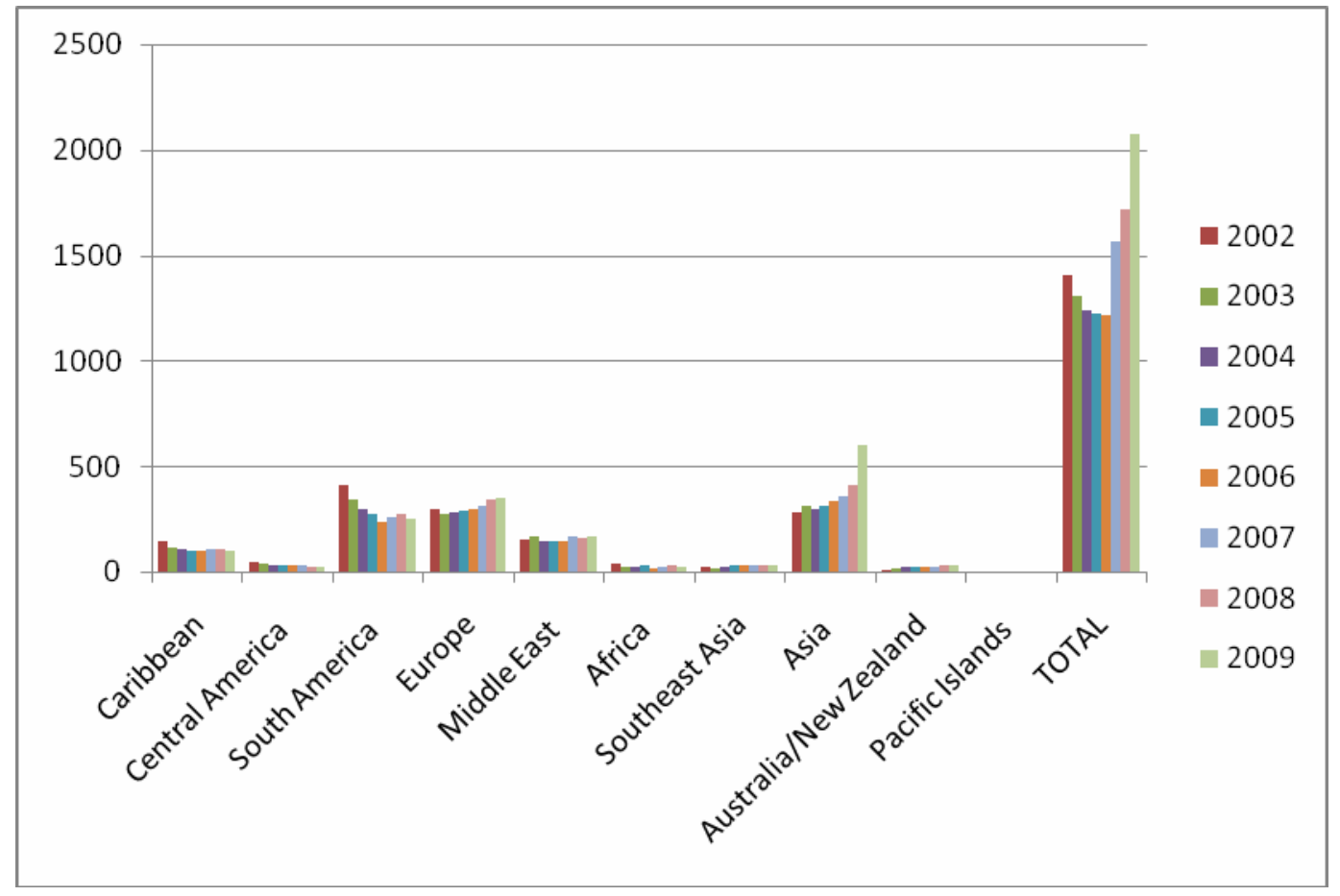

Figure 6. UM international students by world region headcounts (Post-9/11).

Student Participation in Study Abroad Data at UM: 1997 to 2007

According to figures reported to Open Doors by the University of Miami's

Education and International Exchange Programs Office, 231 UM students, who are US citizens or permanent residents, studied abroad in the 1997/98 academic session with the most popular destinations being the United Kingdom (55), Spain (29) and France (28). The figure rose slightly in the $1998 / 99$ session by $17.91 \%$ to 271 , with United Kingdom (51), Spain (33), Peru (23), France (21) and Australia (19) as the popular destinations. The upward trend continued in the 1999/2000 academic year but there was a reversal in the $2000 / 01$ academic year when there was a $1.92 \%$ decrease, just before the $9 / 11$ 
terrorist attacks (see details in Table 7).

Incidentally, there was an upsurge in the participation of UM students in study abroad in the immediate aftermath of the attacks (See details in Table 7). In the 2001/02 Table 7

Student Participation in Study Abroad at UM: 1998-2008

\begin{tabular}{lccl}
\hline Year & N & Annual Difference (\%) & Top Destination Countries \\
\hline 1998 & N/A & 17.31 & UK (55), Spain (29), France (28) \\
1999 & 231 & 15.12 & UK (51), Spain (33), Peru (23) \\
2000 & 271 & -1.92 & UK (55), France (29), Peru (28) \\
2001 & 312 & 10.45 & UK (62), Spain (24), Italy (23) \\
2002 & 306 & 10.05 & UK (83), Australia (37), France (37) \\
2003 & 338 & 17.5 & UK (93), Spain (64), Czech (39) \\
2004 & 404 & 0 & UK (93), Spain (64), Czech Republic (39) \\
2005 & 477 & 6.10 & UK (124), Italy (73), Spain (43) \\
2006 & 544 & 2.02 & UK (104), Spain (86), Czech Republic (34) \\
2007 & 535 & 5.60 & UK (79), Spain (56), Australia (42) \\
2008 & 505 & &
\end{tabular}

Note: Source: Open Doors 1998-2008

academic session, 338 students ventured abroad with UK (50), Spain (46), France (35), Australia and Italy (29) emerging as the most popular. The trend continued from the 2002/03 academic session through the 2004/05 academic session. In the 2006/07 and 2007/2008 academic sessions, there were slight drops to 535 and 505 UM students participating in Study Abroad, respectively. To put this into perspective, although UM 
attracts students from families with high socio-economic status, only $4.8 \%$ of its Fall 2008 population of enrolled students (505 out of 10,422 students) studied abroad, implying that $95.2 \%$ never ventured out of its Miami-area campuses for education purposes.

\section{Organization of the International Education Function}

At the University of Miami, international education is a highly diffused function in the institution. The principal offices responsible for internationalization are the, International Student and Scholars (ISSS), International Education and Exchange Programs, International Admissions and the Intensive English Program of the Continuing and International Education Division. The International Student and Scholars office is directed by Ms. Teresa de la Guardia, who reports to Dr. William Scott Green, Senior Vice Provost and Dean of Undergraduate Education. Prior to recent restructuring and realigning of the university's organizational structure, she reported to the Vice President for Student Affairs, Dr. Patricia Whitely.

De la Guardia is assisted by an Associate Director, Claudia Zitmann, as well as Assistant Directors Kristin Ponge and Cristina Florez and three staff secretaries. The office provides services and programs that support international educational exchange by providing access to cross-cultural experiences for international students and scholars. The idea is to foster exposure and integration of the students and scholars to American society, culture and institutions while giving them a platform to share their heritage with their American counterparts. ISSS professionals thus help their students and scholars prior to their arrival on campus through anticipatory socialization programs, upon their arrival on campus, while pursuing their studies, and when preparing to go back home. 
The Council of International Students and Organizations (COISO), the umbrella body for international student clubs and organizations, is advised by a professional from ISSS.

The International Education and Exchange Programs (IEEP) is headed by a director, Ms. Glenda Hayley, who also reports to Dr. Green. She is assisted by Assistant Directors Elyse Resnick, Erica Jolman and Jasmine Phillips as well as a Staff Associate. The office superintends over a vast array of programs in more than 33 countries as well as UM faculty-led travel abroad programs offering undergraduate and graduate programs.

The Intensive English Program (IEP) of the University of Miami prides itself as the only nationally accredited university-based IEP program in Miami. IEP recruits students worldwide to learn English and prepares them for academic study while providing language support services for the university. Directed by Michele Alvarez, IEP also helps students with their adaptation to university life and American culture and acquisition of academic study skills. Alvarez is assisted by Jenny Vargas, Assistant Director for Student Services, and a secretary to run the program, which currently employs 10 full-time faculty members. Vargas serves as the Designated School Official (DSO) for the Intensive English Program (IEP) handling immigration matters and crosscultural programs. The international admissions office is headed by an executive director, Mark Reid, who indicated on the university's website that his team visits more than 60 cities across the world to recruit students every year. He is assisted by Juan Alvarez, an associate director, and Elissar Kurban, an Assistant Director.

\section{Study Participants}

As earlier indicated, formal personal interviews were conducted with five international student advisors and administrators, who have at least 8 years experience in 
the international education arena. Interviews were conducted with Patricia Whitely, the Vice President of Student Affairs, William Scott Green, Senior Vice Provost and Dean of Undergraduate Education, Elyse Resnick, Assistant Director, International Education and Exchange Programs, Claudia Zitzmann, Associate Director, International Student and Scholar Services and Abraham Varghese, Assistant Provost for International Affairs. I also had background discussions with Mark Reid, Teresa de la Guardia and Michele Alvarez in September 2007.

Patricia Whitely has been with the University of Miami for 20 years and as vice president for student affairs for 13 years. Between 1997 and 2008, International Student and Scholars Services (ISSS) was an integral part of the Division of Student Affairs, over which Whitely superintended. Whitely holds a Bachelor's degree in management with minors in economics and theology from St. John's University, a Masters in student personnel services from the University of South Carolina and a doctorate in higher education administration, which she readily calls her "passion" (personal communication, January 22, 2010). She completed her post-doctoral work in higher education at Harvard University's Institute for Higher Education. As vice president, she is responsible for the overall administration and leadership of 126 staff, a budget exceeding \$53 million, and out-of-class education and learning opportunities supporting 11 colleges and schools serving over 15,000 students.

William Scott Green, Senior Vice Provost and Dean of Undergraduate Education, joined the University of Miami from Rochester University, where he was a Dean, 3 years ago. Educated in the United States, France, and Israel, Green holds a Ph.D. in religion from Brown University. He has functioned as an archaeologist in various countries and is 
credited with enhancing the undergraduate experience at Rochester University. His vision at UM is to link Study Abroad and exchange programs and other international initiatives with academic affairs, making them curriculum-driven. ISSS and International Education and Exchange programs now report to him.

Elyse Resnick, Associate Director of International Education Programs, holds a Bachelor's degree in history from Emory University in Atlanta and a Master's in International Relations from Boston University's graduate center in Brussels, Belgium. She joined the University of Miami as Study Abroad Coordinator in January, 2000, rising through the ranks to her current position. In her position, she assists the office's director in coordinating some 80 programs offered in more than 33 countries on a full academic year, semester, or summer basis as well as UM faculty-led programs during intersession, spring break, and summer. Resnick's specific advising areas are England, Slovenia, Scotland, Ireland, Italy, Monaco and Wales.

Abraham Varghese, assistant provost for international affairs, is originally from India. He joined UM as an assistant director for international marketing as a fresh UM Master's degree holder in mechanical and industrial engineering, in 1995. He also holds a degree in mathematics from Mahatma Ghandi University in India. He then functioned as Director for International Affairs as well as Director of International and Government Relations before becoming assistant provost. Varghese's job is to apply his analytical skills and business acumen to develop global partnerships for UM.

As Associate Director in the International Student and Scholars Services office, Claudia Zitzmann is both a Designated School Official (DSO) by the United States Citizenship and Immigration Services (USCIS) as well as an Alternative Responsible 
Officer (ARO) dealing with scholars on J1 status. A German immigrant, Zitzmann, also manages the observership program for foreign nationals at UM. She has worked in the ISSS office for 16 years.

\section{Themes}

In this section, the perspectives of these key officials are presented and analyzed. They are reinforced by observations and analysis of available documents and internet postings to chart emerging themes and trends.

\section{Early Beginnings: Happenstance and Intentionality}

All but one of the international educators interviewed for this study at UM were quick to admit that they literarily stumbled into the field. Having found international education, however, they grew passionate about this area of student affairs practice. According to them, the student and scholars they interacted with, and helped mold, on a day-to-day, semester-to-semester basis, and the evolving regulations that constituted the world of immigration advising captured their imagination. They added that the constant challenge to develop new ways of engaging with a universe that simultaneously grew more complex as advances in communication shrank the world into a minuscule global village, make international education a truly exciting career.

Claudia Zitzmann of the ISSS office first experienced international education while working as a student assistant. Even though her academic background is in communication studies in which she holds a Master's degree, she has remained in the field for the past 16 years. "It's really by accident. I started as a student assistant and was offered a job here when there was an opening. I was hired as an international student advisor in 1992" (personal communication, January 28, 2010), she recalled. Now an 
Associate Director, Zitzmann, is both a DSO and an ARO. She manages UM's exchange visitors and international observers programs.

Although Elysee Resnick, Assistant Director, International Education and Exchange Programs, University of Miami, has a solid background in the field with a Bachelor's degree in history from Emory University and a Master's degree in International Relations from Boston University's graduate center in Belgium, being an international educator was not something she had thought about. She said her obsession was with human rights and humanitarian aid, but she found it impossible to get a job in those areas. "I had two internships in that field and it was very exciting but difficult to get into at a professional level and it's a tough lifestyle. You have to pick up and move a lot. You have to be where the crisis is (personal communication, January 21, 2010), she said. A Boca Raton native, Resnick said she did not know where else her skills would be useful when she left the Galapagos Islands, where she said she had been "hibernating" with animals, for a job search in Quito, Ecuador in 1996. She said calls started coming in once her husband dropped her resume at the universities.

People started calling me in Quitor, Ecuador. Some ... wanted me to teach human rights and all that sort of stuff. But none of those teaching stuff had any money... Two universities wanted me to do something like we call international education. The woman that turned out to be my boss, she just said we need somebody to create exchange programs with schools around the world - universities. I was like 'yeah, I can do that!' She was like 'let's call you Executive Director for International Relations,' really nice title with really nice business cards. ... That was how I stumbled upon international education and it turned out to be a perfect 
fit for me (personal communication, January 21, 2010).

That "stumble" into international education turned out to be career-defining for Resnick break into the field. She worked at the Universidad Del Pacifico in Quito, Ecuador, for 3 years, making it easier for her to land a job as Study Abroad Coordinator at the University of Miami when she moved back to South Florida in 2000.

Unlike Resnick and Zitzmann, Abraham Varghese intentionally sought out an opportunity to be in international education. Having come to the United States and the University of Miami as a graduate international student, Varghese said he saw several areas within the US educational system that could potentially be improved. Upon graduation in 1995, he approached the Dean of the College of Engineering with his observations. "We had a very good conversation and I came up with a business plan for the school...So I spelled out my business plan and he liked the business plan and he hired me on the spot" (personal communication, October 26, 2009). From that first appointment as Assistant Director for International Marketing, Varghese rose to become UM's Assistant Provost for International Affairs.

In this regard, majority of my study participants at UM cite love of the field and fervent desire to deploy their helping skills to assist their students and scholars for their foray into the profession. Varghese simply stated that "the reason" he "got into international education is to help students" (personal communication, October 26, 2010) by strategically preparing them for the workforce of the future and facilitating the international exposure necessary to achieve relevance in the global job market.

If you are a business student, you have to go out and see what happens in Europe and Africa, the Caribbean and other places. In my opinion, you have a complete 
education of a global nature and that is what we are trying to incorporate into our structure, our curriculum. And that's my passion and that is how I got into international education. And because I have this engineering background, I am in a position where I can logically think and analytically put things in place...process-wise as well as policy-wise because you need processes to get things done, but you need policies to implement them (personal communication, October 26, 2010).

Resnick articulates a similar drive, saying she loves "being able to deal with students" and considers herself lucky to have strayed into international education. "When my husband wanted to move back to Miami, I told him that I finally had a career," she recalled (personal communication, January 21, 2010). Having tasted international education, she would rather stay back in Ecuador, which she loved, than settle for some random job in Miami. According to her, one of the rewarding things about working in Study Abroad is how students - especially the not-so wealthy ones - come back from a stint overseas and tell her how they have been positively impacted.

You know, here at UM, people imagine that every student is wealthy and every student is privileged. Yes, we do have students like that here and maybe the Study Abroad experience for those students doesn't make as much of an impact because they've been abroad before and all that. There are, however, also many Pell-grant qualified financial aid students and students on full UM scholarship, who are able to go abroad because such aids are applicable to Study Abroad (personal communication, January 21, 2010).

She related the story of a Miami-born and bred scholarship student who ventured 
on a Study Abroad trip to L'Aquila as a sophomore studying Italian. She loved it so much she decided that Spain would be her next stop since she spoke Spanish anyway. Before she started the Spain program, however, she secured, over the winter break in Italy, a "legitimately paying marketing job in Turin during the Olympics" (January 21, 2010).

With a proud, wistful glint in her eyes, Resnick added:

She got to meet all these athletes, and she would write e-mails relating her experiences. And then, before she finished, she managed with that experience to get herself a job in Sardinia, Italy doing marketing again. So she stayed there a while. I think she applied for a Fulbright thing, but she didn't get it. She ended up getting a job in Colombia with one of these big companies on a pretty high level so she is shaping up to be a top executive... She is one of those students who take their natural curiosity and sense of adventure and they plug it into the Study Abroad experience. It almost like getting to the airport and walking on that moving walkway and you are zipping by. That's the way I see those kinds of students. I mean she is really exceptional (personal communication, January 21, 2010).

With Claudia Zitzmann of ISSS, working with immigration regulations and laws is something that keeps her focused and excited. She also feels secure in the relationships she had built with colleagues across departments over time that facilitates her ability to bring scholars from different parts of the world to the University of Miami. Also, she said she is enthused with her work with the J1 Exchange Visitors engaged in non-clinical research, and the international observership programs at the Rosenstiel School of Marine and Atmospheric Science and Miller School of Medicine, which, she notes, contribute to 
the advance of science, in addition to fostering connections between people. She stated:

Scholars are usually extremely grateful to be able to come to the university. It enhances their resume for the future and it also improves skills... since I work closely with the departments that bring them here, every once in a while a professor will express to me that because we facilitated people coming here they were able to solve some significant problems with math or science, that this connection with this person led to other things in conjunction with this university or that university. So that's a gratifying thing. It's also gratifying when a scholar contacts a person and says, "Thank you for the advice you have given me, thank you for your helping me bring my wife to this country" (personal communication, January 28,2010$)$.

This demonstration of intrinsic joy and pride in international education work is a predominant denominator among my study participants at UM.

Changing Roles: SEVIS as "Main Outgrowth" of the September 11, 2001, Attacks

The introduction of the Student and Exchange Visitors Information System (SEVIS) in the Fall of 2003 appears, by consensus, to have had the most telling effect on the international education function at the University of Miami. Patricia Whitely, Dean of Student Affairs, who had supervising responsibilities over International Student and Scholar Services (ISSS) from 1997 to 2008 said it became "so much more cumbersome to come here to study" because "there were so many regulations that universities had to comply with" (January, 22, 2010).

Whitely indicated that SEVIS was a cost-center to the university and a sort of unfunded mandate with no additional funds allotted to student affairs to procure the 
necessary software for compliance. "We had to spend a lot of money actually for a sophisticated tracking system that would meet the national regulation that had been established," she said, noting that the tracking of international students became a "really big" and "much more sophisticated operation" with the University of Miami and other universities "much more accountable to the Federal Government" (personal communication, January 22, 2010).

Another piece that Whitely identified was the initial decrease, post-9/11, in the number of international students studying at UM. "Have we seen here a decrease in the number of international students? Initially, yes! There was a decrease in the number of international students studying here. Initially, I would say 5 to $7 \%$. Now, it is way back up and we are $10 \%$ or more above 2000 levels," she stated. As Tables 5 and 7 indicate, Whitely was somewhat in the ballpark. UM enrolled 1,415 international students in year 2000 , witnessing a $2.30 \%$ upswing in the 6 years preceding the $9 / 11$ attacks. The university did not, however, match 2000 international student enrollment levels in the six years following 9/11. In 2007, 1,566 international students were enrolled. This was a $10.67 \%$ increase over year 2000 levels.

ISSS's Associate Director, Claudia Zitzmann struck a more nuanced tone saying that while neither 9/11 nor SEVIS fundamentally changed the nature of her job, the latter has far-reaching effects process. "Everything is computerized now," she noted, adding that she now personally handles a lot of the paper work that the office's support staff handled in the pre-9/11 era:

A lot of people expect that SEVIS would fundamentally change the nature of our job, but I don't think it has really because the information that we are passing to 
immigration, we had to pass on anyway. But it's now a matter of routine putting it into a system that automatically transmits it. Before September 11, everything was done on a paper basis. That meant that the support staff was doing a lot more paper work but now we're doing a lot of our own paper work and we are putting it in the computer; we're transmitting it. For example...I issue all my own DS2019s. So, I spent significantly more time in front of my computer since everything is now electronically-based (personal communication, January 28, 2010).

Even though a couple of the participants in this study deny that the September 11, 2001 attacks had any impact on the internationalization agenda at the University of Miami, none deny the inevitable evolution of the incident as a conversation starter of sorts. It became a canvas on which uncomfortable issues relating to belief-systems, marginality and mattering in the college were laid and dissected. Zitzmann spoke about how ISSS organized various forums to talk about September 11 and Islam:

You know what that meant and to talk about religion in general. Does Islam really call for those kinds of attacks? So those are the kinds of forums where everyone was able to participate. Students were able to say, this is how that made me feel, this is what I think about that and Muslim students were able to say, that is not what our religion calls for. This is why we don't want to be identified with those kinds of attacks (personal communication, January 21, 2010).

It also led to self-reflection on American hubris, its implications and fate after 9/11. As Elysee Resnick put it, the fact that such a brazen act of terror happened on the American 
homeland was enough for many at UM's International Education and Exchange Programs to question received assumptions about America's dominant position in the world and to open discourse strains that include and interrogate the concept of the other. She stated:

we were all worried about what would happen. I think it was the first time that we ever considered the possibility that other countries would be considering if our country is safe for their kids. We have this idea that the rest of the world is so unsafe and our country so very safe. Yet after $9 / 11$ the reality is that we could admit things happen here. The reality is we have guns here everywhere, while in most of the world you are not even allowed to own guns. Miami especially did not have such a great reputation two decades ago....

We have American parents asking: Is London safe? And I ask: Is New York safe? Anything can happen anywhere! It was the first time I really felt like people might not want to come here. It made me feel that international students might think twice about coming into this country. We worried about that. Then about the possible backlash afterwards against Arab and Muslim students, but since we don't exchange with Arab and Muslim countries, we didn't feel that kind of impact (personal communication, January 21, 2010).

The inverted paradigm painted in the foregoing by Resnick contemplated the possibility of other nations pondering over whether or not to issue travel advisory, warning their nationals to avoid an apparently threatened and, probably, unsafe U.S. landscape. This scenario definitely represented a disequilibrium in our world as we knew 
it, pre-9/11. William Green indicated that the conversation also dwelt on how much attention was being paid by colleges nationwide to the "particular culture with the heritage tradition that allegedly generated" the $9 / 11$ attacks:

How many added faculty members - because we didn't do it here - who specialize in South Asia, Pakistan? Do we have a program that studies Afghanistan anywhere? You [researcher] are looking at only two schools so that might not matter but some schools added Arabic positions that they did not have prior to 9/11. Chinese they had already. Now Arabic became a critically important language. Both of my sons studied Arabic. When I went to college, there was nothing like Arabic. Who would teach Arabic? Who would take Arabic? It's like Turkish. Who would study it? ... We still don't have a full time Arabic expert at UM (personal communication, January 21, 2010).

Green was instrumental to adding Arabic to Rochester University's curriculum 2 years before the 9/11 attacks and Whitely suggested that it was time UM adopted the same posture. "To not teach Arabic in this world is like not teaching mathematics. For students to be functional in the world, this is something they would need to study," Green emphasized.

\section{Phobia, Denial, Marginality, and Stagnating Enrollment}

Patricia Whitely, vice president of Student Affairs was quick to dismiss a question on whether fear of another possible attack dominated the environment of international education after 9/11 but she said her office felt a need to be supportive of UM's Muslim students because they "felt a little unwanted" (personal communication, January 22, 2010). She stated: 
Our Muslim students, students from Afghanistan, Pakistan, and Saudi Arabia, they felt disenfranchised, they felt targeted, they thought everybody hated them. They wanted to hide. They were ashamed. So we had to do everything to bring them together to tell them that we cared for them and we would be there for them. And then you had students that lost parents from the New York/Washington area, so we get stories like that (personal communication, January 28, 2010).

As international students and scholars at UM struggled with the foregoing feelings of alienation as articulated by Whitely, Resnick said the Study Abroad office's fear of possible "backlash afterwards against Arab and Muslim students" was somewhat ameliorated by the fact that "we [UM] don't exchange with Arab and Muslim countries," (personal communication, January 21, 2010). Impliedly, the absence of exchange programs between UM and institutions from the Middle East and South Asia was cause for a perceptible sigh of relief even though that put a question mark on UM's global vision and outreach in the pre-9/11 era.

In the post-9/11 period, there was an initial downturn in international student enrollment, especially for students "from Saudi Arabia and those parts of the world in the Middle East," according to Whitely. UM also witnessed the partial grounding of an Islamic Center originally planned for its Coral Gables campus. Whitely, who was one of the prime movers of the project, recalled:

We've always had a very active group of Muslim students on campus. In fact...we were actively trying to raise money, actually... We were trying to raise money working for an Islamic Board for an Islamic Center but, as you can imagine, there was a change after $9 / 11$. The funds sort of dried up. And now they 
are more comfortable having a community center rather than a student center so they are moving it off-campus. It will still be in Coral Gables but it will now be located off-campus (personal communication, January 22, 2010).

In addition to the loss of the Islamic Center, 9/11 also heralded some psychological developments at UM. Glenda Hayley, Director, International Education and Exchange Programs, said her office became acutely more security-consciousness after 9/11. She added: "We reviewed our security measures and implemented additional measures to ensure the safety of our students abroad. We are continually checking and revising safety and security measures, and we have closer contact with the students as well as with our partners overseas" (personal communication, January 25, 2010).

Resnick, her assistant director, dismissed a lot of the fears and feelings of insecurity, particularly from parents, as somewhat unfounded:

We get a lot of calls from parents about terrorism, about safety, but there is only one answer to that: No university will guarantee anyone's safety, it's impossible. Even leaving your house is taking a risk. Think about that Italian boy who was here on New Year eve and got hit by a stray bullet. We have a program in L'Aquilla, Italy - probably the safest place in the world - but an earthquake destroyed the place on April 6 last year, killing about 400 people. Fortunately, our students had opted this time for a new program we were starting in Milan, another Italian city. Things happen! (January 21, 2010)

In effect, the climate of apprehension and fear that gripped all stakeholders in the aftermath of the September 11, 2001 was not always justified or justifiable since risk is a necessary ingredient of life. In reflecting on the post-9/11 syndrome, however, Claudia 
Zitzmann's recollection seemed to run counter to the facts. She stated that "UM always had plenty of students from the Middle East. And those numbers have never gone low even after September 11" because “...they felt comfortable before and they felt comfortable after" (personal communication, January 28, 2010). When I interjected to indicate that the numbers did go down, she insisted that the contrary was the case. It was almost as if she was in denial.

"A Global University" [sans Middle East] Pre-9/11

Despite its origins as a White-only university, UM's quest to be a global university dedicated to expanding the frontiers of knowledge pre-dates the September 11, 2001 attacks. Its mission statement is "to educate and nurture students, to create knowledge, and to provide service to our community and beyond. Committed to excellence and proud of the diversity of our University family, we strive to develop future leaders of our nation and the world." Its core values, predicated on untrammeled inquiry in the quest for truth and excellence, also articulates its commitment to providing its "students with the foundations for ethical citizenship and service to others, a respect for differences among people, and a commitment to high standards of thought and communication.”

With UM faculty receiving about $\$ 300$ million per annum from private and public funding sources for research purposes, the university is able to remain on the cutting edge scientific discovery and leverage its scientific prowess to attract intellectuals from all over the world, supporting over 5,000 graduate students and postdoctoral trainees. In addition to F1 students and J1 scholars, the university's International Observership Program for foreign nationals allows it to host international visitors to observe research, 
teaching and other departmental activities for a limited period of time, for the mutual benefit of its students and foreign observers.

Whitely said foreign nationals still want to come to UM after overcoming the initial shock of 9/11 and following relaxation of some rules, which unduly flagged scientists. According to her, a new wave of students from Asian countries such as China and Japan, have been flocking UM because of its strong reputation for scientific research. This freshman class we had over 150 students so that is great. And I think that since $9 / 11$, if anything, there is much more of a global world. Students are much more interested in languages. More students study abroad trying to learn more about the world... For example, when the earthquake hit Haiti we had 14 students there doing special research projects, so I think there have been some positives that have come out of it in terms of this (personal communication, January 22, 2010).

Varghese said UM is continuing a program of incorporating international experience into its engineering curriculum even though the Accreditation Board for Engineering and Technology's (ABET) requirements make this an arduous process. Strategies like Study Abroad, Internship, Learning Experience, and Cooperative Programs have been deployed to achieve this objective. UM also developed corporate partnerships:

We went out to international corporations and companies and said here are engineering students who are very good in what they do and you need to incorporate your projects to not only provide opportunities for the students but to get the students to work for you at minimal cost or no cost at all. So it was a win- 
win situation between the corporations and the universities. So faculty and students get exposure to the latest technology and trends in the industry while industry get free workers! That was perfect (personal communication, October 26, 2009).

The university also partners with universities such as Nanyang Technology University in Singapore, with which it signed a collaboration agreement for semester and year-long study abroad in academic areas such as engineering, architecture, industrial design and music. He said such international projects require a lot of logistical support which became accentuated in the wake of the 9/11 attacks but UM had surmounted the challenges because of its linkages with governments, embassies and well-positioned alumni. He stated:

It is easier said than done. You've got to get the passport, you've got to get the visa, you've got to get the funds and the time to do it and to find the company to fund the project and the faculty need to approve those projects because they need to be incorporated into the curriculum. Otherwise the accreditation body can come back and say this is not acceptable. So all those things need to be put in place...We also work with some local economic development companies and agencies to expand the position and reputation of the college (personal communication, October 26, 2009).

Despite the global vision it articulated and the existence of its Middle East Studies Institute, the University of Miami did not have significant presence in the Middle East, which is considered the hotbed of Islamic radicalism, prior to the September 11, 2001 attacks. "We have never had any programs in the Middle East on an exchange basis," 
Resnick said. "We don't send students there and we don't receive students from there" (personal communication, January 21, 2010). Claudia Zitzmann quipped that although the September 11, 2001 terror attacks made it more difficult for scholars from the Middle East and Asia to venture into the United States, that did not necessarily affect UM since "those are traditionally not where we [University of Miami] get most of our scholars from anyway" (personal communication, January 28, 2010).

Glenda Hayley, however, indicated that five students participated in spring 2009 in the archaeology-based Galilee program inspired by Green. Another five students are in the program for the spring 2010 semester. "We wouldn't be a good benchmark for that. We used to send students to Israel, but not under an exchange agreement. This was stopped when the travel warnings for Israel were issued," Haley concluded (personal communication, January 21, 2010).

Resnick argued that UM does have to expand its vision and expand its reach to more regions and countries that it tended to avoid in the past. "I don't know if it is fair to say that was because of $9 / 11$. That might have affirmed our underlying fear that they might be more dangerous, that they might be more risky in some way. This is not any real policy but I think we are not looking for dangerous places to send our students," she stated.

Maybe that is why we don't have programs somewhere in Africa and maybe it's not actually more dangerous than anywhere else. I think it's really been the vibe here without really saying it like that. Let's not target places where we know there could be an increased anti-American sentiment. That's just a feeling (personal communication, January 21, 2010). 
The affirmation of fear of the unknown as an unacknowledged, but ever-present driver of policy, here, is telling. It is apparently one of the implicit features of the post-9/11 environment at UM.

\section{Dueling Roles and Tensions}

The post-9/11 ambience at UM is complex, ambiguous and oftentimes contradictory. The tensions manifest between the institution's (UM) and government's (regulatory) responses to the event; between the bi-focal preoccupation of international educators as enforcers of the new regulatory ambience while remaining traditional advocates and counselors for the students and the nationalism versus internationalism dilemma of international students and their domestic counterparts.

Institution vs. government. Agents of Immigration and Customs Enforcement Agency, and even the FBI, began to routinely visit the University of Miami to ferret out students deemed to have run afoul of immigration regulations. According to Patricia Whitely, this signaled a sea change from the pre-9/11 era:

The FBI showed up in our office a little more frequently, checking out people, being a little bit more practical, trying to see if their visas had expired or anything like that. Which was unheard of - that didn't happen before 9/11. I mean Homeland Security does not just show up in our offices! So we had those kind of incidents such as deportations. If an international screws up, unlike my friends over here, they are going to be deported. There is no tolerance level for any kind of misbehavior (personal communication, January 22, 2010).

Whitely said UM was conscious that its behavior in relation to international students and scholars was always under scrutiny, and it could face difficulties if it did not 
comply. Given the multicultural character of the University of Miami and its host city, Whitely did not see $9 / 11$ as being necessarily responsible for the post-9/11 decline in student enrollments. "We had a decrease because the immigration people couldn't allow students to come in smoothly...but our enrollment has shot back up again," she insisted, obviously not connecting the dots between $9 / 11$ and the consequent tightening of student visa rules.

Advocate versus enforcer. International educators usually advocate for their students and scholars by providing support services and providing accurate and timely advice on academic, cultural, personal and immigration matters. Elyse Resnick described advisors as "the first line of contact" for students.

Academic problems they have, we could refer them to someone else on our campus who has more expertise in that area. We are there for them. They have our cell numbers. They are stuck in The Miami Airport at night, they left their I20, they give us a call. They are about to get deported, we get those calls, too. Anything that goes wrong. And the same thing with those UM students who are overseas; you know, loss of passport, didn't realize the exam was on March $5^{\text {th }}$ instead of May $3^{\text {rd }}$ because in some countries, the dates are written backwards...you know what I am saying [laughter] (personal communication, January 21, 2010).

A possible source of hesitancy for international student advisors, who are mostly also DSOs and/or AROs, is the requirement that they terminate the student's SEVIS records if they contravene regulations such as the requirement for F1 students to take a full course of study. FIU's SEVIS Coordinator, Anoush McNamee, said this is a 
responsibility she took "very seriously," one that "weighs on you sometimes" (personal communication, June 5, 2009). She added:

I call. I e-mail, I write. We do initial e-mail, we do second e-mail, we do final email. We do phone calls, we do letters after letters so we put in as much effort as we can to prevent students from falling out of status....We had a student who was dismissed and had to be terminated. I consulted the regs, he had only ten days to get out of the country. After a month they still had not appealed the dismissal, it was now the $38^{\text {th }}$ day, you do not have a choice, you have to terminate. That is something our nation takes seriously. We love our students but at the same time we have to uphold the regulations (personal communication, June 5, 2009). University of Miami’s Zitzmann, a German immigrant herself, however said such heavy lifting need not be the case since the rules are pretty explicit.

The fact that you are allowed to be here and told that you have a status and there are requirements that go along with that status, there are rules that you have to follow and you must not violate those rules, I take that as a given. I also take it as a given that if a person does violate rules, there are consequences for that, so I don't see any kind of conflict. Assisting students and making sure they have all the information they need and at the same time if someone does something wrong, I have told them that there are consequences, I don't think there is any discrepancy between those two (personal communication, January 28, 2010). Zitzmann's rules-driven, no-compromise approach to the work of international student and study abroad advisors is probably the ideal approach craved by USCIS, but the advocacy functions of the profession as spelled out by NAFSA's code of ethics 
sometimes conflicts with this commitment, raising some problematic dilemmas.

Organizational/vision ambiguity. In theory, internationalization is a big priority at UM which aims to be a global university. As Green observed, there were structural problems, which probably worked against the university achieving its potentials in this regard, before and after 9/11. He cited the lumping together of international education and exchange programs department into the continuing education division. "It was not even in mainstream academics. Even after 9/11, they left it where it was," an incredulous Green noted. "Now it's got an academic home under my office...I think universities are coming to appreciate the ways in which foreign students on their campus add an international character to their campus" (personal communication, January 22, 2010).

Green said there has been a paradigm shift at UM, which "used to be sort of a White American university that had people from different countries as opposed to ... an international university." He said the next phase will be to integrate a program of anticipatory socialization into its Study Abroad and Exchange Programs. Now, we are trying to involve students from foreign countries here with our American students who are going to go to their countries. No one has ever done that before. We have a program in France and we have exchange students from France, those French students ought to meet our kids who are going to go to their country and get to know them after they come back because they have a common link (personal communication, January 29, 2010).

The program of anticipatory socialization for international exchange and study abroad students and scholars envisaged by Green already has a precursor, going by some documents I procured from the IEEP office at UM. A "Study Abroad Contact Information Form for Returning UM Students," explicitly asked the returnees if they 
would: (a), Make themselves available to prospective exchange students (b), Be "willing to speak at pre-departure orientations and/or information sessions for UM students planning to go abroad, and (c), Be interested in being part of "a new international exchange student organization. Similarly, a three-page "Study Abroad Program Evaluation Form," included a page in which returnees were asked to give 10 tips to future students traveling to the countries they visited.

Despite this, there seems to be some absence of definitional clarity in UM's overall internationalization agenda. Green would not immediately agree that international students should be factored in when discussing the international education function at the institution. "You mean foreign students who come here. That's not international education. That's education of internationals," he initially stated. He seemed to back off that assertion in the latter part of our interview while maintaining that UM lacks "an institutional vision for foreign students coming here," even though it welcomes them. "We are totally open to it; we accept it. I mean, we admit a large number of Chinese and Indian students. Some of these students are instrumental. It's not driven by anything. It just happens that there are a lot of Chinese who want to come to college here; same thing with India” (personal communication, January 22, 2010).

Claudia Zitzmann seemed to imply that U.S. students do not necessarily need international education. She stated:

I don't think that every student comes to the University of Miami because they want an international education. I think, obviously, if you are an international student but I don't think the American student necessarily wants that. Emn...I know that a lot of professors find it very important that they've begun to 
internationalize aspects to their curriculum because of the world that we live in. I think there are different groups here that may possibly have different responses to that ... (personal communication, January 28, 2010).

With Study Abroad, however, there was more certitude in vision articulation. According to Green, the university's vision for Study Abroad is to increase its program offerings by 200 to $300 \%$ and link all credit-bearing programs to the academic majors of the students so that they are "not just going to a foreign country to hike" (personal communication, January 22, 2010).

\section{Summary}

In this chapter, I provided a brief historical overview of the University of Miami (UM) and how its international education function has evolved over time. I also gave a detailed report and analysis of my interviews with key international student advisors and administrators, of an examination of the institutions data base and of a review of some documents relevant to my study.

Essentially, I found in this chapter that, even though all but one of my interviewees at UM found themselves in the international education arena by sheer happenstance, they all apparently share a passion for the profession before and after 9/11. I also found that SEVIS was overwhelmingly regarded as the main outgrowth of the 9/11 attacks in terms of the ensuing regulatory framework and the demands it made on international education professionals. As international student enrollment stagnated, there was a subtext of phobia of the unfamiliar, growing feeling that Muslim students and Middle Eastern students felt somewhat marginalized from the mainstream and thus needed some reassurance. Even as a major project to locate an Islamic Center on the UM 
campus was derailed by post-9/11 socio-political reality and the university scurried to organize dialogue forums to facilitate better cross-cultural and inter-religious understanding, I could not help but observe that three of my interviewees went to great length to deny a linkage between the $9 / 11$ attacks and these changes.

In addition, I found that the university's positioning as "a global university" was predicated on its unmistakable prowess in scientific research and discoveries while ignoring vast regions of the world such as Africa and the Middle East, especially in the pre-9/11 years. After 9/11, there were dueling roles and tensions at various levels that are linked to the 9/11 attacks and its regulatory, socio-political and psychological aftermath. These include the contradiction between the traditional role of international student advisors and administrators as student advocates and their new roles as DSOs/AROs, expected to report every violation of immigration rules and regulations through SEVIS; unease between international student advisors and agents of Immigration and Customs Enforcement (ICE) regarding limits of information disclosure; and ambiguity cum contradiction in the response of government to the $9 / 11$ terrorist attacks when compared with the response of $\mathrm{UM}$ as a higher education institution, and on the appropriate definition of international education. One underlying thread that must be emphasized here is the way the regulatory paradigm of the post-9/11 syndrome appears to contradict and undermine the university's commitment to internationalization.

In the concluding chapter of my study, I put these findings and that of the previous chapter on FIU, in perspective. I discuss their implications for research, policy and practice, and make appropriate recommendations. 


\section{CHAPTER VI}

\section{DISCUSSION}

In this chapter, I do a recap of my study so far. My findings at FIU and UM are synthesized into overall conclusions in the form of a simple, descriptive thematic framework, with possible implications identified for theory, practice, and policy. Projection is made into the immediate future as to the likely course of the internationalization agenda at the two universities and likely reverberations, if any, beyond the institutional level. Recommendations are made on how the cause of international education can be furthered in the universities under consideration and in the United States in the post-9/11 era. Suggestions are made for future research studies.

\section{Overview of the Study}

The interplay between the September 11, 2001, terrorist attacks and international education in the U.S. was the focus of this study. Specifically, I sought to ascertain how international student advisors and administrators in two Miami-area universities are interpreting and responding to the post-9/11 era of international education. I investigated what has changed about their work, its context, and outcomes in the aftermath of the incident. My study was guided by the following three research questions, which were outlined in chapter 1 :

1. How are international student advisors and administrators across two types of institutions dealing with the "post-9/11 syndrome?"

2. What, if any, are the differences in international education after $9 / 11$ ?

3. What have been the institutional priorities in relation to international education before and after $9 / 11$ ? 
In the same chapter, I discussed the seeming precarious position of the internationalization agenda in U.S. colleges and universities that was apparently exacerbated by the September 11, 2001, terror attacks. In chapter 2, I reviewed the international education literature to show that while international students, admissions professionals, and other international education administrators have faced enormous and unusual challenges in the aftermath of the 9/11 attacks, little research work has been done either to capture this critical period from their perspective, or to understand the experiences of educators and advisors who must contend with the effects of 9/11.

In chapter 3, I discussed the rationale and methods I used in conducting my study. These include the selection of a qualitative methodology for my study, the rationale for the selection of the University of Miami and Florida International University as my two case studies, my approaches to gathering and analyzing data at the two universities, the criteria for selecting my study participants, and the coding and analytical methods I utilized for reaching my conclusions. The chapter ended with a section on how I enhanced the credibility and consistency of my findings.

In chapter 4, I provided a brief historical overview of Florida International University (FIU) and the evolution of its internationalization function over time. I also gave a detailed report and analysis of my interviews with key international student advisors and administrators, of an examination of the institutions data base and of a review of some documents germane to the focus of this study. I found that, despite the accidental nature of their forays into the profession, the passion of international educators at FIU for their work with students has remained largely unaffected by the tedium and additional responsibilities associated with the post-9/11 era. 
Other key themes include the dominant nature of SEVIS as an outgrowth of 9/11, the onset of fear, agitation, and unease as a subtext, stagnating international student enrollment, and a crisis of identity as FIU sought to pivot from its Millennium Vision Document, which consciously and almost exclusively, projected it as a research university, in a bid to rediscover its international roots. Also central to the institution's desire to pivot away from its seeming flight from the definitive internationalism of its formative years are dueling roles and tensions at various levels that are linked to the $9 / 11$ attacks and its regulatory, socio-political and psychological aftermath. These include the contradiction between the traditional role of international student advisors and administrators as student advocates and their new roles as DSOs, expected to report every violation of immigration rules and regulations through SEVIS; tension between wanting to help students by furnishing them with the necessary information, and the prerogative of students as autonomous beings; unease between international student advisors and agents of Immigration and Customs Enforcement (ICE) regarding limits of information disclosure; and ambiguity cum contradiction in the response of government to the $9 / 11$ terrorist attacks when compared with the response of FIU as a higher education institution.

Chapter 5 provided historical context to the University of Miami and the metamorphosis of its international education function over time. It also gave a detailed report and analysis of my interviews with key international student advisors and administrators, of an examination of the institutions data base and of a review of some documents germane to the focus of this study. I found in chapter 5 that, even though all but one of my interviewees at UM found themselves in the international education arena 
by sheer happenstance, they all apparently share a passion for the profession before and after $9 / 11$. I also found that SEVIS was overwhelmingly regarded as the main outgrowth of the 9/11 attacks in terms of its ensuing regulatory framework and the demands it made on international education professionals. As international student enrollment stagnated, there was a subtext of phobia of the unfamiliar, growing feeling that Muslim students and Middle Eastern students felt somewhat marginalized from the mainstream and thus needed some reassurance. Even as a major project to locate an Islamic Center on the UM campus was derailed by post-9/11 socio-political reality and the university scurried to organize dialogue forums to facilitate better cross-cultural and inter-religious understanding, I could not help but observe that three of my five interviewees at UM went to great length to deny a linkage between the 9/11 attacks and these changes. In addition, I found that the university's positioning as "a global university" was predicated on its unmistakable prowess in scientific research and discoveries while ignoring vast regions of the world such as Africa and the Middle East, especially in the pre-9/11 years. After 9/11, there were dueling roles and tensions at various levels that are linked to the $9 / 11$ attacks and its regulatory, socio-political and psychological aftermath. These include the contradiction between the traditional role of international student advisors and administrators as student advocates and their new roles as DSOs, expected to help enforce immigration rules and regulations; unease between international student advisors and agents of Immigration and Customs Enforcement (ICE) regarding limits of information disclosure; and ambiguity cum contradiction in the response of government to the $9 / 11$ terrorist attacks when compared with the response of UM as a higher education institution, and on the appropriate vision for internationalization. 


\section{Conclusions: The "Post-9/11 Syndrome" at FIU and UM}

At the onset of this study, I indicated my desire to investigate how international student advisors and administrators are interpreting and responding to the post-9/11 era of international education. I expressed interest in unraveling what has changed about their work, its context, and outcomes in the aftermath of the September 11, 2001, terror attacks. My choice of the word "syndrome," which implies a pattern of disorder symptomatic of some sickly state in the construct, "post-9/11 syndrome," was to capture the apparent state of panic and disequilibrium in the socio-political, security and educational situation of the U.S. in the wake of the attacks.

Although foreshadowed by other "Islamist"-inspired terrorist attacks such as the destruction of Pan Am flight 103 over Lockerbie Scotland in1988, the 1993 World Trade Center bombings in New York, the 1998 attacks on U.S. embassies in East Africa, and the 2000 attack of the U.S.S. Cole in Yemen, the 9/11 attacks elevated this phenomenon to "new heights of physical devastation, international notoriety, and psychological impact" (Miner, 2005). Higher education's trajectory in the United States was particularly impacted by the 9/11 attacks because of the involvement of Hani Hanjour, who received a student visa but failed to show up at an English-as-a-Second-Language school in Oakland, California. He had two other associates, who were attending flight school in Florida as tourists, while awaiting approval of their application for change of status, which was curiously approved 6 months after the 9/11 terrorist attacks.

As earlier referenced, Hogdaneau-Sotelo (1999) argued that earlier terrorist attacks added the "potential terrorist" or "threat to national security" narrative to the other underlying themes of xenophobic narratives of the country's anti-immigrant activists 
(p.16). Based on my findings in this study, I have developed a thematic aggregation of the "post-9/11 syndrome" at FIU and UM. This straddles seven broad frames, which I summarize here as " 331 " - 3Ms, 3 Ts, and 1 D. They are: Menace of Anxiety and Fear, Menace of Insularity and Insecurity, and Menace of Overregulation and Bigotry; Trajectory of Opportunity, Trajectory of Contradictions and Trajectory of Illusion, Fatalism and Futility; as well as Dominance of Technology. Menace implies some threat, peril, danger or hazard; a trajectory maps out a course, path, trail or arc; while dominance exudes supremacy, ascendancy, control and power. A diagrammatic representation of this descriptive frame is presented in Figure 7.

\section{Menace of Anxiety and Fear}

In recalling her trauma as a survivor of the 1998 bombing of the U.S. embassy in Tanzania, Susan Hirsch, a professor of Conflict Resolution and Anthropology at George Mason University, argued that such an encounter coupled with fear of further attacks possesses the capability of embedding terror in individual survivors (Hirsch, 2006). She added that phobia became a "defining feature" of the post $-9 / 11$ ambience, with national discourse dominated by "fear of enemy cells, luggage handlers, people who cross borders illegally, people of certain religions and ethnicities, or people who stand up simultaneously on a plane flight" (Hirsch, 2008, p. 594).

According to her, the unintended effect of this narrative of anxiety and threat is that others become fearful of overt or implicit rejection, based partly or solely on their phonetic accents, mode of dressing, charitable giving, even jokes e-mailed to colleagues and associates. 


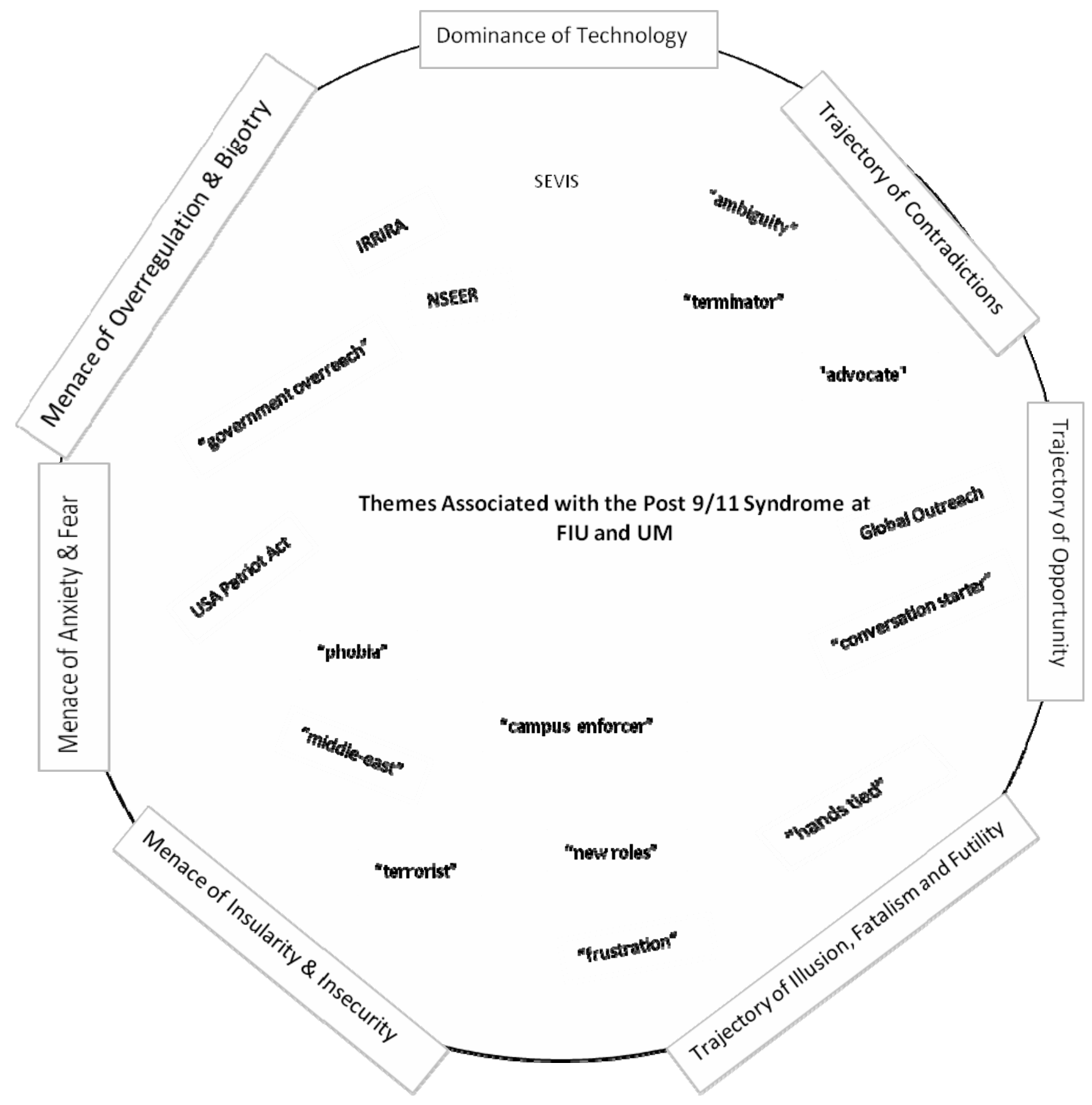

Figure 7. Themes associated with the post-9/11 syndrome at FIU and UM. 
Fear - real, created, or imagined - undergirds the post-9/11 landscape and supports overarching terrors: the fear of the next attack, of the "jihad next door,"' or even of becoming afraid (a strange aftereffect of trauma). And the twisted fear that others might perceive us as fearful has led to unconscionably aggressive tactics worldwide (Hirsch, 2006, p. 594).

Armitage and Nye (2007) agreed. In a bipartisan report produced by a commission of scholars and politicians, they described the post-9/11 period as "one of grief, trauma, and fear...as well as growing anger and anxiety about the direction of U.S. policy and governance."

The findings from UM and FIU validate this narrative, with several international students withdrawing from classes out of fright or opting to continue their education in Europe or Canada out of concern for their personal safety. FIU's Dr. Sippin contended that a new ambience of fear permeated the nation post-9/11 with "everyone very much on alert, a little bit suspicious" and "a little bit more agitated" with each succeeding bomb threat or change in terror alert levels. "People were more edgy about things," she recalled (personal communication, April 9, 2009). Hernandez of FIU's Biscayne Bay campus had similar stories:

After 9/11, there were some students from certain countries that went back home because they were afraid. They feared for their lives. I remember having a $\mathrm{PhD}$ student from Saudi Arabia who came to my office. He was very apologetic. He had to return home. Given the way things were portrayed, in the media and society, he was afraid (personal communication, June 25, 2009). 
In the post-9/11 setting, NSEER countries such as Iraq and Pakistan were more often than not discussed in a security context, a mindset which overlooks the reality that most citizens of NSEER countries are spectators in the pathetic drama of terrorism, not perpetrators of it. UM's Resnick related her experience with parents who feared for the safety of their kids embarking on Study Abroad programs, even as she wondered if foreign exchange students and scholars would still find the U.S. a desirable destination. Not surprising, as the flight to safety gathered momentum, the enrollment figures for international students at our two institutions either stagnated or nosedived in the 6 years following the $9 / 11$ attacks.

\section{Menace of Insecurity and Insularity}

A pervasive perception of insecurity became a mantra that apparently weighed on campus psychological space at both FIU and UM. Former FIU president, Dr. Modesto Maidique noted that the FIU community became more keenly aware of security issues and "more intolerant of security breaches" (personal communication, January 14, 2010). He related several incidences of bomb threats which threatened to shut down FIU in the aftermath of $9 / 11$, but for some symbolic decisions he took that undermined that culture of phobia and insecurity. An interesting example of such symbolism was when he bravely walked into the university's Graham Center, which was in lock-down following an empty bomb threat. Once he bravely stepped into the center, members of his cabinet and hundreds of students immediately joined him to expose the hoax for what it was, an indication that leadership and symbolism matters.

Glenda Hayley, Director, International Education and Exchange Programs at the University of Miami, said "since 9/11, the office's security-consciousness became 
significantly more acute." She added: "We reviewed our security measures and implemented additional measures to ensure the safety of our students abroad. We are continually checking and revising safety and security measures, and we have closer contact with the students as well as with our partners overseas" (personal communication, January 25,2010$)$.

FIU's Hillary Landorf observed that the environment welcomed isolationism and insularity in the wake of the $9 / 11$ attacks. "In the society, there was an initial closing-in and feeling of nationalism, everything international was negative; everything insular was positive," she noted. "The tide changed a couple of years ago when there was a 'knockyour head against the wall' realization that we can't as an institution, as a society that what we do depends on the rest of the world and vice-versa" (personal communication, June 25, 2009). Even then, Liza Carbajo still talked of "a true commitment" by FIU to send more students abroad with the exemption of countries that are probably on the terror list, like Iraq" (personal communication, January 26, 2010).

\section{Menace of Overregulation and Bigotry}

The highly regulated environment imposed on international educators, students and scholars in the post-9/11 era evoked Foucault's discourse on that subject. To Foucault (1971), an individual or "subject" (p.23) traversing social space is invariably objectified and meanings ascribed to him as he is synthesized into a "unity of discourse," which facilitates his control and surveillance by the state. The introduction of SEVIS, NSEERS, DHS, ICE and other bureaucratic abbreviations symbolically depict the attempt to categorize and abbreviate non-indigenous intellectual capital into pre-fabricated boxes. 
Even though every effort was made to avoid explicit profiling of students and scholars, echoes of Foucault were discernible.

Proceeding from this, Matus (2006) has argued that unitary identities are ascribed to all international students, without regard to the complexities of being constituted as an international student before and after 9/11, given their individual, national and cultural identities, and predilections. She isolated four discourses as informing attempts to regulate a unitary identity for all international students, particularly in the post-9/11 world. These are the discourses of the non-immigrant, threat, control, and benefit which are the dominant but often conflicting threads of thought in this arena. They underpin an "essentialist and unitary understanding of international students," which erase historical and social differences among them, leaving them stranded "in a space of uncertainty, dislocation and vulnerability" (p. 3).

As Matus (2006) posits, the discourse of the non-immigrant lumps international students together with ethnic minorities in the United States as having a history of discrimination and dehumanization but bars them from accessing government-sponsored financial aid and other perks associated with that status. This was in play at our two institutions. The discourse of control assumes that international students and scholars are not responsible enough. As purported sources of potential danger to the society, their daily academic and social life must be controlled through regulations that put them "out of status" and thus subject to deportation should they not pursue a full course of study, work off-campus, or fail to complete their education in a timely manner. 
Of particular significance in the post-9/11 world is the discourse of threat upon which the discourse of control is predicated. Matus argues that post-9/11 regulations "structure the exclusion, social isolation and marginalization of international students" (p. 7). They rationalize the need to monitor international students on the imperative of national security and establishing an alert system to detect failure of the student to report to a litany of regulatory bodies. The three foregoing discourses are only counter-balanced by the discourse of benefits, essentially promoted by NAFSA, which sees international education as cultural capital and international students as mobile commodities that yield enormous economic and diplomatic dividends.

NAFSA's narrative serves as some form of validation for the foreign student on a U.S. campus but does not go far enough. It is also akin to the chattel narrative advanced by Farnsworth (2005), who proposes an integrated recruitment strategy by community colleges and universities to attract more international students to the United States. Dubbed 2 plus 2, Farnsworth's approach is for the U.S. to attract international students by promoting the lower banner price of community colleges, where they could spend the first 2 years of a 4-year baccalaureate degree program, through consortium arrangements between community colleges and universities. This approach was similarly highlighted by Anderson (2005) who noted that the World Bank estimated that $1 \%$ of global output (about $\$ 300$ billion) is funneled into higher education. The loss of international student market share by the United States thus carries with it both loss of revenue and deficit of diversity.

As evidenced by my field work at FIU and UM, the various agencies and legislations emplaced in the aftermath of the 9/11 tragedy did impact the environment 
and job content of international educators. International education professionals at UM and FIU grappled with the tedium and challenge of shepherding their institutions, students and scholars through this minefield of regulations and requirements. They had to wear a new hat as enforcers of immigration regulations on campuses, a role that made them the face of the new post-9/11 restrictions on students and scholars. Far from their accustomed roles as counselors, confidants, and advocates for international students and scholars, many of them became the focus of student animosity and jokes. Anoush McNamee, the SEVIS Coordinator at FIU, who picked up a telling nickname, "the terminator," characterizes this shift. The emergent regulatory framework not only altered their job descriptions, it hindered the philosophy and agenda of institutional outreach and global inclusiveness.

Also, the Armitage-Nye report (Armitage \& Nye, 2007) alleged that fear was being used to justify policies of aggression as military force seemingly became the primary tool of U.S. foreign policy and law became a weapon of war, a sentiment echoed in this study by FIU's Hillary Landorf, who brooded about the abandonment of soft power. Beyond a craving for balance and a conscientious effort to eschew profiling while providing support structures for international students and scholars, my participants (international education professionals) largely refrained from questioning the context in which these narratives take place and the relative impact on their institution's integrity. Neither did NAFSA, Association of International Educators, leading to a loss of competitive advantage by the United States in relation to Europe and Canada, which did not jump on the paranoid bandwagon in their treatment of foreign-born intellectuals (Johnson, 2005). 


\section{Trajectory of Opportunity}

As tragic as it was, 9/11 was not without a silver lining. As perceived by virtually all the participants in this study at FIU, the September 11, 2001 terror attacks ushered in a new era of recognition and respect for international education, its practitioners and advocates. There is, of course, a tinge of irony in this since this perceived recognition occurred in tandem with increasing governmental intrusiveness as international educators were statutorily compelled to perform what were, in effect, surveillance activities on their students and scholars.

At FIU, more employees were hired to give the International Student and Scholars office a full complement of staff on its two major campuses. There was an influx of new funds to help the department build the necessary capacity to enable it cope with the demands of SEVIS and other aspects of the post-9/11 firmament for international education. Anoush McNamee said FIU's institutional vision, as she understands it, is to educate students to understand other cultures, to conceive other worlds beyond America... The vision is to educate our students and prepare them for the global world. It's a big world but it's small in connections and relationships" (personal communication, June 5, 2009).

The Office of Global Learning Initiative was established to superintend over across-the-board internationalization of the university's curriculum. The office's director, Hillary Landorf, indicated that 9/11 has, ironically, provided some impetus to FIU's internationalization agenda which has now been integrated into its re-accreditation process as its Quality Enhancement Project (QEP). 
The QEP, as envisioned by FIU, conforms to the imperative of a global work force development (GWD) in our increasingly diverse world. It is also in line with internationalization schema earlier discussed in this study (Boyd, 2003; Knight, 1999). GWD mandates universities to prepare students with a much deeper understanding of the global community including knowledge of other languages and cultures. William Kirwan, Chancellor of the University System of Maryland, identified twin elements of GWD. These are to imbue U.S.-born students with a more sophisticated knowledge of the larger world in which they will be working and adapt the curriculum to educate foreign-born students beyond mastering their disciplines. "We need to be providing these students with a deeper comprehension of American history and culture so that when they go home, they can promote better international understanding and partnerships," Kirwan stated (Bremer, 2006, p. 40).

For the University of Miami, 9/11 represented an opportunity to open up dialogue between the different cultural and religious elements that constitute the university community. Several forums were organized for inter-faith and cross-cultural ventilation of perspectives aimed at ridding its Muslim and Arab population of the shame factor as they sought to distance themselves from the dastardly attacks, while enhancing mutual understanding and respect. Claudia Zitzmann said the whole idea was to make UM's population of Middle Eastern and Muslim students "know that they are a part of this university and they are welcome here by giving students forums to talk about the views and concerns that they have coming out of those attacks and for them to voice their anxieties" (personal communication, January 28, 2010). Zitzmann said it also involved talks about religion "in general." 
Does Islam really call for those kinds of attacks? So those are the kinds of forums where everyone was able to participate. Students were able to say, this is how that made me feel, this is what I think about that and Muslim students were able to say, that is not what our religion calls for. This is why we don't want to be identified with those kind of attacks (personal communication, January 28, 2010). As Samuel Huntington postulated in his seminal but controversial article, The Clash of Civilizations, cultural and religious differences are more difficult to resolve and compromise than political and economic disagreements. This is because they are less a result of differences of opinions and approaches than the very nature of individuals and peoples, identity issues that are virtually cast in stone. "A person can be half-French and half-Arab and simultaneously even a citizen of two countries. It is more difficult to be half-Catholic and half-Muslim," he argued (Huntington, 1993, p 38). Cohabitation in this regard requires finding some common ground that promotes dialogue among competing civilizations. It is a conversation that the $9 / 11$ attacks provided the opportunity and environment for, in varying degrees, at UM and FIU. Instructively, it is a conversation that goes beyond the plastic confines of officialdom to involve social and academic clubs, organizations and individuals at both institutions. In 2009, the anniversary of 9/11 was marked at FIU with the Annual Inter-Faith Remembrance Ceremony while the Student Organization for Human Rights at UM's Law school, hosted a panel on Islam in America Post-9/11. The university's website announced the event thus:

Guest speakers include Imam Foad Farahi, from the Shamsuddin Islamic Center; attorney Khurrum Wahid from Wahid, Viscaino and Maher LLP, who has represented defendants in numerous terrorism trials and is an active civil rights 
activist; and AbdolRahim Javadzadeh, professor of Comparative Sociology at Florida International University and author of "Marxists into Muslims: an Iranian Irony” (UM 2009)

UM also developed a 9/11 themed Executive-In-Residence program, which featured Cantor Fitzgerald, the global financial services firm that lost 658 employees in the attacks. In February 2010, FIU's Middle East Society presented a lecture on racial profiling after 9/11. The lecture was delivered by Cyra Choudhury, an assistant director at FIU's School of Law, who argued that profiling has resulted in increased incarceration of Muslim men with few or no convictions, while real terrorists were left undetected.

In essence, the post $9 / 11$ syndrome has ignited an ongoing dialogue that reprises Huntington's ultimate conclusion that "there will be no universal civilization but instead a world of different civilizations, each of which will have to learn to coexist with the others" (p. 42) through a profound understanding of others. However, while UM's dialogue series and yearly 9/11 remembrance ceremonies at UM and FIU represented efforts to promote amity on the institutions' campuses, UM did not appear to have made concerted efforts to exploit the opportunities offered by the new spotlight on foreign intellectual capital to rapidly advance its internationalization agenda. UM's new Study Abroad program in Galilee, Israel and talks by Green and Whitely of an Arabic Studies program, may foreshadow a more aggressive approach in this regard.

\section{Trajectory of Contradictions}

Perhaps as a symbolic acknowledgement of the ambiguity and complexity of issues relating to multiculturalism and internationalization, there is an undercurrent of subtlety, ambiguity and outright contradiction in the post-9/11 ambience, as found in this 
study. Government, the university, the community, international student advisors and their student/scholars constituted layers and sub-cultures that did not necessarily view the challenges of the post-9/11 era in the same light and this often generated tension, if not outright confrontation. FIU's Sippin noted that while she and her colleagues were professionally obliged to advocate for their students, "that's not it: you are also representing the university and that could be jeopardized by not doing the right thingjeopardizing your whole F1 program" (personal communication, April 6, 2009). There was also some polarity in the treatment of international students and scholars at the institutional (FIU) and governmental/regulatory contexts. Hernandez surmised: "We don't mark anyone as a potential terrorist. Maybe the government does, but as far as we are concerned admission is open to everyone whether you are documented or undocumented" (personal communication, June 5, 2009).

UM's Patricia Whitely said international student/scholars advisors devoted more time and resources to make Muslim and Arab students feel safe and wanted while at the same time providing grief counseling to students who lost friends and relatives in New York as a result of the attacks. While grappling with this, they also faced a more stringent regulatory environment in which schools jealously guarded their authorization to host international students and scholars on non-immigrant visas by helping with the strict enforcement of the new regulations ushered in by the PATRIOT ACT.

Skirting this divide is a major undercurrent of the post-9/11 syndrome. Describing SEVIS as somewhat adversarial in nature, Sippin said it was difficult for the students not to conclude that international educators were only working for the government especially at the initial stage. "Everything was being monitored...," she recalled. "If they violated 
their status, we would tell them right then. So I think the students were feeling like, you know, you are only working for the government. ... it put everybody on edge" (personal communication, April 8, 2009).

Indeed, it could be argued that a major ingredient of the post-9/11 environment of international education was the push-pull dynamic between the U.S. federal government and higher education institutions like the University of Miami. The universities desired to expand their international program offerings, make their campuses more inclusive and accepting, globalize the curriculum, and expand student internship/externship experience across borders. The government decreed new regulatory framework that move the higher education sector towards greater insularity by slowing down visa issuance to students and scholars, by flagging scientists and students from several "unsafe" or "suspect" regions of the world, and by intensively monitoring and controlling the academic and social behavior of prospective and current international students.

The government also compelled international educators to go along in what was akin to borderline profiling through SEVIS, NSEER and other devices in a desperate bid to foreshadow and foil potential terror attacks. These two desires conflicted and undermined, in significant ways, programs like FIU's QEP and UM's global outreach, ultimately limiting the ability of both sides to achieve a win-win outcome. In essence, the framework constructed by the government appeared to have proceeded from the assumption that international education and national security are two diametrically opposed concepts, with one achievable only to the exclusion of the other. If anything, FIU's Landorf was quick to describe the seeming recognition suddenly accorded international education advisors and administrators in the wake of the 9/11 attacks as 
nothing more than "knee-jerk respect" (personal communication, June 25, 2009), an assessment that seemed to resonate when under-funding of the function began to become an issue again as the glow of $9 / 11$ began to fade.

Not everyone would frame the discussion in this manner, however. UM's Claudia Zitzmann (personal communication, January 28, 2010) did not see any substantial contradiction in being an advocate for internationalization and an enforcer of immigration regulations. For her, it was a simple matter of misbehavior and punishment. She defended the approach of ICE agents on the "occasions" they had enquiries on the enrollment status of suspect F1 students. She said they were always "courteous"

They just do what they have to do in terms of looking for a person and when they find that particular person, they enquire what that person was doing and why they were not enrolled in school. They were against stereotype. They were professional and very courteous, which was nice! (personal communication, January 28, 2010). Other international educators, who participated in this study, apparently felt an intense sense of discomfort and ambiguity. They indicated a continuing quest for the middle road, drawing on their inner will and personal repertoire of skills to navigate this complex terrain.

\section{Trajectory of Illusion, Fatalism and Futility}

As Treyster (2003) has argued, focusing so much attention on a small minority of non-immigrants in the country does little to improve national security when millions of people illegally enter the United States each year. Kless (2005) reported that, in addition to countries on the terror alert list, NSEER and the VISA MANTIS system triggered screening of nationals of countries like China for involvement in high-technology fields. 
According to him, the implementation of NSEERS, which targets international students and scholars from certain countries for closer scrutiny, heightened visa problems faced by scholars and students.

Although these measures and the attendant bottlenecks they created were designed to make the U.S. homeland safe from terrorism, international educators at UM and FIU who participated in this study are overwhelmingly skeptical of the reality or possibility of this desired outcome. "No, no!" Sippin laughingly retorted when asked if her institution and the nation is safer as a result of SEVIS and other elements of the post9/11 regulatory and policy framework. Her counterpart on the Biscayne Bay campus, Ms. Hernandez took a long pause and sighed before plainly stating that she doesn't "believe anyone is safer" (personal communication, June 5, 2009). McNamee added that there are enough loopholes in the system and forgetful streak in the U.S. persona that makes it possible for students on terminated I-20s to re-enter the country, even from New York, the enactment point of the $9 / 11$ attacks.

Incidentally, post-9/11 terrorist attacks such as the attempted bombing of a commercial airliner on December 22, 2001 by a Briton, Richard Colvin Reid, the shoe bomber; the massacre of 13 service men and women by the U.S. army's Major Nidal Malik Hassan and yet another attempted bombing of an airliner on Christmas day 2009 by British-educated Nigerian, Omar Faruk Mutalab, have not quite followed the prototype provided by the $9 / 11$ attacks. Impliedly, the potential terrorist narrative which wholly stereotypes students from Arab/Muslim countries and failed states is proving not to be so predictive. 
UM's Claudia Zitzmann seemed to have recognized the compelling complexity of this subject when she disavowed any responsibility for spotting likely terrorists in her work as a DSO/ARO and ISSS Associate Director.

I don't think that is a function of someone who works in my position. Making the United States safer is the function of the State Department and the Department of Homeland Security. I issue a DS2019 for a scholar. I have no way of knowing whether that person has intentions to harm this country... I don't have the responsibility, nor do any of my colleagues with respect to the security of this country," she declared (personal communication, January 28, 2010). If anything, this study found that there is a level in which the very concept of safety could be an illusion, a chimerical concept that could be used to rationalize proxy ideological or philosophical battles. Hernandez said she didn't believe "anyone was safer," (personal communication, June 5, 2009). UM's Resnick added that "no university will guarantee anyone's safety...Things happen" (personal communication, January 21, 2010). Things, indeed, do happen. Several U.S. students were trapped in the rubble of Haiti's recent earthquake as they pursued volunteer and research opportunities. According to Whitely, these included several UM students. Apart from natural disasters, strife, unrest and terrorist attacks often occur in the most unlikely of places at the least expected time.

\section{Dominance of Technology}

For the very paradigm of cross-fertilization of ideas and perspectives which international education and multiculturalism represents, the ascendancy of the Internet and the attendant permeation of social media was a game-changer. Voice and video IP 
and satellite communications have further helped to shrink space and perspective for increasingly more intense and interactive, borderless, people-to-people communication, with far-reaching socio-cultural implications. William Scott Green, UM's Senior ViceProvost and Dean of Undergraduate Studies had a handle on this:

The society is becoming more diverse at a level, but not so at another level. The internet has allowed so many people from different cultures to communicate directly about human experience than any time in history and they most often do it in English. Now, that is international communication, it is not difficult to do. Now, people are in chat networks that are global. You don't go out and meet anybody but you can go on chat networks that are global (personal communication, January 22, 2010).

While this trend preceded $9 / 11$, the computerization of monitoring and reporting mechanisms for students and scholars on non-immigrant visas inevitably integrated international student advisors and administrators into this communication revolution. It also made technology a centerpiece of the post-9/11 work and policy environment for international educators. "Everything is computerized now," Claudia Zitzmann said with unmistakable emphasis. Acronyms of sophisticated software like SEVIS, the VISA Mantis System and CLASS became cultural tattoos in this technology-driven onslaught against assumed potential security risks. 


\section{Implications for Theory}

As earlier referenced, international education has been largely influenced by three theoretical traditions: (a), Critical theory, which demands serious interrogation of the world and its dominant narratives with a view toward recreating a humane and just planet (e.g., Shapiro, 2000); (b), Post-modernism, which rejects the concept of true objectivity, while affirming globalization and the inevitable overlap of local and global knowledge (Back, Davis, \& Olson, 1996); and (c), Relational theorizing, which upholds a "complex vision of liberation pedagogy that validates difference" (Ross, 2002, p. 407).

One implication of my findings on the post-9/11 syndrome at FIU and UM is that the concept of "marginality and mattering" (Schlossberg, 1998, p. 16), which includes the ability of a campus to create a climate that transcends "objectification of others" (Tanaka, 2003, p. 175), could be, and was explored with regards to the work of international students and advisors at those institutions. While there was no doubt as to the passion and commitment of the international educators at both institutions to construct an inclusive climate for all, the restrictive regulatory regime and psychological architecture of the post-9/11 era represented a forceful pull in an opposite direction.

Another theoretical implication is that concepts associated with mainstream student affairs scholarship like the foregoing, as well as theories such as Perry's (1981) theory of intellectual development could be explored with regard to their relevance to international and study abroad students and scholars. The concept of commitment in relativism was, hitherto, exclusively applied to describe that stage in the intellectual development of students when they could interrogate complex issues and phenomena from varied phenomena to arrive at firm conclusion(s) based on their personal conviction 
and values. It involves acceptance of responsibility for their choices and willingness to accept others' right to their own choices. The question arises: Is there a way stages of internationalization of a university and its knowledge community could progressively develop from dualism through multiplicity, and relativism to the commitment in relativism stage? Is there some sense that our two institutions could be said to be moving towards this outcome in the wake of the post-9/11 reality?

The emergence of positivists as key resistors to the internationalization agenda at FIU is a concrete example of this struggle between those steeped in dualism, and those who are able to see grey areas because they have moved away from it. Hillary Landorf spoke of the perception in the hard sciences that conveying the notion of multiple perspectives to students endangers the very basis and methods of science while Maidique offered that cultural elements of the learning process, such as the pedagogical approach and illustrative paradigms, could be made more relevant and inclusive. For researchers in the international education arena, this will continue to be a question with far-reaching implications for theory, methodological design, analysis, and presentation. It also brings to the fore the contention of Huntington (1993) that Westernization and modernization has tended to go hand in hand with only the Japanese having succeeded in modernizing without essentially morphing their civilization into Western civilization.

Yet another implication for theory proceeds from the postulation by Inyatullah (1998) that the modern university stands at the gateway of a range of futures signposted by four trends and emerging issues. These are: globalism (the university as a business), multiculturalism (deep inclusiveness), virtualization (the promise of the internet) and politicization (the role of the violent state) that promise to transform the nature of the 
university. According to him, these changes have affected both the governance and "the character of international education" (p. 591). I found in this study that while both Florida International University, a public university and the University of Miami, a private university, manifest strong signs of multiculturalism and virtualization, they are weak in the areas of globalism and politicization.

Internationalization, by its very nature, is "a way to respect cultural diversity and counterbalance the perceived homogenizing effects of globalization" (Knight 1999, p. 21). Globalism is founded on a philosophy which puts the perceived interests of the entire world above national and parochial interests. Given the findings of my study on the post-9/11 environment of international education in the U.S., it is perhaps not a surprise that the two universities exhibit palpable weakness in this area. However, while the two universities escaped politicization by not aggressively aligning with the more bellicose response of government to continuing in-flow of students and scholars in the wake of the 9/11 attacks, they appeared severely limited in their pursuit of an internationalization agenda, before and after 9/11. As earlier noted, if U.S. universities were to function strictly as businesses, they would increase outreach efforts to attract students from the oilrich Middle Eastern states. Historically, however, neither the University of Miami nor Florida International University has had strong linkages with Middle Eastern educational institutions and governments, a situation that might have been reinforced, if not exacerbated by $9 / 11$. In fact, they seemed to have subscribed to the "kin-country syndrome" (Huntington, 1993, p. 38) in their Study Abroad and International Exchange programs, which appeared totally concentrated in Europe and the Americas. 
Of interest in this regard is UM's Elyse Resnick's contention that fear of the unknown might have been partly responsible for the failure of her university's outreach efforts to include certain supposedly dangerous parts of the world, especially after 9/11. "That might have affirmed our underlying fear that they might be more dangerous, that they might be more risky in some way. This is not any real policy but I think we are not looking for dangerous places to send our students," she stated (personal communication, January 21, 2010). By implication, the role of fear in explicitly and implicitly influencing policy and resource allocation, and distribution decisions, by the federal government and higher educational institutions, before and after $9 / 11$, is an area worthy of exploration by student affairs and social science theorists.

\section{Implications for Practice}

My findings with respect to the post-9/11 syndrome at FIU and UM showed that international student advisors and administrators experienced some tension as a result of their dueling responsibilities to government, the university, the community and their student/scholars. Sippin stated that each of these layers had differing expectations and responses to the challenges posed by the post-9/11 environment. She said while government officials were "wary" of international students, international education professionals at FIU were concerned with defusing tension and helping students seek answers while the university sought to create a safe zone for all stakeholders, UM's Whitely painted a similar scenario of a university holding a memorial service, deploying grief counselors and encouraging dialogue among diverse faiths and cultures as government fast-tracked the implementation of SEVIS and instituted an intrusive regulatory regime that had the effect of slowing the inflow of international students and 
scholars into the United States. Incidentally, my study participants at both institutions portrayed a student population that took things in its stride despite the new layers of regulation.

As higher education institutions, both UM and FIU appeared quite supportive of the students at a time when the dominant response of government was to stoke fear and impose regulations. But the dominant force was government. UM's Whitely said UM was conscious that its behavior in relation to international students and scholars was always under scrutiny and it could face difficulties if it did not comply. By implication, international educators and their institutions felt beholden to government which had the prerogative to certify or decertify them as hosts for international students and scholars in non-immigrant visa categories.

Another implication is that the post-9/11 environment made it inexcusable for our two case studies to ignore huge swathes of the globe, like the Middle East and South East Asia, while pretending to have a "global vision." In essence, the pan Euro-American blurb of the world is no longer enough if institutions of higher learning are really intent on building up global citizens. As Green put it, UM "used to be sort of a White American university that had people from different countries as opposed to we have an international university." In the post-9/11 environment, its challenge is to extend its tentacles beyond Europe into non-traditional areas of the world.

Related to this, the tendency of some institutions to equate study abroad with international education was exposed as a mirage, given the insignificant number of students who actually travel abroad. At FIU, about $1.5 \%$ of the student population (618 out of about 40,000 students) ventured abroad in 2009. This represents the highest 
participation rate ever for the institution but it still left $98.5 \%$ of its students in limbo unless there is a systems and campus-based approach to internationalization. At UM, which attracts students of higher socio-economic status, $4.8 \%$ of its fall 2008 population of enrolled students (505 out of 10,422 students) studied abroad, implying that $95.2 \%$ were left out of this educational experience. The relatively small portion of the students privileged to study abroad underscore the fact that for the two universities to prepare culturally competent students for a globalized world, they will have to pay attention to Internationalization at Home (IaH). This includes the internationalization of the university curriculum, new language offerings, and building an inclusive psychological climate for equal story-telling space for peer-to-peer cross-cultural interaction. "I made an argument 2 years before 9/11 that to not teach Arabic in this world is like not teaching Mathematics," Green stated. "For students to be functional in the world, this is something they would need to study" (personal communication, January 22, 2010).

Another possible implication for practice is that the nature of the recruitment pipeline for international educational professionals might change. In addition to presentday professionals whose primary areas of competence are programming, counseling, and student support services, those who get funneled into the profession, henceforth, might primarily specialize in interpreting and enforcing immigration rules and regulations. Also there is the tendency of the professionals to begin to assume their government-assigned roles as campus enforcers at psychological and literal levels, making them lose the confidence of some of their students. 


\section{Implications for Policy}

One core implication of my findings in this study is that there is yet no explicit international education policy for the United States. In the absence of such a comprehensive blueprint, the 9/11 attacks brought in its wake a policy framework, which apparently assumed that international education and U.S. national security are antithetical to each other. This new framework has functioned as the U.S.'s implicit international education policy in the post 9/11 era, and it is difficult not to conclude that it must be dismantled and replaced for meaningful progress to be recorded on the internationalization front. In this regard, Starobin (2005) suggested that international education should be framed as part of the solution, not part of the terrorist problem, since international education and national security are, not necessarily, contradictory concepts. This kind of course correction is important more so as international educators interviewed at FIU and UM do not regard the nation as any safer despite all the new regulations, extensive paper trail, intrusive internet-based reporting and monitoring and other strictures associated with the 9/11 attacks and its aftermath. Also, they will not find themselves in the kind of win-lose situation that is currently the norm.

\section{Recommendations}

For an internationalization effort that targets the critical mass of students in a costeffective manner and minimizes the three menaces associated with the post-9/11 syndrome at FIU and UM, this study recommends a comprehensive, integrated Internationalization At Home Plus Collaborative Outreach (IAHPCO) model. Elements of this approach should include the enactment of a shared vision, aggressive internationalization of university curriculum, broad global initiatives and partnerships 
incorporating all regions of the world, faculty and staff training, creative funding mechanisms for in-bound and out-bound students, a program of anticipatory/sustained socialization, mentoring of students, scholars, staff and faculty aimed at building savvy global citizens, and advocacy at national level for an enlightened international education policy.

\section{Shared Vision and Program Champion}

The first step in engendering a college environment that values and sustains diversity is for this vision to be well-articulated (and preferably generated through a university-wide visioning process), diffused, understood and owned by all stakeholders in the university - administrators, faculty, staff, students and scholars. It should validate “difference" (Ross, 2002, p. 407) and set realistic benchmarks and programmatic interventions for creating and sustaining relationships between diverse groups.

Since international students and scholars are the major actors in the internationalization process, the findings of Schlossberg, Waters, and Goodman (1995) will be helpful in constructing such an ambience. They identified situation, support, self, and strategies (4 S's) as crucial to managing transitions. Such transitions could be events such as relocation to a new geographic environment or the 9/11 attacks, or a non-event such as unfulfilled expectations tied to the inability of an educational institution to enact an inclusive campus environment. Allied with the extensive body of research on student involvement in institutional life and persistence to graduation (e.g., Pascarella \& Terenzini, 2004), the four S's provide a firm grounding for envisioning an internationalization agenda. 
For such an agenda to have meaning, it must be understood and subscribed to by everyone who has implementation responsibility for it. This seems to be the largely the case at FIU but for some noticeable fissure between the academic and student affairs side of the house and posturing by some post-positivists. At UM, however, vision is conceived as a highly elevated entity which even program directors could not discuss. It seems to have fallen victim to hierarchy and red-tape.

Because of its very nature, however, an internationalization vision must be clear, simple and understood by all who have the responsibility for interpreting and nurturing it. It will also help if it has recognizable champions in all units of the university and a coordination committee or council with powers that transcend the traditional divides between Student Affairs and the academia. Despite the single-mindedness of its internationalization agenda and the passion of its principal champions, the administrative infrastructure currently deployed by FIU for its internationalization agenda appears a little unwieldy. The newly opened School of International and Public Affairs (SIPA), the

Office of Global Learning Initiative (which drives the QEP), Office of Education Abroad, and the International Student and Scholar Offices (ISSS) each report to different Deans and Vice Presidents, who have direct reporting relationship with the Provost. This makes synergy an arduous task between the departments.

\section{Curriculum Internationalization and Global Outreach}

Curriculum development to incorporate other world views and promote crosscultural appreciation/understanding should be a university-wide enterprise coordinated from the office of the President and/or the Provost to demonstrate the level of priority that the institution attaches to it. The rationale for this, as Tanaka (2003) eloquently 
articulated, is the need for the higher education system to help activate an intercultural model that provides the next generation the skills to be more effective leaders in a diverse global society. Tanaka (2003) suggested five areas of possible focus in "diversity work," which are applicable to curriculum internationalization efforts. They are: (a), change in focus from essential categories like race and culture to the individual as an agent or subject; (b), the notion that each individual's development can be linked to helping others to grow, that is complementarities; (c), redirection of the rationale for social change work away from "resistance" and binary opposition to norms of interconnectedness based in interdependence and soul creation; (d), alternative story-telling as a means of engaging individuals in positive social change and (e), the high promise of parallel systems as sites for total change where energy need not be wasted protesting or fighting against entrenched hierarchies. He concluded that "in place of posing the learner as a person in binary opposition to a dominant discourse, or privileged by it, an intercultural society would teach each individual to acquire agency by linking her or his own development to the growth and well-being of others in that society" (p.164). The Office of Global Learning Initiative at FIU is engaged in such an effort which could be deepened to accommodate all these strains. At FIU, there are promotional signs proclaiming "Global Learning for Global Citizenship: FIU's QEP” in offices and alleyways on all campuses. The aesthetically pleasing signs state: "New courses and activities will help you become a global citizen and prepare you for success in the global market place." This message is also widely disseminated on the university's website.

FIU Associate Director, Liza Carbajo, had an interesting way of making the point that the global attitudes, skills and perspectives proceed in part from learned experience 
and concrete interactions. She stated:

You can't become global by just reading a few books or taking a few classes because that is not realistic...Taking the mandatory classes at the beginning can prepare them but there is nothing that can prepare them more than to go and be integrated into a community outside of their own... Wondering how to ask directions in another language in a foreign culture, understanding how people live, how people work and function differently, that's how they are going to become global citizens (personal communication, January 28, 2010).

While Carbajo reminds us that living it is better than just reading or postulating about cross-cultural interaction or immersion, UM's Elysee Resnick stressed the need for the expansion of existing Study Abroad and Exchange programs to non-traditional areas such as Africa and the Middle-East which are, more often than not, considered unsafe. Currently, the existing programs in the two universities studied here are mostly Eurocentric in nature with some Hispanic flavor attributable to the heavy concentration of Cuban and other Spanish-speaking people in the Miami area. At FIU, for instance, about $55 \%$ of sponsored education abroad programs involve European/Nordic, about $40 \%$ are in the Caribbean and the Americas, with the remaining 5\% in other parts of the world.

The kind of broadened vision envisaged here should include conscious and aggressive seeking of partnerships with leading institutions in those hitherto neglected regions. Already FIU has established - in the wake of 9/11 - SIPA and the Middle Eastern Center, with Mohiaddin Mesbahi as director while UM has started the Galilee program. To maintain momentum in this regard, these and other U.S. institutions interested in fostering better understanding between poor and rich nations could initiate 
Adopt -A- College programs in the mould of the existing sister cities project. To be effective, such a program should incorporate, faculty-to-faculty, student-to-students, staff-to-staff and college-to-college interaction, international student recruitment/ retention and college-to college technical assistance in building institutional capacity. Such programs could also be used to build a human counterforce against the forces of fanaticism and terrorism in the world.

Some of those partnerships could be patterned after the highly successful U.S.China 1-2-1 Joint Academic Program which is an international education initiative by American and Chinese universities to offer dual degrees to Chinese undergraduate students who would not otherwise have access to education in the United States. Students' freshman year is at a Chinese university, their sophomore and junior years at an American university, and their senior year back at their original university in China. Upon completing all requirements, students receive baccalaureate degrees from each school. Also, the UM model which incorporates Internship, Learning Experience, and Cooperative Programs into the Engineering curriculum in addition to partnering with international corporations and companies for program sponsorships could be another viable option for a win-win situation between the corporations and the universities or partner country/university as the case might be.

\section{Funding}

At UM and FIU, funding is a major constraint against internationalization. At FIU, international students have to pay out-of-state tuition of $\$ 555.34$ per credit compared with $\$ 142.04$ payable by their domestic counterparts. In the wake of $9 / 11$, they also had to pay the $\$ 100$ SEVIS fee, visa fees, employment authorization fees as well as 
reinstatement fees, should they inadvertently fall out of status. U.S. citizens and permanent residents, who are able to document that they have lived in Florida for at least 1 year, pay in-state fee but many of them are self-sponsored, work full-time and attend school as commuter students. Getting away on a Study Abroad trip entails loss of income as well as steep, out-of-pocket expenses for those who are able to get time off work.

Also, while many UM students can afford the $\$ 1,480$ per credit tuition tag, a significant number are only able to attend the university because they have financial aid or private foundation, government or campus-based scholarship benefits. For this latter category of students, getting the extra money to invest in Study Abroad is daunting, especially in this harsh economic climate.

To bridge the resource gap that makes Study Abroad a pipe dream for many students, universities like UM and FIU must devise creative ways of using financial incentives to drive desired behavior in this regard. FIU's Carbajo said she would prefer Study Abroad to be a mandatory requirement if her institution could provide the necessary incentives for the students. Partnership with foreign and domestic corporations and foundations, embassies, cultural groups, multilateral institutions, fundraisings, grant writing, are some ways that funding could be raised in this regard. A portion of the universities' endowments could also be invested to fund scholarship activities. Faculty and Staff Training and Involvement

Landorf, director of the Office of Global Learning Initiative at FIU, said the position has exposed her to the imperative for faculty development. "The students will be okay, the curriculum will be okay but there is a great need for faculty development so that we can take care of the course delivery aspect, in global learning, in techniques, in 
pedagogy, assessment," she said (personal communication, June 25, 2009). In discussing a competency-based approach to internationalization, Knight (2000) stated that it involves the development of necessary skills, knowledge, values, and attitudes by faculty and staff interested in imparting global competencies to both local and international students. In addition to competency, faculty, administrators and staff also need to be trained based on the ethos-driven approach which is concerned with engendering a campus climate that promotes and supports intercultural initiatives, and the process-based approach which incorporates an international/intercultural dimension to campus activities, policies, and procedures.

To achieve this, faculty members need modest funding to free them from the humdrum of teaching, and enable them to reflect and develop meaningful initiatives and programs. Dr. Peter Stearns of George Mason University, which won an award from the International Institute of Education (IIE) for its innovativeness, listed five strategies his institution adopted: (a) programming for a new Global Assembly to stimulate ideas and collaboration on global themes (b) providing seed money for grant writing (c) advancing funds for international travel and conferences on a competitive basis (d) Investing in topup funds to encourage faculty to engage in international teaching, exchange, and research; and (e) encouraging deans and directors to identify and hire faculty with impressive experience in international teaching and research.

Since internationalization is a university-wide effort, this kind of initiatives need not be confined to faculty. To avoid the traditional faculty-Student Affairs divide, this scheme could be opened up to all interested/qualified administrators, staff and faculty. 


\section{Anticipatory/Sustained Socialization and Mentoring}

The process of integrating international students to campus academic and social life must, of necessity, begin with a well-coordinated routine of anticipatory socialization. This involves matching a prospective foreign student with a current student while the former is still overseas. Information sharing and mutual self-disclosure is encouraged between both parties well before the international student arrives on U.S. shores. Once the student arrives on campus, the integration process could continue by setting him or her up with mentors and minders who also help with the student's cultural and academic crossing. This kind of model is compelling because it relies on both the technological and human elements in communication to transmit a message of warmth with a view to eliciting a desired response of inclusion, recognition and mattering. It is also desirable because there is an adult, hand-holding component that solidifies the student's relationship with the institution.

UM's Dr. Green is already trying to take this principle one step further by applying it to U.S. citizens and permanent residents embarking on Study Abroad. He stated:

We are trying to involve students from foreign countries here with our American students who are going to go to their countries. We have a program in France and we have exchange students from France; those French students ought to meet our kids who are going to go to their country and get to know them after they come back because they have a common link...it brings the international experience more into the mainstream (personal communication, January 22, 2010). 


\section{Advocacy}

If anything, this study shows that most of the themes associated with the post-9/11 syndrome in international education at UM and FIU had much to do with the policy environment foisted on the institutions by policy makers and politicians in the wake of the terror attacks. Several advocacy organizations, including NAFSA - The Association of International Educators - have identified the absence of an international education policy as largely responsible for the misconception of the American brand by other countries. This communication and policy gap was amply spotlighted by the confusion and disorientation of the post- 9/11 firmament.

The U.S.'s chief competitors for intellectual capital seem to have realized the need for a coordinated messaging and marketing plan while U.S. colleges and universities are still basically left to their own devices. With more than one third of the world's international student population, and fresh evidence from FIU and UM that international students are streaming back to our colleges and universities after a hiatus triggered by 9/11 and its aftermath, the advocacy for a comprehensive international education policy for the U.S. must be renewed anew so that the nation could optimize its potentials as the hub of global education. To optimize U.S. potentials in this regard, the major higher education professional associations like NASPA, ACPA, NACADA, ACE, and APLU should join up with NAFSA to organize for sustained advocacy for an overt and comprehensive international education policy that restores the dignity and pride of international education professionals while preserving national security. Such a policy should be predicated on the assumption that international education and national security 
are complementary concepts rather than diametrically opposed ends, and should factor in international education as an element of national power and a legitimate means to sustainable national security.

\section{Suggestions for Future Research}

One gap that I noticed in this study is that none of the participants that I identified at the onset as well as those suggested through snowball sampling, was a Muslim or Arab. For someone who believes so much in giving equal story-telling space for everyone to express themselves this was, indeed, a telling irony. Regretfully, it was not a gap I could easily fill since none of the international educators at FIU and UM is Muslim or Arab. Future researchers interested in this area might, therefore, consider structuring a study that looks at the entire post-9/11 experience from the perspective of Arab and Muslim intellectuals. The ascendancy of Arabic Studies as a language and academic subject as well as the fate of science and technology programs in U.S. colleges and universities might also be of interest to future researchers.

Other possibilities for future research in this area include case studies of selected community colleges or intensive English language institutes; of Colleges of Science and Engineering in two or more universities; or of a number of flight schools, based on the parameters of my study. Interested future researchers might also wish to consider a Comparative Study of International Education in a Minority-Serving Institution, and a Predominantly White institution in the post-9/11 era or a study of the response of countries such as Spain and Great Britain to similar terrorist attacks and possible interplay (if any) with their internationalization agenda and relative competitiveness of their universities in attracting international students and scholars. 


\section{REFERENCES}

Adams, M., Bell, L. A., \& Griffin, P. (1997). Teaching for diversity and social justice. New York: Routledge.

American Council on Education. (2000). Internationalization of U.S. higher education: Preliminary status report. Washington, DC: Author.

American Council of Trustees and Alumni. (2001). Defending civilization: How our universities are failing America and what can be done about it. Washington, DC: Author. Retrieved June 16, 2005, from http://www.goacta.org/reports

Anderson, S. (2005). International students and U.S. policy choices. International Educator, 14(6), 24-33.

Armitage, R., \& Joseph, N. (2007). CSIS Commission on Smart Power: A smarter, more secure America. Washington, DC: Center for Strategic and International Studies.

Astin, A. W. (1977). What matters most in college: Four critical years. San Francisco: Jossey-Bass.

Astin, A. W. (1993). What matters most in college: Four critical years revisited. San Francisco: Jossey-Bass.

Ayer, A. (Ed.). (1959). Logical positivism. New York: The Free Press.

Back, K., Davis, D., \& Olson, A. (1996). Internationalization and higher education: Goals and strategies. Canberra, Australia: Department of Employment, Education, Training and Youth Affairs.

Black, J. S., Mendenhall, M., \& Oddou, G. (1991). Toward a comprehensive model of international adjustment: An integration of multiple theoretical perspectives. Academy of Management Review, 16, 291-317.

Bogdan, R., \& Biklen, S. (2003). Qualitative research for education: An introduction to theories and methods ( $4^{\text {th }}$ ed.). Boston: Allyn \& Bacon.

Borgatti, S. (1999). Elicitation techniques for cultural domain analysis. In J. Schensul \& M. LeCompte (Eds.), Enhanced ethnographic methods: Audiovisual techniques, focused group interviews, and elicitation techniques. The ethnographer's toolkit (3rd ed., pp. 115-151). Walnut Creek, CA: Sage.

Boyd, R. (2003). What should international education be? From emergent theory to practice. International Schools Journal, 22(2), 69-79. 
Bremer, D. (2006). Wanted: Global workers. International Educator, 3, 40-45.

Burger, P., \& Luckman, T. (1966). The social construction of reality: A treatise in the sociology of knowledge. Garden City, NY: Doubleday.

Carden, A., \& Feicht, R. (1991). Homesickness among American and Turkish college students. Journal of Cross-Cultural Psychology, 22, 418-428.

Carlson, J., Burn, B., Useem, J., \& Yachimowicz, D. (1990). Study abroad: The experience of American undergraduates. New York: Greenwood Press.

Carnevale, A. P. (1999). Diversity in higher education: Why corporate America cares. Diversity Digest, 3, 1-6.

Carr, W., \& Kemmis, S. (1986). Becoming critical: Education, knowledge and action research. London: The Falmer Press.

Chickering, A. W. (1969). Education and identity. San Francisco: Jossey-Bass.

Coffey, A., \& Atkinson, P. (1996). Making sense of qualitative data: Complementary research strategies. Thousand Oaks, CA: Sage.

Dassin, J. (2005). Brain gain, not drain, fosters global development and security. International Educator, 14(3), 20-25.

De Wit, H. (1999). Changing rationales for the internationalization of higher education. International Higher Education, 15(1), 2-3.

Dougherty, K. J. (1994). The contradictory college: The conflicting origins, impacts and futures of the community college. Albany: State University of New York Press.

Doumani, B. (2005). Academic freedom post-9/11. ISIM Review, 15, $22-24$.

Dundes, L., \& Rajapaksa, S. (2002). It's a long way home: International student adjustment to living in the United States. College Student Retention, 4(1), 15-28.

Duverneuil, S. (2003). International education: Post-9/11 immigration policy. Masters Abstracts International, 42(02), 386A. (UMI No. 1415502)

Farnsworth, K. (2005). A new model for recruiting international students: The 2+2. International Education, 35, 1, 5-14.

Fernandez, D., \& Sanchez, J. (1993). Acculturative stress among Hispanics: A bidimensional model of ethnic identification. Journal of Applied Social Psychology, 23, 654-668. 
Florida International University. (1974). International...It's our middle name. Miami, FL: Author.

Florida International University. (2001). Millennium strategic plan: 2001-2010. Miami, FL: Author. Retrieved April 7, 2009, from http://www.fiu.edu/oir/docs/msp.pdf

Florida International University. (2009). Global learning for global citizenship: FIU's quality enhancement plan (QEP). Miami, FL: Author. Retrieved July 18, 2009, from http://goglobal.fiu.edu/

Florida International University. (2010). FIU presents lecture on racial profiling after 911. Retrieved May 4, 2010, from http://news.fiu.edu/2010/02/fiu-presents-lectureon-racial-profiling-after-9-11/

Fullerton, J. (2005). Why do they hate us? International attitudes towards America, American brands and advertising. Place Branding, 1(2), 129-140.

Girden, E. R. (2001). Evaluating research articles from start to finish (2nd ed.). Thousand Oaks, CA: Sage.

Glaser, B. G., \& Strauss, A. L. (1967). The discovery of grounded theory: Strategies for qualitative research. Chicago: Aldine Books.

Gonzalez, J. (1990). Personal, academic and social characteristics of immigrant and non-immigrant students in an urban community college. Unpublished doctoral dissertation, Florida International University, Miami.

Guba, E. G., \& Lincoln, Y. S. (1981). Effective evaluation: Improving the usefulness of evaluation results through responsive and naturalistic approaches. San Francisco: Jossey-Bass.

Guba, E. G., \& Lincoln, Y. S. (1989). Fourth generation evaluation. Newbury Park, CA: Sage.

Haigh, M. (2002). Internationalization of the curriculum: Designing inclusive education for a small world. Journal of Geography in Higher Education, 24(1), 49-56.

Hao, S. (2004). Interaction of global politics and higher education. In J. Odin \& P. Manicas (Eds.), Globalization and higher education (pp. 202-218). Honolulu: University of Hawaii Press.

Henderson, G., Milhouse, V. H., \& Cao, L. (1993). Crossing the gap: Analysis of Chinese students' culture shock in an American university. College Student Journal, 27, 380-389. 
Heyneman, S. (2003). International education: A retrospective. Peabody Journal of Education, 78(1), 33-53.

Hirsch, S. F. (2006). In the moment of greatest calamity: Terrorism, grief and a victim's quest for justice. Princeton, NJ: Princeton University Press.

Hirsch, S. F. (2008). Fear and accountability at the end of an era. Law \& Society Review, 42(3), 591-603.

Hondagneu-Sotelo, P. (1999). Gender and contemporary U.S. immigration. American Behavioral Scientist, 42, 565-576.

Huntington, S. P. (1993). The clash of civilizations. Foreign Affairs, 72(3), 22-49.

Inayatullah, S. (1998). Alternative futures of the university: Globalization, multiculturalism, virtualism and politicization. Futures, 30(7), 589-602.

Inayatullah, S. (2004). Corporate, technological, epistemic and democratic challenges: Mapping the political economy of university futures. In J. Odin \& P. Manicas (Eds.), Globalization and higher education (pp. 202-218). Honolulu: University of Hawaii Press.

Institute of International Education. (2003). International students in the U.S. Retrieved June 16, 2005, from http://www.iie.org/opendoors/

Institute of International Education. (2004). International students in the U.S. Retrieved June 16, 2005, from http://www.iie.org/opendoors/

Institute of International Education. (2005). International students in the U.S. Retrieved June 16, 2005, from http://www.iie.org/opendoors/

Institute of International Education. (2006). International students in the U.S. Retrieved February 6, 2007, from http://www.iie.org/opendoors/

Institute of International Education. (2007). International students in the U.S. Retrieved April 4, 2008, from http://www.iie.org/opendoors/

Institute of International Education. (2008). International students in the U.S. Retrieved November 29, 2008, from http://www.iie.org/opendoors/

Irvin, S. (2006). Interviewing as qualitative research: A guide for researchers in education and the social sciences. New York: Teachers College Press. 
Johnson, M. (2003). NAFSA's comment letter to DHS regarding proposed SEVIS fee rule. Washington, DC: NAFSA: Association of International Educators. Retrieved June 16, 2005, from http://www.nafsa.org/content/publicpolicy/NAFSAontheIssues/SEVISFeeComme ntMain.htm

Johnson, B., \& Onwuegbuzie, J. (2004). Mixed methods research: A research paradigm whose time has come. Educational Researcher, 33(7), 14-26.

Karenga, M. (1993). Introduction to Black studies. Los Angeles: University of Sankore Press.

Kim, Y. (1991). Intercultural communication competence: A systems-theoretic view. In S. Ting-Tome \& F. Korean (Eds.), Cross-cultural interpersonal communication (pp. 259-275). Newbury Park, CA: Sage.

Kimberly, S. (2003). Islamic students in U.S. schools since 9/11. The Education Digest, 69(1), 18-22.

Kless, S. (2005, February). The impact of recent law and policy on international students and scholars in the U.S. Paper presented at the Stetson University College of Law 26th National Conference on Law and Higher Education, Clearwater Beach, FL.

Knight, J. (1999). Internationalization of higher education: Practices and priorities. Paris: International Association of Universities.

Kuh, G., Schuh, J., Whitt, E., Andreas, R. E., Lyons, J. W., Strange, C. C., et al. (1991). Involving colleges. San Francisco: Jossey-Bass.

Kvale, S. (1996). InterViews: An introduction to qualitative research interviewing. Thousand Oaks, CA: Sage.

Le Compte, M., \& Preissle, J. (1993). Ethnography and qualitative design in educational research. London: Academic Press.

Levin, J. (2004). The community college as a baccalaureate-granting institution. The Review of Higher Education, 28(1), 1-22.

Lincoln, Y. S., \& Guba, E. G. (1985). Naturalistic inquiry. Beverly Hills, CA: Sage.

Lysgaard, S. (1955). Adjustment in a foreign society: Norwegian Fulbright grantees visiting the United States. International Social Science Bulletin, 7, 45-51.

Matus, C. (2006). Interrupting narratives of displacement: International students in the United States. Perspectives in Education, 24(4), 1-12. 
McBurnie, G. (2000). Pursuing internationalization as a means to advance the academic mission of the university: An Australian case study. Higher Education in Europe, 15(1), 63-74.

McKeown, J. (2003). The impact of 9/11 on study abroad student interest and concern: An exploratory study. International Education, 32(2), 85-95.

Merriam, S. B. (1988). The case study research in education. San Francisco: Jossey-Bass.

Merriam, S. B. (1998). Qualitative research and case study applications in education. San Francisco: Jossey-Bass.

Miles, M. B., \& Huberman, A. M. (1984). Qualitative data analysis: A sourcebook of new methods. Beverly Hills, CA: Sage.

Miner, J. S. (2005, October). Assessing transnational civil society and its response to terrorism. Paper presented at the International Studies Association South Conference, Miami, FL.

Min-Hua, H. (2007). Challenges for international students in higher education: One student's narrated story of invisibility and struggle. College Student Journal, 41(2), 379-391.

Monroe, P. (1928, February). The cross-fertilization of culture: The function of international education. News Bulletin (Institute of Pacific Relations), 1-6.

Moustakas, C. (1990). Heuristic research: Design, methodology, and applications. Newbury Park, CA: Sage.

Mpoyi, R., \& Thomas, R. (2003). Coverage of international issues: Curriculum assessment from a student perception perspective. Journal of Academy of Business and Economics, 11(2), 139-143.

NAFSA: Association of International Educators. (2002). In America's interest: Welcoming international students (Report of the Strategic Task Force on international student access). Washington, DC: Author. Retrieved March 12, 2007, from http://www.nafsa.org.

NAFSA: Association of International Educators. (2003). NAFSA's code of ethics. Washington, DC: Author. Retrieved March 12, 2007, from http://www.nafsa.org.

NAFSA: Association of International Educators. (2007). The economic benefits of international education to the United States for the 2006-2007 academic year: A 
statistical analysis. Washington, DC: Author. Retrieved March 12, 2007, from http://www.nafsa.org/_File/_/eis07/usa.pdf.

National Association of State Universities and Land Grant Colleges. (2004). A call to leadership: The presidential role in internationalizing the university: A report of the NASULGC task force on higher education. Washington, DC: Author.

Nilsson, B. (2003). Internationalization at home from a Swedish perspective: The case of malmö. Journal of Studies in International Education, 7(1), 27-40.

Pascarella, E., \& Terenzini, P. (2004). How college affects students: Findings and insights from twenty years of research. San Francisco: Jossey-Bass.

Patton, M. Q. (1990). Qualitative evaluation and research methods (2nd ed.). Newbury Park, CA: Sage.

Perry, W. (1968). Forms of intellectual and ethical development in the college years: A scheme. New York: Holt, Rinchart \& Winston.

Phinney, J. (1993). A three-stage model of ethnic identity development in adolescence. In M. E. Bernal \& G. P. Knights (Eds.), Ethnic identity formation and transmission among Hispanics and other minorities (pp. 61-80). Albany: State University of New York.

Porter, R. E., \& Samovar, L. A. (1994). An introduction to intercultural communication. In L. A. Samovar \& R. E. Porter (Eds.), Intercultural communication: A reader (pp. 4-25). Belmont, CA: Wadsworth.

Poyrazli, S., \& Lopez, M. (2007). An exploratory study of perceived discrimination and homesickness: A comparison of international students and American students. The Journal of Psychology, 14(3), 263-280.

Poyrazli, S., Arbona, C., Bullington, R., \& Pisecco, S. (2001). Adjustment issues of Turkish college students studying in the United States [Electronic version]. College Student Journal, 35(1), 1-10.

Riley, T. R. (Ed.). (2003). Beyond the tower: The history of Florida International University. Miami, FL: Solo Printing.

Rocker, R. (1937). Nationalism and culture. London: Freedom Press.

Ross, H. (2002). The space between us: The relevance of relational theories to comparative and international education. Comparative Education Review, 46(4), 407-432. 
Rudolph, F. (1962). The American college and university. New York: Knopf.

Sanchez, J., \& Fernandez, D. (1993). Acculturative stress among Hispanics: A bidimensional model of ethnic identification. Journal of Applied Social Psychology, $23,654-668$.

Sandelowski, M. (1986). The problem of rigor in qualitative research. Advances in Nursing Science, 8, 27-37.

Sanford, N. (1962). The American college: A psychological and social interpretation of the higher learning. New York: John Wiley \& Sons.

Schlossberg, N. K. (1989). Marginality and mattering: Key issues in building community. In D. C. Roberts (Ed.), New Directions for Student Services: Vol. 48. Designing campus activities to foster a sense of community (pp. 5-15). San Francisco: Jossey-Bass.

Schlossberg, N., Waters, E., \& Goodman, J. (1995). Counseling adults in transition (2 ${ }^{\text {nd }}$ ed.). New York: Springer.

Schmitt, M. T., Spears, R., \& Branscombe, N. R. (2003). Constructing a minority group identity out of shared rejection: The case of international students. European Journal of Social Psychology, 33, 1-12.

Schuman, D. (1982). Policy analysis, education, and everyday life. Lexington, MA: Heath.

Seidman, S. (1998). Contested knowledge: Social theory in the post-modern era. Oxford, MA: Basil-Blackwell.

Shapiro, S. (2000). Empowerment. In D. A. Dabbard (Ed.), Knowledge and power in the global economy: Politics and the rhetoric of school reform (pp.103-110). Mahwah, NJ: Erlbaum.

Siaya, L., \& Hayward, F. (2003). Mapping internationalization on U.S. campuses: Final report. Washington, DC: American Council of Education.

Smart, R. (1971). The goals and definitions of international education: An agenda for discussion. International Studies Quarterly, 15(4), 442-464.

Smith, D., \& Schonfeld, N. (2000). The benefits of diversity: What the research tells us. About Campus, 5(5), 16-23. 
Sodowsky, G. R., \& Plake, B. S. (1992). Acculturation options for international people and implications for sensitivity to within group differences. Journal of Counseling and Development, 71, 53-59.

Stake, R. E. (2000). Case studies. In N. K. Denzin \& Y. S. Lincoln (Eds.), Handbook of qualitative research (pp. 236-246). Thousand Oaks, CA: Sage.

Starobin, S. (2006). International students in transition: Changes in access to U.S. higher education. New Directions for Student Services, 114, 63-71.

Stringer, R. (2002). Leadership and organizational climate. Upper Saddle River, NJ: Prentice Hall.

Sutton, M. (1998). Global education and the national interest: The last fifty years. The International Journal of Social Education, 13(2), 6-28.

Tanaka, G. (2003). The intercultural campus: Transcending culture and power in American higher education. New York: Peter Lang.

Tebeau, C. (1976). University of Miami: A golden anniversary history, 1926-1976. Coral Gables, FL: University of Miami Press.

Tesch, R. (1990). Qualitative research: Analysis types and software tools. London: Falmer.

The National Commission on Terrorist Attacks upon the United States. (2004). The 9/11 Commission report: Final report of the National Commission on Terrorist Attacks Upon the United States. Washington DC: Author.

Thelin, J. (1947). A history of American higher education. Baltimore: John Hopkins University Press.

Treyster, D. (2003). Foreign students v. national security: Will denying education prevent terrorism? New York Law School Law Review, 46(3-4), 867- 897.

United Nations Development Project. (2004). Human development report 2004: Cultural liberty in today's diverse world. New York: Author.

United States Government Accountability Office. (2009, April). Higher education: Approaches to attract and fund international students in the United States and abroad. Report to the Chairman, Subcommittee on International Organizations, Human Rights. Washington, DC: Author. Retrieved from http://www.gao.gov/htext/d09379.html 
University of Miami. (2008). Executive-in-Residence program brings insight on managing in the wake of 9/11. Retrieved May 3, 2010, from http://www.bus.miami.edu/news-and-media/recent-news/fraser.html

Urias, D. (2003). Federal policy regulations and their impact on foreign student enrollment in selected United States higher education institutions. Charlottesville: University of Virginia.

Veysey, L. (1965). The emergence of the American university. Chicago: University of Chicago Press.

Wagner, P. (2004). Higher education in an era of globalization: What is at stake? In J. Odin \& P. Manicas (Eds.), Globalization and higher education (pp. 202-218). Honolulu: University of Hawaii Press.

Welch, A. (2002). Internationalizing Australian universities. Comparative Education Review, 46(4), 433-471.

Welch, A., \& Denman, B. (1997). Internationalization of higher education: Retrospect and Prospect. Forum of Education, 52(1), 14-28.

Williams, C. (2000). Education and human survival: The relevance of the global security framework to international education. International Review of Education, 46, 183203.

Zimmerman, S. (1995). Perceptions of international communication competence and international student adaptation to an American campus. Communication Education, 44(4), 1-13. 
APPENDICES 


\section{APPENDIX A: INTERVIEW GUIDE \\ Part 1: Life History}

Early Experiences

1. What is your educational and professional background like? How did you get into international education?

Formative Positive and Negative experiences:

1. Please describe your early experiences of your work in international education.

2. What did your work mean for you during this time?

Pivotal experiences (moving towards the present):

1. In what ways have your experiences on the job significantly changed over time?

2. What are the circumstances of those changes?

Second Interview: Details of Present Experience

Day-to-Day Experience:

1. Recall significant moments and issues in your professional career as an international educator before and after $9 / 11$. What has changed in terms of the policy and cultural environment, your students and colleagues, job expectations, attitude of the community and the perspectives of other critical stakeholders?

2. Tell me about your experiences of how nationalism amongst international students and patriotism among American students has evolved in the post-9/11 era?

3. What kind of relationships did your university have with Mid-Eastern and Arab countries/students compared with others prior to $9 / 11$ ? How would you describe these linkages in the post-9/11 era? 
4. How does your institution deal with terrorism? Would you describe one or more examples of this before and after 9/11? To what extent would you consider your institution safer now and free of potential terrorists?

Negative and Positive Experiences:

1. Tell me some positive experience concerning recruitment and provision of support services to address transition issues such as culture shock, language barrier, inadequate orientation, avoidable errors in placement/advisement, as well as marginality and mattering of the foreign students on your campus prior to and after 9/11? To what extent has the environment changed?

Third Interview: Reflections on the Meaning

Past to Present:

1. To what extent does your institution have recognizable advocates of internationalization? How empowered or marginalized would you consider them and why?

2. How would you gauge the success of your university's internationalization efforts in the pre-9/11 era compared with the post-9/11 period? What deeper meanings do these hold for you?

3. How do you reconcile your monitoring responsibilities as a DSO with your job as an advocate for international students?

4. To what extent would you say that there is a "post-9/11 syndrome?" in your institution? How does this affect your work and its context?

\section{The big Picture:}

1. NASULGC (2004) outlined what it called the 3 "A's" (articulate, advocate and act) contending that internationalization is "the single most important leadership 
2. Would you say your institution has articulated a coherent vision for internationalization? If yes, what is it and what does it mean for you and the college community of students and scholars in the light of 9/11? If no, why?

3. How do you expect the international education function to evolve in your institution in the years ahead? What would be the implication of this?

4. How do you envision your future as an international education professional and how would you tie this to the fate of your students and scholars? 


\section{APPENDIX B}

\section{CONTACT SUMMARY SHEET}

(1) Main issues or themes that struck me in this contact.

(2) Information obtained/missed from target questions for contact.

(3) Other salient, interesting, illuminating or important issues.

(4) Unresolved or remaining questions/themes. 


\section{APPENDIX C}

\section{DOCUMENT SUMMARY FORM}

Document Form:

Name/Description of document:

Document \#:

Event or Contact:

Significance or Importance of Document:

Brief Summary of Contacts:
Site: 


\section{APPENDIX D \\ LIST OF STUDY PARTICIPANTS/INTERVIEWEES}

Florida International University

1. Dr. Ana Sippin, Director, International Student and Scholars (ISSS) and USCIS Principal Designated School Official (PDSO)

2. Ms. Nancy Hernandez, USCIS Designated School Official (DSO)/ Director ISSS, Biscayne Bay Campus (BBC)

3. Ms. Anoush McNamee, Assistant Director/SEVIS coordinator (BBC)

4. Dr. Hillary Landorf, Director, Office of Global Learning Initiative

5. Ms. Liza Carbajo, Director, Office of Education Abroad

6. Dr. Modesto A. Maidique, former president and Director, FIU Center for Leadership

$$
\text { University of Miami }
$$

1. Dr. Patricia Whitely, the Vice President of Student Affairs

2. Dr. William Scott Green, Senior Vice Provost and Dean of Undergraduate Education

3. Ms. Elyse Resnick, Assistant Director, International Education and Exchange Programs

4. Ms. Claudia Zitzmann, Associate Director, International Student and Scholar Services

5. Mr. Abraham Varghese, Assistant Provost for International Affairs

6. Background discussion with Mr. Mark Reid, Director of International Admissions, Ms. Teresa de la Guardia, ISSS Director and Ms. Michele Alvarez, Director Intensive Language Institute in September 2007.

7. Discussion/E-mail exchange with Ms. Glenda Hayley, Director International Education Exchange Programs (IEEP), in January, 2009. 


\section{APPENDIX E}

\section{GLOSARY OF ABBREVIATIONS}

1. AACC American Association of Community Colleges

2. ACE American Council of Education

3. ACTA American Council of Trustees and Alumni

4. APLU Association of Public Land Grant University

5. ARO Alternative Responsible Officer

6. CIPRIS Coordinated Interagency Partnership Regulating Intl Students

7. CLASS Consular Lookout \& Support System

8. DHS Department of Homeland Security

9. DSO Designated School Official

10. FIU Florida International University

11. GLI Global Learning Initiative

12. GWD Global Workforce Development

13. IaH Internationalization at Home

14. IAHPCO Internationalization at Home Plus Collaborative Outreach

15. ICE Immigration and Customs Enforcement

16. IEEP International Education and Exchange Programs

17. IEP Intensive English Program

18. IRRIRA Illegal Immigration Reform and Immigrant Responsibility Act

19. ISSS International Student and Scholar Services

20. NAFSA Association of International Educators

21. NSEERS National Security Entry Exit Registration System

22. OECD Organization for Economic Cooperation and Development

23. PDSO Principal Designated Officer

24. QEP Quality Enhancement Plan

25. SACS Southern Association of Colleges and Universities

26. SAP Student Affairs Professionals

27. SEVIS Student and Exchange Visitors Information System

28. TAL Technology Alert List

29. UM University of Miami

30. USCIS United States Citizenship and Immigration Services 
VITA

\section{OLUYINKA TELLA}

August 4, 1966

2004

1998

1986

2004-2009

2002-2004

1993-1999

1987-1991
Born, Ibadan, Nigeria

MS, College Student Personnel

Western Illinois University

Macomb, Illinois

Master of Business Administration Ogun State University

Ago Iwoye, Nigeria

BA, English and Literary Studies

University of Ife

Ile-Ife, Nigeria

International Admissions Coordinator/Counselor Broward College

Fort Lauderdale, Florida

Graduate/Teaching Assistant

Western Illinois University

Macomb, Illinois

Senior Manager

Oasis Savings and Loans Limited

Lagos, Nigeria

Senior Research/Publicity Officer

Kwara State Directorate for Social Mobilization Ilorin, Kwara State

PRESENTATIONS

"Let's Talk! Conversations across Cultures: A Community College's Experience," NAFSA: Association of International Educators National Convention and Expo, Washington DC., May 29, 2008

"First Year Experience: A Learning Community Model," NACADA National Convention, Oct. 2006

"Factors Associated with Admission and Retention of Minority Students," American College Personnel Association Annual National Convention, Philadelphia, PA., April, 2004 